NBER WORKING PAPER SERIES

\title{
MACROECONOMIC SHOCKS AND THEIR PROPAGATION
}

\author{
Valerie A. Ramey \\ Working Paper 21978 \\ http://www.nber.org/papers/w21978
NATIONAL BUREAU OF ECONOMIC RESEARCH
1050 Massachusetts Avenue
Cambridge, MA 02138
February 2016

Prepared for the Handbook of Macroeconomics. I wish to thank John Cochrane, Marco Del Negro, Graham Elliott, Neville Francis, Marc Giannoni, Robert Hall, Arvind Krishnamurthy, Karel Mertens, Christina Romer, David Romer, James Stock, John Taylor, Harald Uhlig, Mark Watson, Johannes Wieland, and participants at the Stanford Handbook of Macro conference and NBER Monetary Economics conference for very helpful discussions. I am grateful to the numerous authors who sent their estimated technology shocks and to Shihan Xie for providing her updated FAVAR factors. I would also like to express appreciation to the American Economic Association for requiring that all data and programs for published articles be posted. In addition, I am grateful to researchers who publish in journals without that requirement but still post their data and programs on their websites. The views expressed herein are those of the author and do not necessarily reflect the views of the National Bureau of Economic Research.

NBER working papers are circulated for discussion and comment purposes. They have not been peerreviewed or been subject to the review by the NBER Board of Directors that accompanies official NBER publications.

(C) 2016 by Valerie A. Ramey. All rights reserved. Short sections of text, not to exceed two paragraphs, may be quoted without explicit permission provided that full credit, including $\bigcirc$ notice, is given to the source. 
Macroeconomic Shocks and Their Propagation

Valerie A. Ramey

NBER Working Paper No. 21978

February 2016

JEL No. E3,E5,E6

\begin{abstract}
$\underline{\text { ABSTRACT }}$
This chapter reviews and synthesizes our current understanding of the shocks that drive economic fluctuations. The chapter begins with an illustration of the problem of identifying macroeconomic shocks, followed by an overview of the many recent innovations for identifying shocks. It then reviews in detail three main types of shocks: monetary, fiscal, and technology shocks. After surveying the literature, each section presents new estimates that compare and synthesize key parts of the literature. The penultimate section briefly summarizes a few additional shocks. The final section analyzes the extent to which the leading shock candidates can explain fluctuations in output and hours. It concludes that we are much closer to understanding the shocks that drive economic fluctuations than we were twenty years ago.
\end{abstract}

Valerie A. Ramey

Department of Economics, 0508

University of California, San Diego

9500 Gilman Drive

La Jolla, CA 92093-0508

and NBER

vramey@ucsd.edu 


\section{Table of Contents}

\section{Introduction}

2. Methods for Identifying Shocks and Estimating Impulse Responses

2.1 Overview: What is a Shock?

2.2 Illustrative Framework

2.3 Common Identification Methods

2.3.1 Cholesky Decompositions

2.3.2 Other Contemporaneous Restrictions

2.3.3 Narrative Methods

2.3.4 High Frequency Identification

2.3.5 External Instruments/Proxy SVARs

2.3.6 Restrictions at Longer Horizons

2.3.7 Sign Restrictions

2.3.8 Factor-Augmented VARs

2.3.9 Estimated DSGE Models

2.4 Estimating Impulse Responses

2.5 The Problem of Foresight

2.6 The Problem of Trends

2.7 Brief Notes on Nonlinearities

2.8 DSGE Monte Carlos

3. Monetary Policy Shocks

3.1 A Brief History Through 1999

3.2 Some Alternatives to the Standard Model

3.2.1 Regime Switching Models

3.2.2 Time-Varying Effects of Monetary Policy

3.2.3 Historical Case Studies

3.3 Main Identification Challenges

3.3.1 The Recursiveness Assumption

3.3.2 The Problem of Foresight

3.4 Summary of Recent Estimates

3.5 Explorations with Three Types of Monetary Shocks

3.5.1 The Christiano, Eichenbaum and Evans (1999) Benchmark

3.5.2 Greenbook/Narrative Identification of Shocks

3.5.3 High Frequency Identification Shocks

3.6 Summary of Monetary Shocks

\section{Fiscal Shocks}

4.1 Government Spending Shocks 
4.1.1 Summary of Identification Methods

4.1.2 Summary of the Main Results from the Literature

4.1.3 Exploration with Several Identified Shocks

4.2 Tax Shocks

4.2.1 Unanticipated Tax Shocks

4.2.1.1 Summary of the Literature

4.2.1.2 Further Explorations

4.2.2 News About Future Tax Changes

4.2.2.1 Summary of the Literature

4.2.2.2 Further Explorations

4.3 Summary of Fiscal Shocks

\section{Technology Shocks}

5.1 Neutral Technology Shocks

5.2 Investment-Related Technology Shocks

5.3 News about Future Technology Changes

5.4 Explorations with Estimated Technology Shocks

5.5 Summary of Technology Shocks

\section{Additional Shocks}

\section{Summary and Conclusions}




\section{Introduction}

At the beginning of the $20^{\text {th }}$ Century, economists began to recognize the importance of impulses and propagation mechanisms for explaining business cycle fluctuations. A key question was how to explain regular fluctuations in a model with dampened oscillations. In 1927, the Russian statistician Eugen Slutsky published a paper titled "The Summation of Random Causes as a Source of Cyclic Processes.” In this paper, Slutsky demonstrated the surprising result that moving sums of random variables could produce time series that looked very much like the movements of economic time series - "sequences of rising and falling movements, like

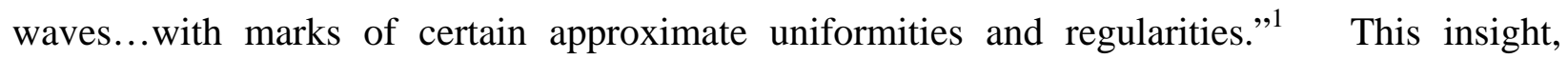
developed independently by British mathematician Yule in 1926 and extended by Frisch (1933) in his paper "Propagation Problems and Impulse Problems in Dynamic Economics," revolutionized the study of business cycles. Their insights shifted the focus of research from developing mechanisms to support a metronomic view of business cycles, in which each boom created conditions leading to the next bust, to a search for the sources of the random shocks. Since then economists have offered numerous candidates for these "random causes," such as crop failures, wars, technological innovation, animal spirits, government actions, and commodity shocks.

Research from the 1940s through the 1970s emphasized fiscal and monetary policy shocks, identified from large-scale econometric models or single equation analyses. The 1980s witnessed two important innovations that fundamentally changed the direction of the research. First, Sims' (1980a) paper “Macroeconomics and Reality” revolutionized the study of systems driven by random impulses by introducing vector autoregressions (VARs). Sims' VARs made the link between innovations to a linear system and macroeconomic shocks. Using his method, it became easier to talk about identification assumptions, impulse response functions, and to do innovation accounting using forecast error decompositions. The second important innovation was the expansion of the inquiry beyond policy shocks to consider important non-policy shocks, such as technology shocks (Kydland and Prescott (1982)).

These innovations led to a flurry of research on shocks and their effects. In his 1994 paper "Shocks," John Cochrane took stock of the state of knowledge at that time by using the by-

\footnotetext{
${ }^{1}$ Page 105 of the 1937 English version of the article published in Econometrica.
} 
then standard VAR techniques to conduct a fairly comprehensive search for the shocks that drove economic fluctuations. Surprisingly, he found that none of the popular candidates could account for the bulk of economic fluctuations. He proffered the rather pessimistic possibility that "we will forever remain ignorant of the fundamental causes of economic fluctuations.” (Cochrane (1994), abstract)

Are we destined to remain forever ignorant of the fundamental causes of economic fluctuations? Are Slutsky’s “random causes” unknowable? In this chapter, I will summarize the new methodological innovations and what their application has revealed about the propagation of the leading candidates for macroeconomic shocks and their importance in explaining economic fluctuations since Cochrane’s speculation.

The chapter progresses as follows. Section 2 begins by defining what a macroeconomic shock is. It then summarizes the many tools used for identifying macroeconomic shocks and computing impulse responses. It also highlights some of the complications and pitfalls, such as the effects of foresight and nonlinearities.

The topic of Section 3 is monetary shocks and their effects on the macroeconomy. The section summarizes the existing literature and the challenges to identification. It then explores the effects of several leading monetary shocks in a framework that incorporates some of the newer innovations.

Section 4 discusses fiscal shocks. It begins by summarizing results on government spending shocks and highlights the importance of anticipations. It estimates the effects of several leading identified shocks in a common framework. The second part of the section looks at tax shocks. It summarizes the literature on both unanticipated tax shocks and news about future tax changes and conducts some robustness checks. .

Section 5 summarizes the literature on technology shocks, including total factor productivity shocks, investment-specific technology shocks, and marginal efficiency of investment shocks. It also discusses news about future technology. It compares a wide variety of identified shocks from the literature.

Section 6 briefly discusses four other candidate shocks: oil shocks, credit shocks, uncertainty shocks, and labor supply (or “wage markup”) shocks.

Section 7 concludes by synthesizing what we have learned about shocks. It conducts a combined forecast error variance decomposition for output and hours to determine how much of 
the fluctuations can be accounted for by some of the leading shocks discussed in the earlier sections. It concludes that we have made substantial progress in understanding the shocks that drive the macroeconomy.

\section{Methods for Identifying Shocks and Estimating Impulse Responses}

\subsection{Overview: What is a Shock?}

What, exactly, are the macroeconomic shocks that we seek to estimate empirically? There is some ambiguity in the literature about the definition because of some researchers' use of the term shock when they mean innovation (i.e. the residuals from a reduced form vector autoregression model (VAR)) or instrument. Sims (1980a) equated innovations with macroeconomic shocks, despite claiming to be atheoretical. Others have used the word shock when they mean instrument (e.g. Cochrane (2004)). In this chapter, I view shocks, VAR innovations, and instruments to be distinct concepts, although identification assumptions may equate them in many cases. Shocks are most closely related to the structural disturbances in a simultaneous equations system. I adopt the concept of shocks used by researchers such as Blanchard and Watson (1986), Bernanke (1986), and Stock and Watson (forthcoming). According to Bernanke (1986), the shocks should be primitive exogenous forces that are uncorrelated with each other and they should be economically meaningful (pp. 52-55).

I view the shocks we seek to estimate as the empirical counterparts to the shocks we discuss in our theories, such as shocks to technology, monetary policy, fiscal policy, etc. Therefore, the shocks should have the following characteristics: (1) they should be exogenous with respect to the other current and lagged endogenous variables in the model; (2) they should be uncorrelated with other exogenous shocks; otherwise, we cannot identify the unique causal effects of one exogenous shock relative to another; and (3) they should represent either unanticipated movements in exogenous variables or news about future movements in exogenous variables. With regard to condition (2), one might counter with situations in which both fiscal and monetary policy respond to some event and argue that therefore the fiscal and monetary shocks would be correlated. I would respond that these are not primitive shocks, but rather the 
endogenous responses of policies to a primitive shock. A primitive shock may directly enter several of the equations in the system. For example, a geopolitical event might lead to a war that causes both fiscal and monetary policy to respond endogenously. The geopolitical event would be the primitive shock from the standpoint of our economic models (though it might be considered an endogenous response from the standpoint of a political science model). ${ }^{2}$

To match these theoretical shocks, we want to link the innovations in a structural vector autoregression (SVAR) to these theoretical ("structural") shocks, to estimate them in a structural dynamic stochastic general equilibrium (DSGE) model, or to measure them directly using rich data sources.

\subsection{Illustrative Framework}

In this section, I lay out a simple framework in order to discuss the problem of identification and to illustrate some of the leading identification methods. I begin with the problem of identifying shocks to fiscal policy in a simple model with no dynamics. I then generalize the model to a dynamic trivariate model.

Consider first a simple model of the link between fiscal variables and GDP in a static setting. Suppose the structural relationships are given by the following equations:

$$
\begin{aligned}
& \tau_{t}=b_{\tau g} g_{t}+b_{\tau y} y_{t}+\varepsilon_{\tau t} \\
& g_{t}=b_{g \tau} \tau_{t}+b_{g y} y_{t}+\varepsilon_{g t} \\
& y_{t}=b_{y \tau} \tau_{t}+b_{y g} g_{t}+\varepsilon_{y t}
\end{aligned}
$$

where $\tau$ is taxes, $g$ is government spending, and $y$ is GDP. The $\varepsilon$ 's are the macroeconomic shocks we seek to identify. We assume that they are uncorrelated and that, in this simple example, each one affects only one equation. $\varepsilon_{\tau t}$ is the tax shock; it might represent legislation resulting from a change in political power. $\varepsilon_{g t}$ might capture the sudden outbreak of war, which raises desired military spending. $\varepsilon_{y t}$ might capture technological progress. The $b$ 's capture the usual interactions. For example, we would expect that government spending would raise output

${ }^{2}$ Of course, the war might be caused by something like rainfall, in which case the primitive shock would be the rainfall. This shock would enter even more equations, such as the equations for government spending, GDP, productivity, etc. 
while taxes would lower it, so $b_{y g}>0$ and $b_{y \tau}<0$. Because of automatic stabilizers, however, the fiscal variables should also respond to GDP, i.e., $b_{g y}<0$ and $b_{\tau y}>0$. This means that a simple regression of GDP on government spending and taxes will not uncover $b_{y g}$ and $b_{y \tau}$ because $g_{t}$ and $\tau_{t}$ are correlated with the shock to GDP, $\varepsilon_{y t}$. For example, we might observe no correlation between GDP and government spending, but this correlation is consistent with both no structural relationship between GDP and government spending (i.e. $b_{y g}=b_{g y}=0$ ) and with $b_{y g}$ and $b_{g y}$ being large, with equal but opposite signs. Without further assumptions or data, we cannot identify either the parameters or the shocks.

Now let us move to a simple trivariate model with three endogenous variables, $Y_{1}, Y_{2}$, and $Y_{3}$, in which dynamics are potentially important. ${ }^{3}$ In the monetary context, these variables could be industrial production, a price index, and the federal funds rate; in the fiscal context, they could be GDP, government purchases, and tax revenue; and in the technology shock context, they could be labor productivity, hours, and investment. Let $Y_{t}=\left[Y_{1 t}, Y_{2 t}, Y_{3 t}\right]$ be the vector of endogenous variables. Suppose that the dynamic behavior of $Y_{t}$ is described by the following structural model:

$$
Y_{t}=B(L) Y_{t}+\Omega \varepsilon_{t}
$$

where $B(L)=B_{0}+\sum_{k=1}^{p} B_{k} L^{k}$ and $E\left[\varepsilon_{t} \varepsilon_{s}^{\prime}\right]=D$ if $t=s$, and 0 otherwise, where $\mathrm{D}$ is a diagonal matrix. The $\varepsilon$ 's are the primitive structural shocks. Since a primitive shock can in principle affect more than one variable, I initially allow $\Omega$ to have nonzero off-diagonal elements.

The elements of $B_{0}$ are the same as the $b$ 's from equation (2.1), with $b_{j j}=0$. Thus, the easiest way to address the dynamics is to recast the problem in terms of the innovations from a reduced form vector autoregression (VAR):

$$
A(L) Y_{t}=\eta_{t}
$$

\footnotetext{
${ }^{3}$ See Stock and Watson's chapter (forthcoming) in this Handbook for a more precise analysis of identification using SVARs. I use the same notation they do.
} 
where $A(L)$ is a polynomial in the lag operator and $A(L)=I-\sum_{k=1}^{p} A_{k} L^{k} \cdot \eta_{t}=$ $\left[\eta_{1 t}, \eta_{2 t}, \eta_{3 t}\right]$ are the reduced form VAR innovations. We assume that $E\left[\eta_{t}\right]=0, E\left[\eta_{t} \eta_{t}^{\prime}\right]=\Sigma_{\eta}$ and that $E\left[\eta_{t} \eta_{s}^{\prime}\right]=0$ for $s \neq t$. We then can link the innovations $\eta$ in the reduced form VAR equation (2.3) to the unobserved structural shocks, $\varepsilon$, in the structural equation (2.2) as follows:

$$
\begin{aligned}
& \eta_{t}=B_{0} \eta_{t}+\Omega \varepsilon_{t} \\
& \quad \text { or } \\
& \eta_{t}=H \varepsilon_{t}, \quad \text { where } H=\left[I-B_{0}\right]^{-1} \Omega .
\end{aligned}
$$

I will now write out the system in equation (2.4a) explicitly in a way that incorporates a commonly used identification assumption and a normalization. These restrictions are (i) $\Omega$ is the identity matrix (meaning each shock enters only one equation); and (ii) the structural shocks have unit effect (i.e. the diagonal elements of $H$ are unity). ${ }^{4}$ The system can then be written as:

$$
\begin{aligned}
& \eta_{1 t}=b_{12} \eta_{2 t}+b_{13} \eta_{3 t}+\varepsilon_{1 t} \\
& \eta_{2 t}=b_{21} \eta_{1 t}+b_{23} \eta_{3 t}+\varepsilon_{2 t} \\
& \eta_{3 t}=b_{31} \eta_{1 t}+b_{32} \eta_{2 t}+\varepsilon_{3 t}
\end{aligned}
$$

This equation is the dynamic equivalent of equation (2.1). The only difference is that instead of writing the structural relationships in terms of the variables such as GDP, government spending, and taxes themselves, we now write them in terms of the reduced form VAR innovations. The interpretations of the $b$ 's, however, are the same if the structural relationships depend on contemporaneous interactions.

As discussed at the start of this section, we cannot identify the coefficients or the shocks without more restrictions. We require at least three more restrictions for identification of all three shocks, potentially fewer if we want to identify only one shock. Since a number of the common identification methods depend on contemporaneous restrictions, I will refer to the system of equations in (2.5) when discussing them.

\footnotetext{
4 An alternative normalization to (ii) is the assumption that the structural shocks have unit standard deviation (i.e. the variances of the $\boldsymbol{\varepsilon}$ 's are unity).
} 


\subsection{Common Identification Methods}

In this section, I briefly overview some of the most common methods for identification. This section is not meant to be comprehensive. See Stock and Watson (forthcoming) for more detailed treatments of the methods I summarize, as well as for a few other methods I do not summarize, such as set identification and identification through heteroscedasticity. I use the term "policy variable” for short, but it should be understood that it can represent any variable from which we want to extract a shock component.

\subsubsection{Cholesky Decompositions}

The most commonly used identification method in macroeconomics imposes alternative sets of recursive zero restrictions on the contemporaneous coefficients. This method was introduced by Sims (1980a), and is also known as "triangularization." The following are two widely-used alternatives.

A. The policy variable does not respond within the period to the other endogenous variables. This could be motivated by decision lags on the part policymakers or other adjustment costs. Let $Y_{1}$ be the policy variable and $\eta_{1}$ be its reduced form innovation. Then this scheme involves constraining $b_{12}=b_{13}=0$ in equation (2.5), which is equivalent to ordering the policy variable first in the Cholesky ordering. For example, Blanchard and Perotti (2002) impose this constraint to identify the shock to government spending; they assume that government spending does not respond to the contemporaneous movements in output or taxes. ${ }^{5}$

B. The other endogenous variables do not respond to the policy shock within the period. This could be motivated by sluggish responses of the other endogenous variables to shocks to the policy variable. This scheme involves constraining $b_{21}=b_{31}=0$, which is

\footnotetext{
5 To implement this identification using ordinary least squares (OLS), one would simply regress government spending on $p$ lags of all of the variables in the system and call the residual the government spending shock.
} 
equivalent to ordering the policy variable last in the Cholesky ordering. For example, Bernanke and Blinder (1992) were the first to identify shocks to the federal funds rate as monetary policy shocks and used this type of identification. ${ }^{6}$

Several of the subsequent sections will discuss how these timing assumptions are not as innocuous as they might seem at first glance. For example, forward-looking behavior or superior information on the part of policy-makers may invalidate these restrictions.

\subsubsection{Other Contemporaneous Restrictions}

Another more general approach (that nests the Cholesky decomposition) is what is known as a Structural VAR, or SVAR, introduced by Blanchard and Watson (1986) and Bernanke (1986). This approach uses either economic theory or outside estimates to constrain parameters. Consider, for example, Blanchard and Perotti’s (2002) identification of government spending and net tax shocks. Let $Y_{1}$ be net taxes, $Y_{2}$ be government spending, and $Y_{3}$ be GDP. They identify the shock to government spending using a Cholesky decomposition in which government spending is ordered first (i.e. $b_{21}=b_{23}=0$ ). They identify exogenous shocks to net taxes by setting $b_{13}=$ 2.08, an outside estimate of the cyclical sensitivity of net taxes. ${ }^{7}$ These three restrictions are sufficient to identify all of the remaining parameters and hence all three shocks.

\subsubsection{Narrative Methods}

Narrative methods involve constructing a series from historical documents to identify the reason and/or the quantities associated with a particular change in a variable. Friedman and Schwartz (1963) is the classic example of using historical information to identify policy shocks. Hamilton (1985) and Hoover and Perez (1994) used narrative methods to identify oil shocks.

6 To implement this identification using OLS, one would regress the federal funds rate on contemporaneous values of the other variables in the system, as well as $p$ lags of all of the variables, and call the residual the monetary policy shock.

7 One way to implement the tax shock identification is to construct the variable $\eta_{1}-2.08 \eta_{3}$ from the estimated reduced form residuals. One would then regress $\eta_{3}$ on $\eta_{1}$ and $\eta_{2}$, using $\eta_{1}-2.08 \eta_{3}$ as the instrument for $\eta_{1}$. (Note that the assumption that $b_{21}=b_{23}=0$ identifies $\eta_{2}$ as $\varepsilon_{2 t}$, which is uncorrelated with $\varepsilon_{3 t \mathrm{t}}$ by assumption) This regression identifies $b_{31}$ and $b_{32}$. The residual is the estimate of $\varepsilon_{3 t \mathrm{t}}$. 
These papers isolated political events that led to disruptions in world oil markets. Other examples of the use of narrative methods are Poterba's (1986) tax policy announcements, Romer and Romer's (1989, 2004) monetary shock series based on FOMC minutes, Ramey and Shapiro (1998) and Ramey's (2011) defense news series based on Business Week articles, and Romer and Romer's (2010) narrative series of tax changes based on reading legislative documents.

Until recently, these series were used either as exogenous shocks in sets of dynamic single equation regressions or embedded in a Cholesky decomposition. For example, in the framework above, we could set $Y_{1}$ to be the narrative series and constrain $b_{12}=b_{13}=0$. As a later section details, recent innovations have led to an improved method for incorporating these series.

A cautionary note on the potential of narrative series to identify exogenous shocks is in order. Some of the follow-up research has operated on the principle that the narrative alone provides exogeneity. It does not. Shapiro (1984) and Leeper (1997) made this point for monetary policy shocks. Another example is in the fiscal literature. A series on fiscal consolidations, quantified by narrative evidence on the expected size of these consolidations, is not necessarily exogenous. If the series includes fiscal consolidations adopted in response to bad news about the future growth of the economy, the series cannot be used to establish a causal effect of the fiscal consolidation on future output.

\subsubsection{High Frequency Identification}

Research by Bagliano and Favero (1999), Kuttner (2001), Cochrane and Piazzesi (2002), Faust, Swanson, and Wright (2004), Gürkaynak, Sack and Swanson (2005), Piazzesi and Swanson (2008), Gertler and Karadi (2015), Nakamura and Steinsson (2015) and others has used high frequency data (such as news announcements around FOMC dates) and the movement of federal funds futures to identify unexpected Fed policy actions. This identification is also based in part on timing, but because the timing is so high frequency (daily or higher), the assumptions are more plausible than those employed at the monthly or quarterly frequency. As I will discuss in the foresight section below, the financial futures data is ideal for ensuring that a shock is unanticipated. 
It should be noted, however, that without additional assumptions the unanticipated shock is not necessarily exogenous to the economy. For example, if the implementation does not adequately control for the Fed's private information about the future state of the economy, which might be driving its policy changes, these shocks cannot be used to estimate a causal effect of monetary policy on macroeconomic variables.

\subsubsection{External Instruments/Proxy SVARs}

The "external instrument," or "proxy SVAR," method is a promising new approach for incorporating external series for identification. This method was developed by Stock and Watson (2008) and extended by Stock and Watson (2012) and Mertens and Ravn (2013). This approach takes advantage of information developed from "outside" the VAR, such as series based on narrative evidence, shocks from estimated DSGE models, or high frequency information. The idea is that these external series are noisy measures of the true shock.

Suppose that $Z_{t}$ represents one of these external series. Then this series is a valid instrument for identifying the shock $\varepsilon_{1 t}$ if the following two conditions hold:

$$
\begin{array}{r}
E\left[Z_{t} \varepsilon_{1 t}\right] \neq 0, \\
E\left[Z_{t} \varepsilon_{i t}\right]=0 \quad \mathrm{i}=2,3
\end{array}
$$

Condition (2.6a) is the instrument relevance condition: the external instrument must be contemporaneously correlated with the structural policy shock. Condition (2.6b) is the instrument exogeneity condition: the external instrument must be contemporaneously uncorrelated with the other structural shocks. If the external instrument satisfies these two conditions, it can be used to identify the shock $\varepsilon_{1 t}$.

The procedure is very straightforward and takes place with the following steps. ${ }^{8}$

\footnotetext{
${ }^{8}$ This exposition follows Merten and Ravn (2013a, online appendix). See Mertens and Ravn (2013a,b) and the associated online appendices for generalizations to additional external instruments and to larger systems.
} 
Step 1: Estimate the reduced form system to obtain estimates of the reduced form residuals, $\eta_{t}$.

Step 2: Regress $\eta_{2 t}$ and $\eta_{3 t}$ on $\eta_{1 t}$ using the external instrument $Z_{t}$ as the instrument. These regressions yield unbiased estimates of $b_{21}$ and $b_{31}$. Define the residuals of these regressions to be $v_{2 t}$ and $v_{3 t}$.

Step 3: Regress $\eta_{1 t}$ on $\eta_{2 t}$ and $\eta_{3 t}$, using the $v_{2 t}$ and $v_{3 t}$ estimated in Step 2 as the instruments. This yields unbiased estimates of $b_{12}$ and $b_{13}$.

As an example, Mertens and Ravn (2014) reconcile Romer and Romer's (2010) estimates of the effects of tax shocks with the Blanchard and Perotti (2002) estimates by using the Romer's narrative tax shock series as an external instrument $Z_{t}$ to identify the structural tax shock. Thus, they do not need to impose parameter restrictions, such as the cyclical elasticity of taxes to output. As I will discuss in section 2.4 below, one can extend this external instrument approach to estimating impulse responses by combining it with Jordà's (2005) method.

\subsubsection{Restrictions at Longer Horizons}

Rather than constraining the contemporaneous responses, one can instead identify a shock by imposing long-run restrictions. The most common is an infinite horizon long-run restriction, first used by Shapiro and Watson (1988), Blanchard and Quah (1989), and King, Plosser, Stock and Watson (1991). Consider the moving average representation of equation (2.3):

$$
Y_{t}=C(L) \eta_{t}
$$

where $C(L)=[A(L)]^{-1}$. Combining equation (2.4b) with (2.7), we can write the Y's in terms of the structural shocks:

$$
Y_{t}=D(L) \varepsilon_{t}
$$

where $D(L)=C(L) H$. Suppose we wanted to identify a technology shock as the only shock that affects labor productivity in the long-run. In this case, $Y_{1}$ would be the growth rate of labor 
productivity and the other variables would also be transformed to induce stationary (e.g. firstdifferenced). Letting $D^{i j}(L)$ denote the (i,j) element of the $\mathrm{D}$ matrix and $D^{11}(1)$ denote the lag polynomial with $\mathrm{L}=1$, we impose the long-run restriction by setting $D^{12}(1)=0$ and $D^{13}(1)=0$. This restriction constrains the unit root in $Y_{1}$ to emanate only from the shock that we are calling the technology shock. This is the identification used by Galí (1999).

An equivalent way of imposing this restriction is to use the estimation method suggested by Shapiro and Watson (1988). Let $Y_{1}$ denote the first-difference of the log of labor productivity and $Y_{2}$ and $Y_{3}$ be the stationary transformations of two other variables (such as hours). Then, imposing the long-run restriction is equivalent to identifying the error term in the following equation as the technology shock:

$$
Y_{1 t}=\sum_{j=1}^{p} \omega_{11, j} Y_{1 t-j}+\sum_{j=1}^{p-1} \omega_{12, j} \Delta Y_{2 t-j}+\sum_{j=1}^{p-1} \omega_{13, j} \Delta Y_{3 t-j}+\zeta_{t}
$$

We have imposed the restriction by specifying that only the first differences of the other stationary variables enter this equation. Because the current values of those differences might also be affected by the technology shock, and therefore correlated with the error term, we use lags 1 through $p$ of $Y_{2}$ and $Y_{3}$ as instruments for the terms involving the current and lagged values of those variables. The estimated residual is the identified technology shock. We can then identify the other shocks, if desired, by orthogonalizing the error terms with respect to the technology shock.

This equivalent way of imposing long-run identification restrictions highlights some of the problems that can arise with this method. First, identification depends on the relevance of the instruments. Second, it requires additional identifying restrictions in the form of assumptions about unit roots. If, for example, hours have a unit root, then in order to identify the technology shock one would have to impose that only the second difference of hours entered in equation (2.9). ${ }^{9}$

Another issue is the behavior of infinite horizon restrictions in small samples (e.g. Faust and Leeper (1997)). Recently, researchers have introduced new methods that overcome these problems. Building on earlier work by Faust (1998) and Uhlig (2003, 2004), Francis, Owyang,

\footnotetext{
${ }^{9}$ To be clear, all of the $\mathrm{Y}$ variables must be trend stationary in this system. If hours have a unit root, then $Y_{2}$ must be equal to $\Delta$ hours $_{t}$, so the constraint in (2.9) would take the form $\Delta^{2}$ hours $_{t}$
} 
Roush, and DiCecio (2014) identify the technology shock as the shock that maximizes the forecast error variance share of labor productivity at some finite horizon $h$. A variation by Barsky and Sims (2011) identifies the shock as the one that maximizes the sum of the forecast error variances up to some horizon $h$. See those papers for details on how to implement these methods.

\subsubsection{Sign Restrictions}

A number of authors had noted the circularity in some of the reasoning analyzing VAR specifications in practice. In particular, whether a specification or identification method is deemed "correct" is often judged by whether the impulses they produce are "reasonable," i.e. consistent with the researcher's priors. Faust (1998) and Uhlig (1997, 2005) developed a new method to incorporate "reasonableness" without undercutting scientific inquiry by investigating the effects of a shock on variable $Y$, where the shock was identified by sign restrictions on the responses of other variables (excluding variable Y). Work by Canova and De Nicoló (2002) and Canova and Pina (2005) introduced other variations.

The sign restriction method has been used in many contexts, such as monetary policy,

fiscal policy and technology shocks. Recently, there have been a number of new papers on sign restrictions using Bayesian methods. For example, Arias, Rubio-Ramirez, and Waggoner (2015) propose methods involving agnostic priors in one dimension and by Baumeister and Hamilton (2015) propose methods involving agnostic priors in another dimension. Amir and Uhlig (2015) combine sign restrictions with Bayesian Factor-Augmented VARs (FAVARs). See Stock and Watson (forthcoming) for more discussion of sign restrictions as an identification method.

\subsubsection{Factor-Augmented VARs}

A perennial concern in identifying shocks is that the variables included in the VAR do not capture all of the relevant information. The comparison of price responses in monetary VARs with and without commodity prices is one example of the difference a variable exclusion can make. To address this issue more broadly, Bernanke, Boivin, and Eliasz (2005) developed the 
Factor-Augmented VARs (FAVARS) based on earlier dynamic factor models developed by Stock and Watson (2002) and others. The FAVAR, which typically contains over one hundred series, has the benefit that it is much more likely to condition on relevant information for identifying shocks. In most implementations, though, it still typically relies on a Cholesky decomposition. Amir and Uhlig's (2015) new methods using sign restrictions in Bayesian FAVARs is one of the few examples that does not rely on Cholesky decompositions. One shortcoming of FAVAR methods is that all variables must be transformed to a stationary form, which requires pretesting and its concomitant problems (e.g. Elliott (1998), Gospodinov, Herrera, and Pesavento (2013)). See Stock and Watson (forthcoming) for an in depth discussion of dynamic factor models.

\subsubsection{Estimated DSGE Models}

An entirely different approach to identification is the estimated dynamic stochastic general equilibrium (DSGE) model, introduced by Smets and Wouters (2003, 2007). This method involves estimating a fully-specified model (a New Keynesian model with many frictions and rigidities in the case of Smets and Wouters) and extracting a full set of implied shocks from those estimates. In the case of Smets and Wouters, many shocks are estimated including technology shocks, monetary shocks, government spending shocks, wage markup shocks, and risk premium shocks. One can then trace out the impulse responses to these shocks as well as do innovation accounting. Other examples of this method appears in work by Justiano, Primiceri, Tambolotti (2010, 2011) and Schmitt-Grohe and Uribe (2012). Christiano, Eichenbaum and Evans (2005) take a different estimation approach by first estimating impulse responses to a monetary shock in a standard SVAR and then estimating the parameters of the DSGE model by matching the impulse responses from the model to those of the data.

These models achieve identification by imposing structure based on theory. It should be noted that identification is less straightforward in these types of models. Work by Canova and Sala (2009), Komunjer and Ng (2011), and others highlight some of the potential problems with identification in DSGE models. On the other hand, this method overcomes some of the potential problems of unrestricted VARs highlighted by Fernández-Villaverde, Rubio-Ramírez, Sargent and Watson (2007). 


\subsection{Estimating Impulse Responses}

Suppose that one has identified the economic shock through one of the methods discussed above. How do we measure the effects on the endogenous variables of interest? The most common way to estimate the impulse responses to a shock uses nonlinear (at horizons greater than one) functions of the estimated VAR parameters. In particular, estimation of the reduced form system provides the elements of the moving average representation matrix $C(L)=[A(L)]^{-1}$ in equation (2.7) and identification provides the elements of $B_{0}$. Recalling that $D(L)=C(L) H$, we write out $D(L)=D_{0}+D_{1} L+D_{2} L^{2}+D_{3} L^{3}+\cdots$, and denoting $D_{h}=\left[d_{i j h}\right]$, we can express the impulse response of variable $Y_{i}$ at horizon $t+h$ to a shock to $\varepsilon_{j t}$ as:

$$
\frac{\partial Y_{i, t+h}}{\partial \varepsilon_{j, t}}=d_{i j h}
$$

These $d_{i j h}$ parameters are nonlinear functions of the reduced form VAR parameters.

If the VAR adequately captures the data generating process, this method is optimal at all horizons. If the VAR is mispecified, however, then the specification errors will be compounded at each horizon. To address this problem, Jordà (2005) introduced a local projection method for estimating impulse responses. The comparison between his procedure and the standard procedure has an analogy with direct forecasting versus iterated forecasting (e.g. Marcellino, Stock, and Watson (2006)). In the forecasting context, one can forecast future values of a variable using either a horizon-specific regression (“direct” forecasting) or iterating on a one-period ahead estimated model ("iterated" forecasting). Jordà's method is analogous to the direct forecasting whereas the standard VAR method is analogous to the iterated forecasting method. Chang and Sakata (2007) introduce a related method they call long autoregression and show its asymptotic equivalence to Jordà's method.

To see how Jordà's method works, suppose that $\varepsilon_{1 t}$ has been identified by one of the methods discussed in the previous section. Then, the impulse response of $Y_{i}$ at horizon $h$ can be estimated from the following single regression:

$$
Y_{i, t+h}=\theta_{i, h} \varepsilon_{1 t}+\text { control variables }+\xi_{t+h}
$$


$\theta_{i, h}$ is the estimate of the impulse response of $Y_{i}$ at horizon h to a shock $\varepsilon_{1 t}$. The control variables need not include the other Y's as long as $\varepsilon_{1 t}$ is exogenous to those other $Y$ 's. Typically, the control variables include deterministic terms (constant, time trends), lags of the $Y_{\mathrm{i}}$, and lags of other variables that are necessary to "mop up;” the specification can be chosen using information criteria. One estimates a separate regression for each horizon and the control variables do not necessarily need to be the same for each regression. Note that except for horizon $h=0$, the error term $\xi_{t+h}$ will be serially correlated because it will be a moving average of the forecast errors from $t$ to $t+h$. Thus, the standard errors need to incorporate corrections for serial correlation, such as a Newey-West (1987) correction.

Because the Jordà method for calculating impulse response functions imposes fewer restrictions, the estimates are often less precisely estimated and are sometimes erratic. Nevertheless, this procedure is more robust than standard methods, so it can be very useful as a heuristic check on the standard methods. Moreover, it is much easier to incorporate statedependence with this method (e.g. Auerbach and Gorodnichenko (2013)).

One can extend the Jordà method in several ways that incorporates some of the new methodology. First, one can incorporate the advantages of the FAVAR method (see Section 2.3.8) by including estimated factors as control variables. Second, one can merge the insights from the external instrument/proxy SVAR method (see Section 2.3.5). To see this, modify equation (2.11) as follows:

$$
Y_{i, t+h}=\theta_{i, h} Y_{1, t}+\text { control variables }+\zeta_{t+h} \text {, }
$$

where we have replaced the shock $\varepsilon_{1 t}$ with $Y_{1, t \cdot}$ As discussed above, an OLS regression of $Y_{i}$ on $Y_{1}$ cannot capture the structural effect if $Y_{1}$ is correlated with $\zeta_{t+h}$. We can easily deal with this issue, however, by estimating this equation using the external instrument $Z_{t}$ as an instrument for $Y_{1, t}$. For example, if $Y_{i}$ is real output and $Y_{1, t}$ is the federal funds rate, we can use Romer and Romer's (2004) narrative-based monetary shock series as an instrument. As I will discuss below, in some cases there are multiple potential external instruments. We can readily incorporate these in this framework by using multiple instruments for $Y_{1}$. In fact, these overidentifying restrictions can be used to test the restrictions of the model (using a Hansen’s $J$-statistic, for example). 


\subsection{The Problem of Foresight}

The problem of foresight presents serious challenges to, but also opportunities for, the identification of macroeconomic shocks. ${ }^{10}$ There are two main foresight problems: (i) foresight on the part of private agents; and (ii) foresight on the part of policy makers. I will discuss each in turn.

It is likely that many changes in policy or other exogenous shocks are anticipated by private agents in advance. For example, Beaudry and Portier (2006) explicitly take into account that news about future technology may have effects today even though it does not show up in current productivity. Ramey (2011) argues that the results of Ramey and Shapiro (1998) and Blanchard and Perotti (2002) differ because most of the latter's identified shocks to government spending are actually anticipated. Building on work by Hansen and Sargent (1991), Leeper, Walker, and Yang (2013) work out the econometrics of "fiscal foresight" for taxes, showing that foresight can lead to a non-fundamental moving average representation. The growing importance of "forward guidance” in monetary policy means that many changes in policy rates may be anticipated.

Consider the following example, based on Leeper et al. (2013), of a simple growth model with a representative household with log utility over consumption, discount factor $\beta$, and a production function $Y_{t}=A_{t} K_{t-1}^{\alpha}$, with $\alpha<1$. The government taxes output $Y$ at a rate $\tau_{t}$ and there are i.i.d. shocks, $\hat{\tau}_{t}$, to the tax rate relative to its mean $\tau$. Shocks to technology, $\varepsilon_{A t}$, are also i.i.d. Suppose that agents potentially receive news in period t of what the tax rate will be in $t+q$, so that $\hat{\tau}_{t}=\varepsilon_{\tau, t-q}$. If the shocks are unanticipated $(\mathrm{q}=0)$, the rule for capital accumulation is:

$$
k_{t}=\alpha k_{t-1}+\varepsilon_{A, t}
$$

\footnotetext{
10 The general problem was first recognized and discussed decades ago. For example, Sims (1980) states: "It is my view, however, that rational expectations is more deeply subversive of identification than has yet been recognized."
} 
which reproduces the well-known result that unanticipated i.i.d. tax rate shocks have no effect on capital accumulation. If the tax rate shock is anticipated two periods in advance $(q=2)$, however, then optimal capital accumulation is:

$$
k_{t}=\alpha k_{t-1}+\varepsilon_{A, t}-\kappa\left\{\varepsilon_{\tau, t-1}+\theta \varepsilon_{\tau, t}\right\}
$$

where $\theta=\alpha \beta(1-\tau)<1$ and $\kappa=(1-\theta) \frac{\tau}{1-\tau}$. Can we uncover the tax shocks by regressing capital on its own lags? No, we cannot. Because $\theta<1$, this representation is not invertible in the current and past $k$ 's; we say that $\left\{\varepsilon_{\tau, t-j}\right\}_{j=0}^{\infty}$ is not fundamental for $\left\{k_{t-j}\right\}_{j=0}^{\infty}$. If we regress $\mathrm{k}_{\mathrm{t}}$ on its own lags and recover the innovations, we would be recovering the discounted sum of tax news observed at date $t$ and earlier, i.e., "old" news. Adding lagged taxes to the VAR does not help.

Beaudry, Fève, and Guay (2015) develop a diagnostic to determine whether nonfundamentalness is quantitatively important. They argue that in some cases the non-fundamental representation is close to the fundamental representation.

The second foresight problem is foresight on the part of policymakers. Sometimes policymakers have more information about the state of the economy than private agents. If this is the case, and we do not include that information in the VAR, part of the identified shock may include the endogenous response of policy to expectations about the future path of macroeconomic variables. Consider the "price puzzle" in monetary VARs, meaning that some identified monetary policy shocks imply that a monetary contraction raises prices in the shortrun. Sims (1992) argued that the "price puzzle" was the result of typical VARs not including all relevant information for forecasting future inflation. Thus, the identified policy shocks included not only the exogenous shocks to policy but also the endogenous policy responses to forecasts of future inflation. In the fiscal context, governments may undertake fiscal consolidations based on private information about declining future growth of potential GDP. If this is not taken into account, then a finding that a fiscal consolidation lowers output growth may be confounding causal effects with foresight effects.

The principal methods for dealing with the problem of foresight are measuring the expectations directly, time series restrictions, or theoretical model restrictions. For example, 
Beaudry and Portier (2006) extracted news about future technology from stock prices; Ramey (2011) created a series of news about future government spending by reading Business Week and other periodicals; Fisher and Peters (2010) created news about government spending by extracting information from stock returns of defense contractors; Poterba (1986) and Leeper, Richter, Walker (2012) used information from the spread between federal and municipal bond yields for news about future tax changes; and Mertens and Ravn (2012) decomposed Romer and Romer's (2010) narrative tax series into one series in which implementation was within the quarter ("unanticipated”) and another series in which implementation was delayed ("news”). In the monetary shock literature, many papers use high frequency financial futures prices to extract the anticipated versus unanticipated component of interest rates changes (e.g. Rudebusch (1998), Bagliano and Favero (1999), Kuttner (2001), and Gürkaynak, Sack and Swanson (2005).

The typical way that news has been incorporated into VARs is by adding the news series to a standard VAR, and ordering it first. Perotti (2011) has called these "EVARs" for "Expectational VARs." Note that in general one cannot use news as an external instrument in Mertens and Ravn's proxy SVAR framework. The presence of foresight invalidates the interpretation of the VAR reduced form residuals as prediction errors, since the conditioning variables may not span the information set of forward looking agents (Mertens and Ravn (2013, 2014)).

\subsection{The Problem of Trends}

Most macroeconomic variables are nonstationary, exhibiting behavior consistent with either deterministic trends or stochastic trends. A key question is how to specify a model when many of the variables may be trending. Sims, Stock and Watson (1990) demonstrate that even when variables might have stochastic trends and might be cointegrated, the log levels specification will give consistent estimates. While one might be tempted to pretest the variables and impose the unit root and cointegration relationships to gain efficiency, Elliott (1998) shows that such a procedure can lead to large size distortions in theory. More recently, Gospodinov, Herrera, and Pesavento (2013) have demonstrated how large the size distortions can be in practice. 
Perhaps the safest method is to estimate the SVAR in log levels (perhaps also including some deterministic trends) as long as the imposition of stationarity is not required for identification. One can then explore whether the imposition of unit roots and cointegration lead to similar results but increase the precision of the estimates. For years, it was common to include a linear time trend in macroeconomic equations. Many analyses now include a broken trend or a quadratic trend to capture features such as the productivity slowdown in 1974 or the effect of the baby boom moving through the macroeconomic variables (e.g. Perron (1989), Francis and Ramey (2009)).

\subsection{Some Brief Notes on Nonlinearities}

In the previous sections, we have implicitly assumed that the relationships we are trying to capture can be well-approximated with linear functions. There are many cases in which we believe that nonlinearities might be important. To name just a few possible nonlinearities, positive shocks might have different effects from negative shocks, effects might not be proportional to the size of the shock, or the effect of a shock might depend on the state of the economy when the shock hits.

A thorough analysis of nonlinearities is beyond the scope of this chapter, so I will mention only three items briefly. First, Koop, Pesaran, and Potter (1996) provide a very useful analysis of the issues that arise when estimating impulse responses in nonlinear models. Second, if one is interested in estimating state dependent models, the Jordà (2005) local projection method is a simple way to estimate such a model and calculate impulse response functions. Auerbach and Gorodnichenko (2013) and Ramey and Zubairy (2014) discuss this application and how it relates to another leading method, Smooth Transition VARs.

The third point is a cautionary note when considering the possibility of asymmetries. Many times researchers posit that only positive, or only negative, shocks matter. For example, in the oil shock literature, it is common to assume that only oil price increases matter and to include a variable in the VAR that captures increases but not decreases. Kilian and Vigfusson (2011) demonstrate the serious biases and faulty inference that can result from this specification. Their explanation is simple. Suppose $Y$ is a linear function of $X$, where $X$ takes on both negative and positive values. If one imposes the restriction that only positive values matter, one is in essence 
setting all of the negative values of $X$ to zero. Figure 1 of Kilian and Vigfusson's paper demonstrates how this procedure that truncates on the $X$ variable produces slope coefficients that are biased upward in magnitude. Thus, one would incorrectly conclude that positive $X$ 's have a greater impact than negative $X$ 's, even when the true relationship is linear. To guard against this faulty inference, one should always make sure that the model nests the linear case when one is testing for asymmetries. If one finds evidence of asymmetries, then one can use Kilian and Vigfusson’s (2011) methods for computing the impulse responses correctly.

\subsection{DSGE Monte Carlos}

Much empirical macroeconomics is linked to testing theoretical models. A question that arises is whether shocks identified in SVARs, often with minimal theoretical restrictions, are capable of capturing the true shocks. Fernández-Villaverde et al. (2007) study this question by comparing the state-space representation of a theoretical model with the VAR representation. They note that in some instances an invertibility problem can arise and they offer a method to check whether the problem is present.

Erceg, Guerrieri, and Gust (2005) were perhaps the first to subject an SVAR involving long-run restrictions to what I will term a "DSGE Monte Carlo.” In particular, they generated artificial data from a calibrated DSGE model and applied SVARS with long-restrictions to the data to see if the implied impulse responses matched those of the underlying model.

This method has now been used in several settings. Chari, Kehoe, and McGrattan (2008) used this method to argue against SVARs' ability to test the RBC model, Ramey (2009) used it to show how standard SVARs could be affected by anticipated government spending changes, and Francis, Owyang, Roush, and DiCecio (2014) used this method to verify the applicability of their new finite horizon restrictions method. This method seems to be a very useful tool for judging the ability of SVARs to test DSGE models. Of course, like any Monte Carlo, the specification of the model generating the artificial data is all important.

\section{Monetary Policy Shocks}


Having discussed the definition of macroeconomic shocks and the leading methods for identifying them, I now turn to the first of the candidate shocks that will be discussed in detail: monetary policy shocks. In this section, I review the main issues and results from the empirical literature seeking to identify and estimate the effects of monetary policy shocks. I begin with a brief overview of the research before and after Christiano, Eichenbaum, and Evan's (1999) Handbook of Macroeconomics chapter on the subject. I revisit Christiano, Eichenbaum and Evan's specification, and then focus on two leading types of externally identified monetary policy shocks, Romer and Romer's (2004) narrative/Greenbook shock and Gertler and Karadi's (2015) recent high frequency identification shocks identified using fed funds futures. I focus on these two types of shocks in part because they both imply very similar effects of monetary policy on output, despite using different identification methods and different samples.

Before beginning, it is important to clarify that the "shocks" identified in the monetary shock literature are not always the empirical counterparts to the shocks from our theoretical models, as discussed in Section 2.1. Because monetary policy is typically guided by a rule, most movements in monetary policy instruments are due to the systematic component of monetary policy rather than to deviations from that rule. ${ }^{11}$ We do not have many good economic theories for what a structural monetary policy shock should be. Other than "random coin flipping," the most frequently discussed source of monetary policy shocks is shifts in central bank preferences, caused by changing weights on inflation vs. unemployment in the loss function or by a change in the political power of individuals on the FOMC. A few papers explicitly link the empirically identified shocks to shifts in estimated central bank preferences (e.g. Owyang and Ramey (2004) and Lakdawala (2015)), but most treat them as innovations to a Taylor rule, with no discussion of their economic meaning. ${ }^{12}$

If many macroeconomists now believe that monetary policy shocks themselves contribute little to macroeconomic outcomes, why is there such a large literature trying to identify them? The reason is that we want to identify nonsystematic movements in monetary policy so that we can estimate causal effects of money on macroeconomic variables. As Sims (1998) argued in his response to Rudebusch's (1998) critique of standard VAR methods, we need instruments in order to identify key structural parameters. Analogous to the supply and demand framework where we

\footnotetext{
${ }^{11}$ Milton Friedman argued, however, that most fluctuations in monetary instruments before 1960 were due to nonsystematic components of monetary policy.

${ }^{12}$ Christiano, Eichenbaum and Evans (1999) discuss a few other possibilities, such as measurement error in preliminary data (pp. 71-73).
} 
need demand shift instruments to identify the parameters of the supply curve, in the monetary policy context we require deviations from the monetary rule to identify the response of the economy to monetary policy. Thus, much of the search for "shocks" to monetary policy is a search for instruments rather than for primitive macroeconomic shocks.

\subsection{A Brief History through 1999}

The effect of monetary policy on the economy is one of the most studied empirical questions in all of macroeconomics. The most important early evidence was Friedman and Schwartz's path-breaking 1963 contribution in the form of historical case studies and analysis of historical data. The rational expectations revolution of the late 1960s and 1970s highlighted the importance of distinguishing the part of policy that was part of a rule versus shocks to that rule, as well as anticipated versus unanticipated parts of the change in the policy variable. Sims (1972, 1980a, 1980b) developed modern time series methods that allowed for that distinction while investigating the effects of monetary policy. During the 1970s and much of the 1980s, shocks to monetary policy were measured as shocks to the stock of money (e.g. Sims (1972), Barro (1977, 1978)). This early work offered evidence that (i) money was (Granger-) causal for income; and (ii) that fluctuations in the stock of money could explain an important fraction of output fluctuations. Later, however, Sims (1980b) and Litterman and Weis (1985) discovered that the inclusion of interest rates in the VAR significantly reduced the importance of shocks to the money stock for explaining output, and many concluded that monetary policy was not important for understanding economic fluctuations. ${ }^{13}$

There were two important rebuttals to the notion that monetary policy was not important for understanding fluctuations. The first rebuttal was by Romer and Romer (1989), who developed a narrative series on monetary policy shocks in the spirit of Friedman and Schwarz's (1963) work. Combing through FOMC minutes, they identified dates at which the Federal Reserve "attempted to exert a contractionary influence on the economy in order to reduce inflation” (p. 134). They found that industrial production decreased significantly after one of these “Romer Dates.” The Romer and Romer series rapidly gained acceptance as an indicator of

13 Of course, this view was significantly strengthened by Kydland and Prescott's (1982) seminal demonstration that business cycles could be explained with technology shocks. 
monetary policy shocks. ${ }^{14}$ A few years later, though, Shapiro (1994) and Leeper (1997) showed that Romer and Romer's dummy variable was, in fact, predictable from lagged values of output (or unemployment) and inflation. Both argued that the narrative method used by Romer and Romer did not adequately separate exogenous shocks to monetary policy, necessary for establishing the strength of the causal channel, from the endogenous response of monetary policy to the economy. ${ }^{15}$

The second rebuttal to the Sims and Litterman and Weiss argument was by Bernanke and Blinder (1992). Building on an earlier idea by McCallum (1983), Bernanke and Blinder turned the money supply vs. interest rate evidence on its head by arguing that interest rates, and in particular the federal funds rate, were the key indicators of monetary policy. They showed that both in Granger-causality tests and in variance decompositions of forecast errors, the federal funds rate outperformed both M1 and M2, as well as the three-month Treasury bill and the 10month Treasury bond for most variables.

The 1990s saw numerous papers that devoted attention to the issue of the correct specification of the monetary policy function. These papers used prior information on the monetary authority's operating procedures to specify the policy function in order to identify correctly the shocks to policy. For example, Christiano and Eichenbaum (1992) used nonborrowed reserves, Strongin (1995) suggested the part of nonborrowed reserves orthogonal to total reserves, and Bernanke and Mihov (1998) generalized these ideas by allowing for regime shifts in the type of monetary instrument that is targeted. ${ }^{16}$ Another issue that arose during this period was the "Price Puzzle," a term coined by Eichenbaum (1992) to describe the common result that a contractionary shock to monetary policy appeared to raise the price level in the short-run. Sims (1992) conjectured that the Federal Reserve used more information about future movements in inflation than was commonly included in the VAR. He showed that the price puzzle was substantially reduced if commodity prices, often a harbinger of future inflation, were included in the VAR.

Christiano, Eichenbaum, and Evans' 1999 Handbook of Macroeconomics chapter “Monetary Policy Shocks: What Have We Learned and To What End?” summarized and

\footnotetext{
${ }^{14}$ Boschen and Mills (1995) also extended the Romers' dummy variables to a more continuous indicator.

${ }^{15}$ See, however, Romer and Romer's (1997) response to Leeper.

${ }^{16}$ An important part of this literature was addressed to the "liquidity puzzle," that is, the failure of some measures of money supply shocks to produce a negative short-run correlation between the supply of money and interest rates.
} 
explored the implications of many of the 1990 innovations in studying monetary policy shocks. Their benchmark model used a particular form of the Cholesky decomposition in which the first block of variables consisting of output, prices, and commodity prices was assumed not to respond to monetary policy shocks within the quarter (or month). They called this identification assumption the "recursiveness assumption." On the other hand, they allowed contemporaneous values of the first-block variables to affect monetary policy decisions. Perhaps the most important message of the chapter was the robustness of the finding that a contractionary monetary policy shock, whether measured with the federal funds rate or nonborrowed reserves, had significant negative effects on output. On the other hand, the price puzzle continued to pop up in some specifications.

\subsection{Some Alternatives to the Standard Model}

Not all research on monetary policy shocks has been conducted in the canonical timeinvariant linear SVAR model. In this section, I briefly highlight some of the research that generalizes the linear models or uses completely different methods.

\subsubsection{Regime Switching Models}

In addition to the switch between interest rate targeting and nonborrowed reserve targeting (discussed by Bernanke and Mihov (1998)), several papers have estimated regime switching models of monetary policy. The idea in these models is that monetary policy is driven not just by shocks but also by changes in the policy parameters. In an early contribution to this literature, Owyang and Ramey (2004) estimated a regime switching model in which the Fed's preference parameters could switch between "hawk" and "dove” regimes. They found that the onset of a dove regime leads to a steady increase in prices, followed by decline in output after approximately a year. Primiceri (2005) investigated the roles of changes in systematic monetary policy versus shocks to policy in the outcomes in the last 40 years. While he found evidence for changes in systematic monetary policy, he concluded that they are not an important part of the explanation of fluctuations in inflation and output. Sims and Zha (2006a) also considered regime switching models and found evidence of regime switches that correspond closely to changes in 
the Fed chairmanship. Nevertheless, they also concluded that changes in monetary policy regimes do not explain much of economic fluctuations.

\subsubsection{Time-Varying Effects of Monetary Policy}

In their summary of the monetary policy literature in their chapter in the Handbook of Monetary Economics, Boivin, Kiley, and Mishkin (2010) focus on time variation in the estimated effects of monetary policy. I refer the reader to their excellent survey for more detail. I will highlight two sets of results that emerge from their estimation of a factor-augmented VAR (FAVAR), using the standard Cholesky identification method. First, they confirm some earlier findings that the responses of real GDP were greater in the pre-1979Q3 period than in the post1984Q1 period. ${ }^{17}$ For example, they find that for the earlier period, a 100 basis point increase in the federal funds rate leads to a decline of industrial production of 1.6 percent troughing at 8 months. In the later period, the same increase in the funds rate leads to a -0.7 percent decline troughing at 24 months. The second set of results concerns the price puzzle. They find that in a standard VAR the results for prices are very sensitive to the specification. Inclusion of a commodity price index does not resolve the price puzzle, but inclusion of a measure of expected inflation does resolve it in the post-1984:1 period. In contrast, there is no price puzzle in the results from their FAVAR estimation. Boivin et al. (2010) discuss various reasons why the monetary transmission mechanism might have changed, such as changes in the regulatory environment affecting credit and the anchoring of expectations.

Barakchian and Crowe (2013) estimate many of the standard models, such as by those by Bernanke and Mihov (1998), CEE (1999), Romer and Romer (2004), and Sims and Zha (2006b), splitting the estimation sample in the 1980s and showing that the impulse response functions change dramatically. In particular, most of the specifications estimated from 1988 - 2008 show that a positive shock to the federal funds rate raises output and prices in most cases.

Another source of time variation is state-dependent or sign-dependent effects of monetary shocks on the economy. Cover (1992) was one of the first to present evidence that negative monetary policy shocks had bigger effects (in absolute value) than positive monetary shocks. Follow-up papers such as by Thoma (1994) and Weisse (1999) found similar results. Recent

\footnotetext{
${ }^{17}$ See, for example, Faust (1998), Barth and Ramey (2002) and Boivin and Giannoni (2006).
} 
work by Angrist, Jordà, and Kuersteiner (2013) finds related evidence that monetary policy is more effective in slowing economic activity than it is in stimulating economic activity. Tenreyro and Thwaites (2014) also find that monetary shocks seem to be less powerful during recessions.

Olivei and Tenreyro (2007) estimate important seasonality in the effects of monetary shocks that is well-explained by sticky wage models. They find that monetary shocks that take place in the first two quarters of the year have sizeable, but temporary effects, on output whereas shock that take place in the third and fourth quarters of the year have little effect on output. They explain these results with evidence on uneven staggering of labor contracts over the year: a shock that hits near the end of the year has little effect because the bulk of wage contracts are reset then, so wages can adjust immediately.

Since fall 2008, the federal funds rate has been near the zero lower bound. Thus, a key question that has arisen is how to measure shocks in light of this nonlinear constraint. Wu and Xia (forthcoming) use a multifactor Shadow Rate Term Structure Model to estimate a shadow federal funds rate. This shadow rate can capture additional features, such as quantitative easing. $\mathrm{Wu}$ and Xia find that unconventional monetary policy has a noticeable impact on the macroeconomy.

\subsubsection{Historical Case Studies}

Given the important impact of Friedman and Schwartz's (1963) case study of monetary policy during the Great Depression, it is surprising that more case studies have not been conducted. Romer and Romer (1989)'s first narrative monetary analysis was designed to be a quasi-case study in the spirit of Friedman and Schwartz. Their dummy variable series was assigned to episodes in which the Fed decided to risk a recession in order to reduce inflation.

Velde (2009) presents one of the most striking case studies of monetary nonneutrality, based on an episode in 1724 France. In that year, the French government cut the money supply three times, resulting in a cumulative drop of 45 percent! The action was taken for a variety of reasons, such as long-term price targeting and worries that soldiers and creditors of the state were being hurt by the rise in prices during the previous six years. Velde finds that while prices on foreign exchange markets adjusted instantly, other prices adjusted slowly and incompletely and 
industrial output fell by 30 percent. The circumstances of that episode are unusually clean for a historical case study, so his evidence of monetary nonneutrality is quite compelling.

\subsection{Main Identification Challenges}

Several parts of Section 2 discussed some of the challenges to identification in general. Here, I review the issues that are particular important for the identification of monetary policy shocks.

\subsubsection{The Recursiveness Assumption}

A key assumption used by Christiano, Eichenbaum, and Evans (1999) (CEE) was the "recursiveness assumption." Consider the trivariate model from equation (2.5) in the last section, rewritten here for convenience:

$$
\begin{aligned}
& \eta_{1 t}=b_{12} \eta_{2 t}+b_{13} \eta_{3 t}+\varepsilon_{1 t} \\
& \eta_{2 t}=b_{21} \eta_{1 t}+b_{23} \eta_{3 t}+\varepsilon_{2 t} \\
& \eta_{3 t}=b_{31} \eta_{1 t}+b_{32} \eta_{2 t}+\varepsilon_{3 t}
\end{aligned}
$$

CEE include more than three variables in the system, so we should think of each $\eta_{t}$ as representing a block of variables: $\eta_{1 t}$ includes output, a general price index, and a commodities price index; $\eta_{2 t}$ is the federal funds rate; and $\eta_{3 t}$ contains a monetary stock measure such as M1 or M2, nonborrowed reserves, and total reserves. CEE interpret the equation for $\eta_{2 t}$ as the Fed's feedback rule and $\varepsilon_{2 t}$ as the monetary policy shock. They assume that current values of the $\eta_{1 t}$ enter the Fed's rule, so $b_{21} \neq 0$, but the money stock and reserves do not enter the rule, so $b_{23}=0$. These are still not enough assumptions to identify the monetary policy shock because if the monetary policy shock can affect output, etc. within the period, $\eta_{1 t}$ will be correlated with $\varepsilon_{2 t}$ so we cannot use OLS. CEE thus add the additional recursiveness assumptions that none of the $\eta_{1 t}$ variables (output and prices) is affected by the monetary policy shock or the monetary aggregates within the period, i.e., $b_{12}=b_{13}=0$. In practice, this is just a Cholesky 
decomposition generalized to blocks of variables. Since CEE focused only on the monetary policy shock, they did not need to make more assumptions to identify shocks within the first and third block.

It is important to emphasize, however, the importance of the recursiveness assumption for identification. All of CEE's results depend on setting $b_{12}=0$, meaning that output and prices are not allowed to respond to changes in the federal funds rate within the period. Note that this assumption is at odds with some later estimated New Keynesian DSGE models. For example, Smets and Wouters' (2007) estimated model implies that output, hours, and inflation should respond immediately to the monetary policy shock (see Figure 6 of their paper). The estimated DSGE model of Christiano, Eichenbaum and Evans (2005) does not imply an immediate response, but only because they assume that no agents can react to the monetary policy shock within the period. They make this theoretical assumption because they estimate their model parameters to match the impulse responses of their VARs which identify the monetary policy shock with the recursiveness assumption.

Even research that develops external instruments typically uses the recursiveness assumption. For example, Romer and Romer (2004) develop a new measure of monetary policy shocks using narrative methods and Greenbook forecasts, but when they study the effects on output and prices, they impose the additional constraint that $b_{12}=b_{13}=0$. They do so because they do not view their estimated shock as being pure, and thus also use the recursivity assumption as “exogeneity insurance.” Coibion's (2012) generalization of the Romer and Romer procedures also imposes the constraint. Barakchian and Crowe (2013) use high frequency identification from fed funds futures, but nevertheless invoke the recursiveness assumption in their VARs. The typical FAVAR models, such as those by Bernanke, Boivin, and Eliasz (2005) and Boivin, Kiley, and Mishkin (2010), use the recursiveness assumption as well.

Some of the few papers that do not use the recursiveness assumption are those that use sign restrictions. Uhlig (1997, 2005), Faust (1998), Faust, Swanson, Wright (2004), Arias, Caldara, Rubio-Ramírez (2015) and Amir and Uhlig (2015) are able to avoid imposing the zero restriction associated with the recursiveness assumption by instead using sign restriction, also known as "set identification" or partial identification. For example, Uhlig $(1997,2005)$ imposes the restriction that contractionary monetary policy shocks cannot raise prices. Faust, Swanson, and Wright (2004) constrain $-0.1 \leq b_{12} \leq 0$ for the output and price equations. The sign 
restriction papers can often yield confidence sets that imply possibly positive effects of contractionary monetary policy on output (e.g. Uhlig (2005), Faust, Swanson, and Wright (2004), Amir and Uhlig (2015)).

In section 3.4, I will investigate the importance of the recursiveness assumption in more detail.

\subsubsection{Foresight Problems}

Section 2.5 discussed how two types of foresight could create problems in identifying shocks and their effects. Both types of foresight are particularly important for monetary policy, and significant progress has been made recently both in appreciating their importance and in developing methods for addressing them.

The first type of foresight problem is foresight on the part of policymakers. As an illustration of the problem, suppose the Fed follows a simple policy rule:

$$
f f_{t}=\alpha_{1} E_{t}\left(\Delta_{h} y_{t+h}\right)+\alpha_{2} E_{t}\left(\Delta_{h} \pi_{t+h}\right)+\varepsilon_{f t},
$$

where $f f$ is the fed funds rate, $y$ is log output, and $\pi$ is inflation. $\Delta_{h}$ is the change in the variable from $t$ to $t+h$. The Fed sets interest rates based on its expectations of the future path of output and inflation because is aware of the lags in the effects of monetary policy. I have modeled this simply as expectations of changes from $t$ to $t+h$, but the argument applies for more general notions of expectations about the path.

The usual SVAR specification assumes that the Fed's expectations about the future paths of output and inflation are adequately captured by the current and lagged values of the (typically) few macroeconomic variables included in the SVAR. This is a strong assumption. The idea that identified monetary shocks might be incorrectly mixing systematic responses to the Fed's expectations was first highlighted by Sims (1992), who argued that the price puzzle was due to the Fed observing more information on inflation. He advocated the incorporation of sensitive commodity prices to address the problem. However, this inclusion does not always get rid of the price puzzle. Bernanke, Boivin, and Eliasz's (2005) Factor-Augmented VARs (FAVARS) are another method for incorporating more information. The FAVAR, which typically contains over 
one hundred series, has the benefit that it is much more likely to condition on relevant information for identifying shocks. The FAVAR method nonetheless relies on the assumption that linearly combinations of publicly available series fully capture the Fed's expectations.

In a 2000 paper, Romer and Romer presented evidence suggesting that the Fed had superior information when constructing inflation forecasts compared to the private sector. To see the problem this asymmetric information presents, rewrite equation (3.2) as:

$$
\begin{aligned}
f f_{t}= & \alpha_{1} E_{t}^{p}\left(\Delta_{h} y_{t+h}\right)+\alpha_{2} E_{t}^{p}\left(\Delta_{h} \pi_{t+h}\right)+\alpha_{1}\left[E_{t}^{f}\left(\Delta_{h} y_{t+h}\right)-E_{t}^{p}\left(\Delta_{h} y_{t+h}\right)\right] \\
& +\alpha_{2}\left[E_{t}^{f}\left(\Delta_{h} \pi_{t+h}\right)-E_{t}^{p}\left(\Delta_{h} \pi_{t+h}\right)\right]+\varepsilon_{f t},
\end{aligned}
$$

In this equation, $E_{t}^{p}$ denotes expectations based on private agent information and $E_{t}^{f}$ denotes expectations based on the Fed's information. If information is symmetric and publicly available, then the two terms in square brackets will be zero and methods that incorporate sufficient amounts of public information should be able to identify the monetary policy shock $\varepsilon_{f t}$ correctly. If, on the other hand, the Fed has superior information, the terms in brackets will not be zero and an SVAR or FAVAR will produce an incorrectly identified monetary policy shock, $\tilde{\varepsilon}_{f t}$ that consists of two components, the true shock as well as a component based on the informational superiority of the Fed:

$$
\tilde{\varepsilon}_{f t}=\varepsilon_{f t}+\alpha_{1}\left[E_{t}^{f}\left(\Delta_{h} y_{t+h}\right)-E_{t}^{p}\left(\Delta_{h} y_{t+h}\right)\right]+\alpha_{2}\left[E_{t}^{f}\left(\Delta_{h} \pi_{t+h}\right)-E_{t}^{p}\left(\Delta_{h} \pi_{t+h}\right)\right]
$$

Barth and Ramey (2002) suggested that the problem might be corrected by controlling for Fed forecasts in VARs. They augmented their monetary VARs with Greenbook forecasts of inflation and output in order to determine whether controls for the Fed's superior information would make the price puzzle disappear in their early sample from 1965 to 1979. They found that even with the controls for the Greenbook forecasts, the price puzzle was still very strong in this early sample (see Figure 7 of their paper).

Romer and Romer (2004) (R\&R) combined the use of Greenbook forecasts with narrative methods to construct a new measure of monetary policy shocks. First, they derived a series of 
intended federal funds rate changes during FOMC meetings using narrative methods. Second, in order to separate the endogenous response of policy to information about the economy from the exogenous shock, they regressed the intended funds rate change on the current rate and on the Greenbook forecasts of output growth and inflation over the next two quarters. They then converted the estimated residuals based on the FOMC meeting frequency data to monthly and used them in dynamic regressions for output and other variables. They found very large effects of these shocks on output.

John Cochrane’s (2004) NBER EFG discussion of the Romer and Romer paper highlights how their method can identify movements in monetary policy instruments that are exogenous to the error term of the model. If the Greenbook forecast of future GDP growth contains all of the information that the FOMC uses to make its decisions, then that forecast is a "sufficient statistic." Any movements in the target funds rate that are not predicted by the Greenbook forecast of future output can be used as an instrument to identify the causal effect of monetary policy on output. Analogously, any movements in the target funds rate that are not predicted by the Greenbook forecast of inflation can be used as an instrument to identify the causal effect of monetary policy on inflation. The idea is that if the Fed responds to a shock for reasons other than its effect on future output or future inflation, that response can be used as an instrument for output or inflation. Cochrane states the following proposition in his discussion:

Proposition 1: To measure the effects of monetary policy on output it is enough that the shock is orthogonal to output forecasts. The shock does not have to be orthogonal to price, exchange rate, or other forecasts. It may be predictable from time t information; it does not have to be a shock to the agent's or the Fed's entire information set. (Cochrane (2004)).

Cochrane's conceptualization of the issue of identifying movements in monetary policy that are exogenous to the error term in the equation is an important step forward. Note, however, that what Cochrane calls a "shock" is not the same as the definition of shock that I use in this chapter. Cochrane's notion of a shock is not a primitive structural shock, but rather a useful instrument for estimating the effect of monetary policy on output, etc. 
The possibility of asymmetric information between the Fed and the private sector leads to a further complication, though. If the Federal Reserve has superior information, then any action or announcement by the Fed presents a signal extraction problem for private agents. Private agents observe $\tilde{\varepsilon}_{f t}$ in equation (3.2) above, but they know that it is composed of the true shock as well as the systematic component of the Fed's rule based on the Fed's informational advantage. The problem can easily be extended to include the possibility that $\tilde{\varepsilon}_{f t}$ also contains time-varying inflation or output targets that are unobserved the public. Gürkaynak, Sack and Swanson (2005) argue that their estimated negative effects of an unanticipated rise in the federal funds rate on long-term forward rates can be explained as the response to information revealed by the Fed action about inflation targets.

The second type of foresight problem is news about future policy actions. Campbell, Evans, Fisher, and Justiniano (2012) argue that the Fed has been using forward guidance since the early 1990s. This means that many changes in the federal funds rate are in fact anticipated in advance. As discussed in Section 2.5 on foresight, foresight about future movements in policy variables can lead to a non-fundamental moving average representation. This would imply that standard VARs typically cannot be used to identify the shocks.

Fortunately, the monetary literature has developed excellent methods for identifying news shocks. As discussed in Section 2.3.4, research by many, such as Kuttner (2001), Cochrane and Piazzesi (2002), Gürkaynak, Sack and Swanson (2005), Piazzesi and Swanson (2008), Barakchian and Crowe (2013), Gertler and Karadi (2015), and Nakamura and Steinsson (2015), has used the movements of federal funds and other interest rate futures in small windows around FOMC announcements to identify unexpected Fed policy actions. Exploiting the information in interest rate futures is an ideal way to construct “news” series. D’Amico and King (2015) study the effects of anticipated monetary policy by combining information on expectations, as in Campbell et al. (2012), with sign restrictions in an SVAR. In particular, they identify a monetary news shock by restricting the responses of the expected short term rate to move in the opposite direction of expected inflation and expected output.

\subsection{Summary of Recent Estimates}


Table 3.1 summarizes some of the main results from the literature on the impact of the identified monetary shock on output, the contribution of monetary shocks to output fluctuations, and whether the price puzzle is present. Rather than trying to be encyclopedic in listing all results, I have chosen leading examples obtained with the various identifying assumptions. In addition, I attempted to standardize the results by normalizing the peak of response of the federal funds rate to 100 basis points; this standardization does not control for differences in persistence of the response as I discuss below.

As the table shows, the standard CEE (1999) SVAR, the Faust, Swanson, Wright (2004) high frequency identification, Uhlig's (2005) and Amir and Uhlig's (2015) sign restrictions, Smets and Wouters' (2007) estimated DSGE model, and Bernanke, Boivin and Eliasz's (2005) FAVAR all produce rather small effects of monetary policy shocks. Also, most are plagued by the price puzzle to greater or lesser degree. On the other hand, Romer and Romer (2004), Coibion (2012), Barakchian-Crowe (2013), and Gertler-Karadi (2015) all find larger impacts of a given shock on output.

I will also summarize briefly the effects on other variables from some of the leading analyses. A particularly comprehensive examination for many variables is conducted by Boivin, Kiley, and Mishkin's (2010) with their FAVAR. Recall that they obtained different results for the pre- versus post-1980 period. For the period from 1984m1 - 2008m12, they found that a positive shock to the federal funds rate leads to declines in a number of variables, including employment, consumption expenditures, investment, housing starts, and capacity utilization.

\subsection{Explorations with Three Types of Monetary Shocks}

I now explore the robustness of the effects of monetary policy shocks using some of the new methods introduced in the literature to deal with both the foresight problems and the recursiveness assumption. For reference, I begin by estimating the classic Christiano, Eichenbaum, and Evans’ (1999) type of specification and then move on to the Romer and Romer (2004) shock and Gertler and Karadi’s (2015) high frequency identification shock. 


\subsubsection{The Christiano, Eichenbaum and Evans (1999) Benchmark}

Christiano, Eichenbaum, and Evans (1999) presented estimates based on shocks identified using the recursiveness assumption and showed robust results that were generally consistent with conventional views on the effect of monetary shocks. Here I study how the results change when the sample is updated.

I estimate a specification similar to Christiano, Eichenbaum, and Evans' (1999) specification, but use Coibion's (2012) macroeconomic variables for the first block. In particular, I use monthly data and include log industrial production, the unemployment rate, the log of the CPI, and the log of a commodity price index in the first block. The second block consists of the federal funds rate. The third block consists of the logs of nonborrowed reserves, total reserves and M1. Thus, the innovation to the federal funds rate (orthogonal to contemporaneous values of the first block variables and lags of all of the variables) is identified as the monetary policy shock

Figure 3.1 shows the estimated impulses for this SVAR. The solid black line and shaded areas are the point estimates and 90 percent bootstrap confidence bands for the system estimated over CEE's sample period, 1965m1 - 1995m6. The responses look like classic effects of monetary policy shocks. The Federal funds rate jumps up temporarily, but then falls back to 0 by six months. This temporary blip in the funds rate, however, sets off a prolonged recession. Industrial production begins to fall in the next month and troughs 21 months later. Unemployment rises and peaks around 23 months later. Both unemployment and industrial production return to normal after four years. Prices rise slightly for the first few months, but then follow a steady path down, settling at new lower level after four years. Nonborrowed reserves, total reserves and M1 fall and then recover after three years. Nonborrowed reserves display some unusual oscillations, though. For the most part, these responses look very similar to the ones shown in Figure 3 of CEE (1999).

The blue short dashed lines in the same figures show the responses for the sample from $1983 \mathrm{~m} 1$ - 2007m12. The sample stops in 2007 both to exclude the financial crisis and for the practical reason that nonborrowed reserves became negative starting in 2008. The results change dramatically and imply that increases in the federal funds rate lower the unemployment rate. These results echo those of Barakchian and Crowe (2013), who show that the leading specifications imply expansionary effects in the sample from 1988 through 2007. 
The red long dashed lines show the results of a simplified model for the sample 1983m1 - 2007m12. This model omits M1, nonborrowed reserves, and total reserves. In this specification, there is still a small amount of expansionary effect on output and unemployment at the beginning, but then the more standard contractionary effects take hold. Prices never fall, however.

Table 3.2 shows various measures of the importance of monetary policy shocks for industrial production in CEE's specification. The first column shows the trough effect on output of a shock that raises the funds rate to a peak of 100 basis points. Even in CEE's original sample, the effects are very modest, less than a -0.5 percent fall. When estimated over the period 1959 through 2007, the effects are less than half. The other columns show the forecast error variance decompositions at 24 months. These indicate that monetary policy shocks account for less than seven percent of the forecast error variance in the original sample and less than one percent in the longer sample. A reasonable interpretation of the decline in the contribution of monetary shocks to output volatility is improved, less erratic monetary policy.

\subsubsection{Greenbook/Narrative Identification of Shocks}

Next, I explore the effects of the shocks identified by Romer and Romer (2004). As discussed in Section 3.3.2, Romer and Romer (2004) (R\&R) sought to overcome the problem of superior Federal Reserve information by regressing the federal funds target rate on the Greenbook forecasts at each FOMC meeting date and using the residual as the monetary policy shock. They find much larger effects of monetary policy than CEE do. Coibion (2012) explores many possible reasons for the differences and provides very satisfactory and revealing answers. In particular, he finds that R\&R's main results, based on measuring the effect of their identified shock using a single dynamic equation, is very sensitive to the inclusion of the period of nonborrowed reserves targeting, 1979 - 1982, and the number of lags (the estimated impact on output is monotonically increasing in the number of lags included in the specification). In addition, their large effects on output are linked to the more persistent effects of their shock on the funds rate. In contrast, R\&R's hybrid VAR specification, in which they substituted their (cumulative) shocks for the federal funds rate (ordered last) in a standard VAR, produces results implying that monetary policy shocks have "medium” effects. Coibion (2012) goes on to show 
that the hybrid model results are consistent with numerous other specifications, such as GARCH estimates of Taylor Rules (as suggested by Hamilton (2010) and Sims-Zha (2006a)) and timevarying parameter models as in Boivin (2006) and Coibion and Gorodnichenko (2011). Thus, he concludes that monetary policy shocks have “medium” effects. In particular, a 100 basis point rise in the federal funds rate leads industrial production to fall $2-3$ percent at its trough at around 18 months.

I thus work with the Coibion version of the R\&R hybrid VAR, which is a monthly VAR with the log of industrial production, the unemployment rate, the log of the CPI, the log of a commodity price index in the first block, and the cumulative Romer and Romer shock replacing the federal funds rate. This specification uses the recursiveness assumption as well, placing the funds rate last in the ordering and thus assuming that the monetary shock cannot affect the macroeconomic variables within the month.

Figure 3.2A shows the results, with the solid lines and confidence bands estimated using the original R\&R shocks on the original R\&R sample of $1969 \mathrm{~m} 3-1996 \mathrm{~m} 12$. These results also match the classic monetary policy effects. Output falls within a month or two, while unemployment rises. Prices remain constant until around nine months, when they fall steadily until they bottom out during the fourth year after the shock. A qualitative difference with the CEE results is that the response of the federal funds rate is more persistent in the R\&R VAR.

The short dashed blue lines show the responses based on the sample from 1983m1 2007m12. I constructed new R\&R shocks by re-estimating their FOMC meeting regression for the later sample, using the updates by Wieland and Yang (2015). I converted these shocks to monthly and then used them in the VAR estimated over the same later sample. The results are similar to those found by Barakchian and Crowe (2013): contractionary monetary policy shocks appear to be expansionary.

The long dashed red lines show the responses based on the sample from 1969m3 2007m12. The R\&R shock is based on re-estimating their FOMC meeting regression for the entire sample. The results for the full sample look more like those for the original R\&R sample, but with more muted effects on output and unemployment.

Rows 3 and 4 of Table 3.2 show the trough effects and variance decompositions for the R\&R VAR. In their original sample, the trough effect on output is -1.38 , which is substantially 
larger than the results using CEE. ${ }^{18}$ The forecast error variance decomposition implies that monetary policy shocks account for 9 percent of the variance for horizons at 24 months. ${ }^{19}$ As with most monetary shock specifications, however, the effects are considerably less if we include more recent periods in the sample.

An odd feature of the impulse responses shown in Figure 3.2A is the robust rebound of industrial production after two years of recession. The peak of industrial production at 48 months is the same magnitude as the trough at 13 months. One possible explanation is that misspecification of the VAR is distorting the estimated impulse responses. One way to assess this hypothesis is to use Jordà's (2005) local projection method. As discussed in Section 2.4, the Jordà method puts fewer restrictions on the impulse responses. Rather than estimating impulse responses based on nonlinear functions of the reduced form parameters, the Jordà method estimates regressions of the dependent variable at horizon $t+h$ on the shock in period $t$ and uses the coefficient on the shock as the impulse response estimate.

To investigate the results of this less restrictive specification, I estimate the following series of regressions:

$$
z_{t+h}=\alpha_{h}+\theta_{h} \text { shock }_{t}+\text { control variables }+\varepsilon_{t+h}
$$

The $z$ is the variable of interest. The control variables include two lags of the $R \& R$ shock, the federal funds rate, the log of industrial production, the unemployment rate, the log of the CPI, and the $\log$ of the commodity price index. ${ }^{20}$ In addition, to preserve the recursiveness assumption, I include contemporaneous values of the $\log$ of industrial production, unemployment rate and the logs of the two price indices. The coefficient $\theta_{h}$ gives the response of $z$ at time $t+h$ to a shock at time $t$. As discussed in Section 2, $\varepsilon_{t+h}$ will be serially correlated, so the standard errors must incorporate a correction, such as Newey-West.

\footnotetext{
${ }^{18}$ My numbers are slightly different from those of Coibion's for the original sample because he normalized by the impact effect on the funds rate rather than the peak response of the funds rate. Emi Nakamura has suggested that it might be better to compare the integral of the output response to the integral of the funds rate response because this measure incorporates persistence. I found that this measure sometimes behaved oddly because of the tendency of some of the variables to oscillate around zero.

${ }^{19}$ Neither Romer and Romer (2004) nor Coibion (2012) conducted forecast error variance decompositions. Their claim of large or "medium" effects was based on comparing the actual paths of output to the predicted paths implied by the estimated monetary policy shocks.

${ }^{20}$ The point estimates are similar if more lags are included.
} 
Figure 3.2B shows the impulse responses estimated using the Jordà method on R\&R's original sample 1969m3 - 1996m12. The relevant impulse responses are indicated by the black solid lines. While the responses are somewhat more erratic, they display more coherent dynamics. In particular, rather than the swing from recession to boom for industrial production implied by the VAR estimates, the Jordà estimates imply a more persistent decline in output (and rise in unemployment) that slowly returns to normal.

As discussed above, the R\&R VAR still imposes the recursiveness assumption. If one believes that the Greenbook forecasts incorporate all relevant information used by the Fed, then one does not need to impose the additional CEE recursiveness assumption. To determine the effect of removing the restriction that output and prices cannot respond to the shock within the month, I re-estimate the Jordà regressions omitting the contemporaneous values of all variables other than the R\&R shock. The results of this estimation are shown by the green dashed lines in Figure 3.2B. Many aspects of the responses are similar to those obtained with the recursiveness assumptions. However, there are several key differences. First, the estimates imply that a shock that raises the funds rate is initially expansionary: industrial production rises and the unemployment rate falls for the first several months, and the points estimates are statistically different from zero (not shown). Second, there is a pronounced price puzzle for the first two years, and most of those estimates are statistically different from zero.

One possible explanation for these puzzles is a failure of the Greenbook forecasts to capture all of the information the Federal Reserve uses. To examine whether expanding the information set helps eliminate the price puzzle, I re-estimate the nonrecursive Jordà model with the following alternative controls: two lags each of the R\&R shock, the federal funds rate, the dependent variable, and updates of Boivin, Kiley, and Mishkin's (2010) five FAVAR factors. ${ }^{21}$ The results are shown as the dashed purple line in Figure 3.2B. In this case, the price puzzle is even worse and the initial expansionary effects on output and unemployment are no better. Thus, including FAVAR-type factors does not reproduce the results obtained using the recursiveness assumption.

The proxy SVAR is another method that can be used to relax the recursiveness assumption. Kliem and Kriwoluzky (2013) use this method to reconcile VAR monetary shocks with the Romers’ narrative shocks. They do not, however, explore effects on output, prices, or

\footnotetext{
${ }^{21}$ I am indebted to Shihan Xie for providing her updates of the Boivin et al. estimated factors.
} 
other variables. To investigate the results using this method, I estimate the reduced form of Coibion's system with the federal funds rate substituted for the cumulative R\&R shock and with R\&R's monetary policy shock as an external instrument following Stock and Watson's (2012) and Mertens and Ravn’s (2013) proxy SVAR method (see Section 2 for a description).

Figure 3.2C shows the results for the original sample (1969 - 1996) and the full sample from 1969 through 2007. The shaded areas are 90\% confidence bands using Mertens and Ravn’s methods for the original sample estimates. In both samples, a shock to monetary policy raises the federal funds rate, which peaks at 1.4 percent by the month after the shock and falls slowly to 0 thereafter. The response of industrial production is different from the one obtained using the hybrid VAR (shown as the red long dashed line in Figure 3.2). In particular, industrial production now rises above normal for about 10 months, then begins falling, hitting a trough at about 29 months. Normalized by the funds rate peak, the results imply that a shock that raises the funds rate to a peak of 100 basis points first raises industrial production by 0.5 percent at its peak a few months after the shock and then lowers it by -0.9 percent by 29 months. The unemployment rate exhibits the same pattern in reverse. After a contractionary monetary policy shock, it falls by 0.1 percentage points in the first year, then begins rising, hitting a peak of about 0.2 percentage points at month 30. The behavior of the CPI shows a pronounced, statistically significant prize puzzle.

In sum, relaxing the recursiveness assumption imposed by Romer and Romer's hybrid VAR leads to several puzzles. A contractionary monetary policy shock is now expansionary in its first year and the price puzzle is very pronounced.

The most obvious explanation for these results is that the FOMC responds to more information than even the Greenbook forecast and FAVAR factors captures, and making the R\&R shock orthogonal to current output and prices (i.e. the recursiveness assumption) helps cleanse the shock of these extra influences. However, this means that even with the R\&R shock, one is forced to make the recursiveness assumption, which does not have a solid economic basis. As discussed above, leading New Keynesian models, such as Smets and Wouters (2007), imply immediate effects of monetary policy shocks on output and prices.

This exploration highlights the importance of additional restrictions imposed in standard monetary models, as well as the importance of the sample period when estimating the effects of monetary shocks. Without the additional recursiveness assumption, even narrative methods can 
produce puzzling results. Furthermore, as highlighted by Barakchian and Crowe (2013), many of the methods that produce classic monetary shock results in samples through the mid-1990s produce puzzles when estimated over later samples. In particular, contractionary monetary shocks seem to have expansionary effects in the first year and the price puzzle is pervasive. A plausible explanation for the breakdown in results in the later sample is an identification problem: because monetary policy has been conducted so well in the last several decades, true monetary policy shocks are rare. Thus, it is difficult to extract meaningful monetary shocks that aren't contaminated by problems with foresight on the part of the monetary authority.

\subsubsection{High Frequency Identification Shocks}

As discussed in previous sections, numerous papers have used high frequency identification methods (HFI) to deal with possible foresight about monetary policy changes. Part of the literature focuses only on the effects on interest rates and asset prices (.e.g. Krishnamurthy and Vissing-Jorgensen (2011) and Hanson and Stein (2015)). Nakamura and Steinsson (2015) link their estimated interest rate changes to output effects by calibrating a New Keynesian model. The strength of the effect, however, depends crucially on the assumed intertemporal elasticity of substitution. For this reason, it is also important to estimate direct links in the data as well.

A recent paper by Gertler and Karadi (2015) combines high frequency identification methods (HFI) with proxy SVAR methods to investigate the effects on macroeconomic variables. They have two motivations for using these methods. First, they seek to study the effect of monetary policy on variables measuring financial frictions, such as interest rate spreads. The usual Cholesky ordering with the federal funds rate ordered last imposes the restriction that no variables ordered earlier respond to the funds rate shocks within the period. This is clearly an untenable assumption for financial market rates. Second, they want to capture the fact that over time the Fed has increasingly relied on communication to influence market beliefs about the future path of interest rates ("forward guidance").

In the implementation, Gertler and Karadi estimate the residuals using monthly data from 1979 to 2012, but then execute the proxy SVAR from 1991-2012 since the instruments are only available for that sample. Figure 3.3A replicates the results from Gertler and Karadi's baseline 
proxy SVAR for Figure 1 of their paper. ${ }^{22}$ This system uses the three-month ahead fed funds futures (ff4_tc) as the shock and the one-year government bond rate as the policy instrument. The other variables included are $\log$ of industrial production, $\log$ CPI, and the GilchristZakrajsek (2012) excess bond premium spread. The results show that a shock raises the one-year rate, significantly lowers industrial production, does little to the CPI for the first year, and raises the excess bond premium. In order to put the results on the same basis as other results, I also estimated the effect of their shock on the funds rate. The results imply that a shock that raises the federal funds rate to a peak of 100 basis points (not shown) lowers industrial production by about -2 percent.

I explore the robustness of the results by estimating the effects of their shocks in a Jordà local projection framework. The control variables are two lags of the shock itself, the interest rate on one-year government bonds, industrial production, the CPI, and the Gilchrist-Zakrajsek (2012) excess bond premium spread. I do not include current values of these other variables, so I am not imposing the recursiveness assumption.

Figure 3.3B shows the results. The impulse responses look very different from those using the proxy SVAR method. The interest rate rises more slowly, but then remains high for a much longer time. Output does not respond for a year, but then rises. Prices respond little for the first 30 months, but then finally fall.

I then conducted some further investigations of the Gertler-Karadi shock. Several features emerge. First, the shock is not zero mean. The mean is -0.013 and is statistically different from zero. Second, it is serially correlated; if I regress it on its lagged value the coefficient is 0.31 with a robust standard error of 0.11 . This is not a good feature since it is supposed to capture only unanticipated movements in interest rates. In my local projection framework implementation, I include lagged values of the shock, so my procedure purges the shock of this serial correlation. I discovered that the serial correlation is induced by the method that Gertler and Karadi use to convert the announcement day shocks to a monthly series. ${ }^{23}$ Third, if I used FOMC-frequency data to regress the shock on all of the Greenbook variables that the Romers used to create their shock, the R-squared of the regression is 0.21 and I can reject that the coefficients are jointly zero with a p-value of $0.027 .{ }^{24}$ Thus, the Gertler-Karadi variable is predicted by Greenbook

\footnotetext{
${ }^{22}$ The only difference is that I used $90 \%$ confidence intervals to be consistent with my other graphs.

${ }^{23}$ See footnote 11 of Gertler and Karadi (2015) for details.

${ }^{24} \mathrm{I}$ am indebted to Peter Karadi for sharing with me the announcement date series.
} 
projections. Gertler and Karadi also worried about this issue, but they performed a robustness check based only on the difference between private forecasts and Greenbook forecasts. They found a much lower R-squared (see their Table 4). When they use their purged measure, they find greater falls in industrial production. I explored the effect of using a version of their measure that was (i) orthogonal to the Romer Greenbook variables; and (ii) converted to a monthly basis the same way that the Romers converted their data, in the Jordà framework. The results were still puzzling.

Why does the Jordà method give such different estimates from the proxy SVAR? One possible explanation is the different method and sample used to estimate the impulse response function. Gertler and Karadi's impulse responses functions are constructed as nonlinear functions

of the reduced-form VAR parameters estimated on data from 1979 through 2012; the Jordà method estimates are for the 1991 to 2012 sample and are direct projections rather than functions of reduced-form VAR parameters. Since the estimates of the impact effects on industrial production are near zero for both methods, the entire difference in the impulse responses is due to the differences in the dynamics implied by Gertler and Karadi's reduced form VAR parameter estimates. A second possible explanation for the difference is that the rising importance of forward guidance starting in the mid-1990s means that the VAR underlying the proxy SVAR is misspecified. As discussed in Section 2.5, anticipations of future policy actions can lead to the problem of a non-fundamental moving average representation. Gertler and Karadi's fed funds futures variable captures news well, but they do not include it directly in the SVAR; they only use it as an instrument.

\subsection{Summary of Monetary Shocks}

When Christiano, Eichenbaum, and Evans (1999) wrote their Handbook chapter, they provided what became a benchmark framework for identifying monetary policy shocks and tracing their effects. As long as the recursiveness assumption was incorporated, the results were quite robust. Since then, the literature has incorporated new methods and faced new challenges. Researchers now take instrument identification and relevance much more seriously when estimating monetary policy shocks. New methods, such as FAVARs and Greenbook forecasts, have improved the conditioning set for estimating monetary policy shocks. Structural VARS, 
sign restrictions and regime switching models have provided alternatives to the usual Cholesky decomposition. Moreover, new measures of monetary shocks have been developed using rich external data, such as narrative data, Greenbook projections, and high frequency information from financial markets. Recently published work using shocks estimated with external data results in similar conclusions. In particular, Coibion's (2012) reconciliation of the Romer results with the VAR results suggests that a 100 basis point rise in federal funds rate lowers industrial production by about -2 percent at 18 months. Those results are based on data from 1969 through 1996. Gertler and Karadi's (2015) research uses high frequency identification from fed funds futures and external instruments/ proxy SVAR methods to find very similar results for a later sample.

This rosy reconciliation picture disappears, however, when the specifications are subjected to some robustness tests. My explorations have highlighted several potential issues, some of which were already noted in the literature. First, the original Christiano, Eichenbaum, and Evans (1999) specification, as well as many other specifications, do not hold up well in later samples. Second, lifting the recursiveness assumption can lead to estimates that imply expansionary effects of contraction monetary policy in the short-run. Third, one needs to be very careful when estimating models in samples where anticipation effects may be important. For example, it is not clear that HFI shocks should be used as external instruments for otherwise standard VARs.

How should we interpret these results? I would argue that the most likely reason for the breakdown of many specifications in the later sample is simply that we can no longer identify monetary policy shocks well. Monetary policy is being conducted more systematically, so true monetary policy shocks are now rare. It is likely that what we now identify as monetary policy shocks are really mostly the effects of superior information on the part of the Fed, foresight by agents, and noise. While this is bad news for econometric identification, it is good news for economic policy.

What, then, are we to conclude about the output effects of monetary shocks? I would argue that the best evidence still remains the historical case studies, such as Friedman and Schwarz, and the times series models estimated on samples that exclude recent decades. Of course, one worries that the structure of the economy may have changed in the last few decades, but we simply don’t have enough information to produce estimates with any great certainty. 
Monetary policy can have big effects, but it is likely that monetary shocks are no longer an important source of macro instability.

\section{Fiscal Shocks}

This section reviews the main identification methods and summarizes existing results from the empirical literature seeking to identify and estimate the effects of fiscal policy shocks. It also presents some new results comparing several leading identified shocks.

In contrast to a monetary policy shock, a fiscal shock is a more straightforward economic concept. Because the legislative and executive branches of government often make tax and spending decisions based on concerns that are orthogonal to the current state of the macroeconomy, the notion of regularly occurring fiscal policy shocks is more plausible than regularly occurring monetary policy shocks.

Measuring the empirical effects of changes in government spending and taxes on aggregate GDP and its components was an active research area for a number of decades. The large Keynesian models of the 1960s included fiscal variables and numerous academic papers estimated their effects in behavioral equations. For several decades afterwards, though, research on the aggregate effects of tax and spending shocks experienced a lull, punctuated by only a few papers. Most empirical research on shocks during the 1980s, 1990s and 2000s instead focused on monetary policy. With the onset of the Great Recession and the zero lower bound, however, research energy immediately shifted to the effects of fiscal policy. The recent literature has built on and extended the strides made by the few authors working on the topic during the long dormant period.

The following sections will discuss some of the literature since 1990 that has sought to

analyze the effects of fiscal shocks. I will begin by considering government spending shocks and then discuss tax shocks.

\subsection{Government Spending Shocks}


In this section, I discuss shocks to government spending. When I use the term government spending, I mean government purchases, i.e. $G$ in the NIPA identity. In common parlance, however, government spending typically refers to government outlays, which include both government purchases and transfer payments. Economists usually consider transfer payments to be negative taxes. Thus, I will include a discussion of transfer payments in the section on the effects of tax shocks.

\subsubsection{Summary of Identification Methods}

Many of the identification methods summarized in Section 2 are used in the literature that analyzes the effects of shocks to government spending. These methods include SVARs with contemporaneous restrictions, sign restrictions, medium horizon restrictions, narrative methods, and estimated DSGE models.

Perhaps the first example of what looks like a VAR-type analysis of the effects of fiscal shocks is Rotemberg and Woodford's (1992) analysis of the effects of military spending and employment on macroeconomic variables. Their purpose was to provide evidence in favor of their counter-cyclical markup model, showing that a "demand" shock would lead to countercyclical markups. To do this, they estimated systems with military spending, military employment, and a macroeconomic variable of interest (such as private value added and private hours worked). They included lags of the variables in the system, but restricted the VAR so that there was no feedback of the macroeconomic variables onto the military variables. In their system, identification was achieved as follows. To identify government purchases shocks that were exogenous to the economy, they followed Hall $(1980,1986)$ and Barro $(1981)$ who argued that defense spending is driven by military events rather than macroeconomic events. To identify unanticipated shocks, they regressed the military variables on their own lags and used the residuals. This identification strategy assumes that all relevant information for predicting military spending and employment is contained in lags of military spending and employment. They showed that their identified shocks to defense spending raised real wages.

In a paper analyzing the effects of sectoral shifts in the presence of costly mobility of capital across sectors, Ramey and Shapiro (1998) used narrative techniques to create a dummy variable capturing major military buildups. They read through Business Week in order to isolate 
the political events that led to the buildups in order to create a series that was exogenous to the current state of the economy. They also used this narrative approach to ensure that the shock was unanticipated. They stated: "We believe this approach gives a clearer indicator of unanticipated shifts in defense spending than the usual VAR approach, since many of the disturbances in the VAR approach are due solely to timing effects on military contracts and do not represent unanticipated changes in military spending. “ (Ramey and Shapiro (1998), p. 175.) Ramey and Shapiro (1998) estimated the effects of "war dates" by regressing each variable of interest on current values and lags of the war dates and lags of the left-hand side variable. A number of follow-up papers embedded the war dates in VARs, ordered first in the Cholesky decomposition, creating “Expectational VARs” or EVARs, a term coined by Perotti (2011). These papers include Edelberg, Eichenbaum, and Fisher (1999), Burnside, Eichenbaum, and Fisher (2004), and Cavallo 2005). Most applications typically found that while government spending raised GDP and hours, it lowered investment, consumption and real wages. Most of these papers did not specifically estimate a multiplier, though one can typically back out the implied multiplier from the impulse responses.

In contrast, Blanchard and Perotti (2002) used a structural VAR (SVAR) to identify both government purchases and tax shocks. They assumed that government purchases were predetermined within the quarter, and identified the shock to government purchases using a standard Cholesky decomposition with government spending ordered first. They found that government purchases shocks raised not only GDP, but also hours, consumption and real wages. Follow-up work, such as by Fatás and Mihov (2001), Perotti (2005), Pappa (2009) and Galí, López-Salido, and Vallés (2007), found similar results. Mountford and Uhlig (2009) used sign restrictions and found only weak effects on GDP and no significant effect on consumption.

In Ramey (2011a), I sought to reconcile why the war dates were producing different results from the SVARs that used Cholesky decompositions. I argued that most government spending is anticipated at least several quarters in advance, so that the standard SVAR method was not identifying unanticipated shocks. In support of this idea, I showed that the shocks from an SVAR were indeed Granger-caused by the Ramey and Shapiro (1998) war dates. To create a richer narrative variable to capture the "news" part of government spending shocks, I read Business Week starting in 1939 and created a quantitative series of estimates of changes in the expected present value of government purchases, caused by military events. I then embedded the 
news series in a standard VAR, with the news ordered first in the Cholesky decomposition. In that work, I found results that were broadly consistent with the estimates based on the simple war dates.

In follow-up work, Owyang, Ramey, and Zubairy (2013) and Ramey and Zubairy (2014) extended the military news series back to 1889. The military news variable tends to have low instrument relevance for samples that begin after the Korean War, though. In Ramey (2011a), I augmented my analysis by also considering shocks that were orthogonal to professional forecasts of future government purchases. Fisher and Peters (2010) created an alternative series of news based on the excess returns of defense contractor stocks for the period starting in 1958. Recent work by Ben Zeev and Pappa (forthcoming) uses the medium-horizon identification methods of Barsky and Sims (2011) to identify news shocks to defense spending from a time series model. In particular, Ben Zeev and Pappa identify defense spending news as a shock that (i) is orthogonal to current defense spending; and (ii) best explains future movements in defense spending over a horizon of five years.

All of these measures of anticipations have weaknesses, though. First, because they are associated with military events, there are likely confounding effects (e.g. rationing, price controls, conscription, patriotic increases in labor supply). Second, as I show below, some of the shocks suffer from low first-stage F-statistics in some samples, indicating that they might not be relevant instruments.

Thus, there are two main differences in the shocks identified across these two classes of models. First, the SVAR shocks are more likely to be plagued by foresight problems. As I discussed in Section 2, this problem of foresight can be a serious flaw in SVARs. Second, the news alternatives are not rich enough in some subsamples and there may be confounding influences.

A more structural way to identify shocks to government purchases is through an estimated DSGE model. For example, one of the shocks identified by Smets and Wouters (2007) is a government purchases shock. Cogan, Cwik, Taylor and Wieland (2010) also estimate government spending multipliers in the context of an estimated DSGE model.

\subsubsection{Summary of the Main Results from the Literature}


Typically, the literature on government spending has sought to answer one or both of two main questions: (1) Are the empirical results consistent with theoretical DSGE models? (2) What are the government spending multipliers?

Let us begin by considering results that shed light on the first question. Most versions of standard neoclassical theory and standard new Keynesian theory predict that a rise in government purchases (financed with deficits or lump-sum taxes and not spent on public infrastructure, etc.) should raise GDP and hours, but should decrease consumption and real wages. Whether investment initially rises or falls depends on the persistence of the increase in government spending. It is only when one adds extra elements, such as rule-of-thumb consumers and off-the-labor supply behavior of workers that one can produce rises in consumption and real wages in a model (e.g. Galí, López-Salido, Vallés (2006)).

Both SVARs and expectational VARs (EVARs) that use a news variable produce qualitative similar results for some variables. For example, both typically estimate an increase in GDP and hours and a fall in investment (at least after the first year) in response to a positive government spending shock. In contrast, the SVAR typically implies a rise in consumption and real wages whereas the EVAR predicts a fall in consumption and real wages.

The second question the literature seeks to answer is the size of "the" government purchases multiplier. Unfortunately, most estimates are not for pure deficit financed multipliers since most rises in government spending are accompanied by a rise in distortionary taxes, typically with a lag. This caveat should be kept in mind in the subsequent discussion of multiplier estimates.

One might assume that SVARs produce bigger multipliers since they predict increases in consumption. They don't. In Ramey (2013a), I compared the effects of government spending on private spending, i.e. GDP minus government spending, of several shocks based on the various identification methods. If the government spending multiplier is greater than unity, then private spending must increase. I found that all of the shocks lowered private spending, but that the Blanchard-Perotti (2002) shocks lowered it more, implying a smaller multiplier.

The estimated DSGE models of Smets and Wouters (2007) and Cogan, Cwik, Taylor, and Wieland (2010) produce results that are close to the neoclassical model. In both cases, a shock to government spending lowers consumption and results in a multipliers below unity. 
In my survey of the literature on multipliers in Ramey (2011b), I found that most estimates of the government spending multiplier in aggregate data were between 0.8 and 1.2. The only multipliers that were larger were (1) those estimated on states or regions; and (2) some of those estimated allowing state-dependence. As suggested in my survey, and as shown formally by Nakamura and Steinsson (2014) and Farhi and Werning (2012), the link between estimates of multipliers in a fiscal union (e.g. across U.S. states or regions) for aggregate multipliers are not entirely clear. Most of the cross-state or cross-region studies look at the effect of federal spending on a locality. Unfortunately, because constant terms or time fixed-effects are included, these regressions difference out the effects of the financing, since taxes that finance federal spending are levied at the national level. ${ }^{25}$ This explains why multipliers on federal spending at the state level will be higher than the aggregate multipliers. I will discuss the issue of state dependence in more detail momentarily.

Since writing that survey, I realized that there were two potential biases in the way that many researchers calculated their multiplier, and as a result many reported estimates are not comparable. First, many researchers followed Blanchard and Perotti’s (2002) lead and calculated multipliers by comparing the peak output response to the initial government spending impact effect. While comparing values of impulse responses at peaks or troughs is a useful way to compare impulse responses, it is not a good way to calculate a multiplier. As argued by Mountford and Uhlig (2009), Uhlig (2010) and Fisher and Peters (2010), multipliers should instead be calculated as the integral (or present value) of the output response divided by the integral government spending response. The integral multipliers address the relevant policy question because they measure the cumulative GDP gain relative to the cumulative government spending during a given period. In many cases, Blanchard and Perotti’s ratio of peak-to-impact method gives a higher number for the multiplier than the integral method. Second, most researchers estimating VARs use logarithms of variables. To convert the estimates to multipliers, they usually multiply the estimates by the sample mean of GDP to government spending ratio. As Owyang, Ramey,and Zubairy (2013) point out, this can lead to serious biases in samples with significant trends in the GDP to government spending ratio. In the few cases where I have been

\footnotetext{
${ }^{25}$ A notable exception is the paper by Clemens and Miran (2012), which identifies exogenous variation in state-level spending. Interestingly, they find multipliers around 0.5 , which is closer to those found at the national level.
} 
able to adjust the estimates of multipliers to be integral multipliers, I have found that the multipliers are often below one.

With this additional caveat in mind, Table 4.1 shows a summary of a few of the estimates of multipliers for government purchases. Even with the variety of ways of calculating multipliers from the estimated impulse response functions, most of the estimates are from 0.6 to 1.5 .

A number of researchers and policy-makers have suggested that multipliers may be state dependent. Auerbach and Gorodnichenko (2012) use a smooth transition vector autoregression model (STVAR) and find evidence of larger multipliers in recessions. Ramey and Zubairy (2014) use the Jordà (2005) method (also used by Auerbach and Gorodnichenko (2013) in a panel of countries) and find little evidence of state dependence, based on recessions, elevated unemployment rates or the zero lower bound. They argue that their different finding is not so much due to the underlying parameter estimates but rather to the additional assumptions that Auerbach and Gorodnichenko (2012) made when transforming those estimates into multipliers.

Most of the studies I have summarized focus on government purchases that do not involve infrastructure spending. The reason for the paucity of research on infrastructure spending is the difficulty of identifying shocks to infrastructure spending, particularly in the U.S. The U.S. highway system was an important part of government purchases starting in the late 1950s through the early 1970s. The problem with identifying the aggregate effects is that most of the spending was anticipated once the highway bill was passed in 1956. Most of the credible analyses have used clever indirect methods or used variation in cross-state expenditures. Fernald (1999) provides very strong evidence for a causal effect of the highway system on productivity by showing its greater effect on vehicle-intensive industries. These estimates do not directly inform us about aggregate effects, though. Leduc and Wilson (2012) identify news shocks about highway spending in a panel of U.S. states using the arrival of new information about institutional formula factors. However, as discussed above, the multipliers they find cannot be converted to aggregate multipliers.

Gechert (forthcoming) conducts a meta-analysis of 104 studies of multiplier effects across a variety of countries, including many different types of analyses from reduced form empirical to estimated DSGE models. With the caveat that the context and experiment varies across studies, Gechert finds that public spending multipliers are close to one, while public investment multipliers are around 1.5. 


\subsubsection{Explorations with Several Identified Shocks}

I now study the effects of several of the leading identified government spending shocks in the Jordà local projection framework. This exploration is useful not only for gauging the robustness of the results to local projection methods, but also for comparing the effects of the identified shocks using the same data, same specification, and the same way to calculate multipliers. Thus, any differences in results will be due to the identification methods rather than differences in data or implementation.

The three main shocks I study are (i) the shock identified using Blanchard and Perotti's (2002) method (which simply orders government spending first in a Cholesky decomposition); ii) my narrative military news shock, updated in Ramey and Zubairy (2014); and (iii) Ben Zeev and Pappa’s (forthcoming) defense news shock identified using Barsky and Sims’ (2012) medium run horizon method. ${ }^{26}$ I also comment briefly on results using Fisher and Peters’ (2010) military contractor excess returns.

In all cases, I use the following data transformations and functional forms. The first set of transformations is intended to facilitate the direct estimation of multipliers in order to avoid ad hoc transformation of estimates based on logs, as discussed by Owyang, Ramey, and Zubairy (2013). One can use either the Hall (2009) and Barro-Redlick (2011) transformation or a Gordon-Krenn (2010) transformation. The Hall-Barro-Redlick transformation constructs variables as $\left(t+h-X_{t-1}\right) / Y_{t-1}$, where $\mathrm{X}$ is the NIPA variable deflated by the GDP deflator and $Y_{t-1}$ is real GDP before the shock hits in period t. The Gordon-Krenn transformation divides all NIPA variables by “potential GDP,” estimated as an exponential trend. Both methods give similar results. I follow the Gordon-Krenn procedure, fitting log real GDP to a quadratic trend. ${ }^{27}$ Thus, the NIPA variables are transformed to be $z_{t}=X_{t} / Y_{t}^{*}$, where $Y_{t}^{*}$ is the estimated trend in real GDP. The impulse responses using this transformation look qualitatively similar to those using log levels, but often have more narrow confidence bands.

\footnotetext{
${ }^{26}$ I estimated the Blanchard-Perotti shock using logarithms of real government spending, GDP, and taxes and four lags. Ben Zeev and Pappa kindly provided me with estimates of their shock.

${ }^{27}$ One could use the CBO estimate of real potential GDP instead. I found, however, that when I used the CBO estimate, the implied multipliers were noticeably smaller than when I used Hall-Barro-Redlick or Gordon-Krenn with either a quadratic or quartic log trend.
} 
The non-NIPA variables are transformed as follows. The average tax rate is federal current receipts divided by nominal GDP. The hours variable is the log of total hours per capita, where the total population is used in the denominator. Wages are given by the log of nominal compensation in the business sector, deflated by the price deflator for private business. The real interest rate is the 3-month Treasury bill rate minus the rate of inflation calculated using the GDP deflator.

The equation used to estimate the impulse responses for each variable $z$ at each horizon $h$ is given by:

$$
z_{t+h}=\alpha_{h}+\theta_{h} \text { shock }_{t}+\varphi_{h}(L) y_{t-1}+\text { quadratic trend }+\varepsilon_{t+h}
$$

where $z$ is the variable of interest, shock is the identified shock, $y$ is a vector of control variables, and $\varphi_{h}(L)$ is a polynomial in the lag operator. All regressions include two lags of the shock (to mop up any serial correlation), transformed real GDP, transformed real government purchases, and the tax rate. Regressions for variables other than real GDP, government purchases and tax rates also include two lags of the left-hand side variable. The coefficient $\theta_{h}$ gives the response of $z$ at time $t+h$ to the shock at time $t$.

As discussed above, the correct way to calculate a multiplier is as the integral under the impulse response of GDP divided by the integral of the impulse response of government spending. We could compute the multiplier using the following multi-step method: (1) estimate equation (4.1) for GDP for each horizon and sum the coefficients $\theta_{h}$ up to some horizon H; (2) estimate equation (4.1) for government purchases for each horizon and sum the coefficients $\theta_{h}$ up to some horizon $\mathrm{H}$; and (3) construct the multiplier as the answer from step (1) divided by the answer from step (2). Estimating the standard error, however, requires some ingenuity, such as estimating all of the regressions jointly in a panel estimation.

Alternatively, we can easily estimate the multiplier estimate and its standard error in one step if we cumulate the variables and reformulate the estimation problem as an instrumental variables (IV) estimation. In particular, we can estimate the following equation:

$$
\sum_{i=0}^{h} z_{t+i}=\beta_{h}+m_{h} \sum_{i=0}^{h} g_{t+i}+\chi_{h}(L) y_{t-1}+\text { quadratic trend }+v_{t+h}
$$


where the dependent variable is the sum of real GDP (or other NIPA variable) from $t$ to $t+h$ and the government spending variable is the sum of the government purchases variable. We use the identified shock as the instrument for the sum of government purchases. The estimated coefficient, $m_{h}$, is the multiplier for horizon $h$. There are several advantages to this one-step IV method. First, the standard error of the multiplier is just the standard error of the coefficient $m_{h}{ }^{28}$ Second, the shock can have measurement error as long as the measurement error is not correlated with any measurement error in government spending. Third, formulating the estimation as an IV problem highlights the importance of instrument relevance.

Thus, I first consider how relevant each of the identified shocks is as an instrument for the integral of government spending. The Stock, Wright and Yogo (2002) argue that the firststage F-statistic should be above 10 for the IV estimates to be reliable, but their threshold applies only to first-stage regressions with serially uncorrelated error terms. Fortunately, follow-up work by Montiel and Pflueger (2013) constructs thresholds for cases with serial correlation. For the first stage of equation (4.2), the thresholds are 23 for the ten percent level and 37 for the five percent level. $^{29}$ F-statistics below those thresholds indicate a possible problem with instrument relevance.

Figure 4.1 shows the first-stage F-statistics for the sum of government purchases on each identified shock for each horizon up to 20 quarters. Values above 50 have been capped at 50 for ease of viewing. The graph at the left shows the results for the sample starting in 1947 and the graph on the right shows the results for the sample starting in 1954, after the Korean War. Several results emerge. First, the Blanchard-Perotti (BP) identified shock always has very high F-statistics. This is not surprising because the shock is equal to the portion of government spending not predicted by four lags of government spending, GDP, and taxes. Second, the FisherPeters defense contractor excess returns shock has very low F-statistics for all horizons and both samples, indicating that the stock return variable is not a good instrument for government spending. Third, the Ramey and Ben Zeev-Pappa (BZP) news shocks have low relevance for short horizons, but this is to be expected since those shocks capture news about future government spending. Fourth, in the full sample at horizons beyond three quarters, the Ramey news shock has F-statistics above the Montiel-Pflueger thresholds, whereas the Ben Zeev-Pappa

\footnotetext{
${ }^{28}$ Because of the serial correlation in the errors, any procedures for estimating standard errors should use methods that account for serial correlation.

${ }^{29}$ These thresholds were derived using Pflueger and Wang's (2015) “weakivtest” Stata module.
} 
news shock F-statistics lie below them and range between 8 and 14. Fifth, in the sample that excludes the Korean War, all of the F-statistics are very low except for the Blanchard-Perotti shock. Thus, the BP shock surpasses the relevance safety threshold for all horizons in both samples, the Ramey news shock does so for the full sample for horizons at four to 20 quarters, while the Ben Zeev-Pappa shock may have relevance problems at most horizons and the FisherPeters shock always has very low relevance. I thus exclude the Fisher-Peters shock from the rest of the analysis.

Figure 4.2 shows the impulse responses estimated using equation (4.1), with estimates normalized across specifications to have the same peak in government purchases. The scales in the graphs of the NIPA variables should be interpreted as dollars; i.e. a rise in government purchases that peaks at $\$ 1$ leads to rise in GDP that peaks at 75 cents. The scales of the other graphs are in percentage points. The confidence bands are 90 percent bands based on NeweyWest corrections of standard errors. They do not, however, take into account that two of the shocks are generated regressors.

Consider first the upper left graph in Figure 4.2. Both the Ramey and BZP news variables imply similar paths of government purchases, with little effect for the first few quarters rising to a peak around five quarters after the shock. In contrast, the BP shock leads to an immediate rise in government spending. The graph in the top right shows that in response to all three shocks, GDP jumps immediately. The response of GDP is greatest for the BZP shock, but GDP begins to fall back to normal even before government purchases have hit their peak.

The tax rate series is simply federal receipts divided by GDP. This variable can rise either because of tax legislation or because higher GDP pushes more households into higher tax brackets. According to the estimates, tax rates begin to rise immediately for the BZP shock but only gradually for the Ramey news shock. Tax rates gradually fall after BP shock. Real interest rates (measured as the 3-month Tbill rate minus inflation) fall after a news shock, but rise slightly after a BP shock. Examination of the responses of the components of the real interest rate (not shown) reveals that the fall is due to both a drop in the nominal interest rate and a rise in inflation. As explained by Ramey (2011a), the rise in inflation is in large part driven by the spike up in prices at the beginning of the Korean War: with recent memories of WWII, firms thought that price controls were coming and raised their prices in advance. 
Consider now four components of the national income accounts, shown in the middle graphs in Figure 4.2. Nondurable plus services consumption falls after a Ramey news shock, responds little after a BZP shock, but rises after a BP shock. In Ramey (2009a), I show using simulations of a DSGE model that one can estimate a rise in consumption if one treats an anticipated shock as an unanticipated shock. I argue that the rise in consumption after a BP shock can be explained by this type of identification problem.

Durable consumption spikes up initially and then falls after the two news shocks. As in the cast of prices, this initial spike on the arrival of news is driven mostly by the response of consumers to the beginning of the Korean War in 1950: with recent memories of WWII, consumers worried that rationing of durable goods was imminent so they hurried out to buy durable goods. Nonresidential investment rises in response to the BZP shock, but falls in response to both the Ramey news and BP shock. Residential investment falls in response to the two news shocks, but rises after a year in response to the BP shock.

Finally, both news shocks imply a rise in hours and a fall in the real wage, while the BP shock predicts very little response of hours, but a rise in the real wage.

Table 4.2 shows the estimated multipliers for various horizons. ${ }^{30}$ The impact multipliers for the two news shocks are negative because output jumps up while government spending falls slightly. For the next few quarters, the multipliers for the two news shocks are large because output responds immediately to news of future government spending which has not yet fully transpired. Once government spending has risen to its peak, the implied multipliers using the Ramey news shock are just below unity, whereas those using the BZP news shock are above unity. For example, the BZP news shock multiplier is 1.4 at 8 quarters and 1.1 at 16 quarters. The responses in Figure 4.2 reveal that the reason for the larger multiplier after a BZP shock is the large rise in nonresidential investment. It should be noted, though, that the BZP multipliers are estimated rather imprecisely as evidenced by the standard errors. This is one manifestation of the possible low instrument relevance of the BZP news shock. On the other hand, the multipliers implied by the Blanchard and Perotti shock are all low, most below 0.5. However, the estimates are not precise enough to reject a multiplier of either 0 or 1 at standard significance levels.

I now consider what each shock implies about the contribution to the forecast error variance of output. Although one can calculate forecast error variances using the estimated local

\footnotetext{
${ }^{30}$ These estimates are based on the one-step method shown in equation (4.2).
} 
projection coefficients, I found that the shares sometimes exceeded 100 percent. Thus, for present purposes I calculate the forecast error variance in a standard VAR with the shock, log government spending, log real GDP, and log taxes. The shock is ordered first and four lags are included, along with a quadratic trend.

Table 4.3 shows the forecast error variance decompositions of each of the three identified government spending shocks for government spending and output. Despite having the lowest contribution for government spending, the BZP shock has the highest contribution for output, but it is still 13 percent or below. The BP and Ramey news contributions tend to be 5 percent of below. Thus, none of the three shocks is an important contributor to the variance of output.

To summarize, most of the aggregate analyses find government spending multipliers between 0.6 and 1.5. The BP shock leads to smaller multipliers, but does imply that government spending leads to rises in consumption and real wages along with GDP and hours. In contrast, both the Ramey news and BZP news shocks lead to falls in real wages. Both news shock lead to an initial spike in durable consumption (due to the consumer fears of rationing), followed by a decline. The BZP shock produces a temporary blip in nondurable consumption, but then it falls to 0 . The Ramey news shock implies a decline nondurable consumption. None of the methods suggests that government spending shocks explain an important part of GDP fluctuations.

\subsection{Tax Shocks}

I now turn to the literature on tax shocks. Taxes were often an important component of the big Keynesian econometric models of the 1960s. The public finance literature has analyzed many details of the effects of taxes. In this section, I will focus on estimates of the effects of taxes in the macroeconomic literature since the 1990s.

\subsubsection{Unanticipated Tax Shocks}

\subsubsection{Summary of the Literature}

Macroeconomists have used both estimated DSGE models and time series models to estimate the effects of taxes. One of the first systematic analyses of macroeconomic tax effects in 
an estimated DSGE model was by McGrattan (1994). She extended the Kydland and Prescott (1982) model to include government consumption, labor income taxes, and capital income taxes and estimated the parameters using maximum likelihood. She found that the role of technology in business cycle fluctuations was much reduced, 41 percent rather than Kydland and Prescott's 75 percent estimate. She found that shocks to government consumption accounted for 28 percent of the forecast error variance of output, labor income tax shocks for 27 percent, and capital income tax shocks for 4 percent.

Among time series approaches, Blanchard and Perotti (2002) used a structural VAR (SVAR) approach in which they identified tax shocks by imposing the elasticity of net taxes to GDP estimated from other studies. Returning to the discussion of the simple trivariate model from Section 2, consider the following system:

$$
\begin{aligned}
& \eta_{1 t}=b_{12} \eta_{2 t}+b_{13} \eta_{3 t}+\varepsilon_{1 t} \\
& \eta_{2 t}=b_{21} \eta_{1 t}+b_{23} \eta_{3 t}+\varepsilon_{2 t} \\
& \eta_{3 t}=b_{31} \eta_{1 t}+b_{32} \eta_{2 t}+\varepsilon_{3 t}
\end{aligned}
$$

where $\eta_{1 t}$ is the reduced form residual of net taxes, $\eta_{2 t}$ is the reduced form residual of government spending, and $\eta_{3 t}$ is the reduced form residual of GDP. Blanchard and Perotti (2002) identify the shock to government spending using a Cholesky decomposition in which government spending is ordered first (i.e. $b_{21}=b_{23}=0$ ). They identify exogenous shocks to net taxes by setting $b_{13}=2.08$, an outside estimate of the cyclical sensitivity of net taxes. These three restrictions are sufficient to identify all of the remaining parameters and hence all three shocks. Blanchard and Perotti's estimated “impact multipliers" was -0.78. Their impact multiplier was calculated as the trough of GDP relative to the initial shock to taxes.

Mountford and Uhlig (2009) use sign restrictions to identify tax and spending shocks. Their results imply a multiplier of -5 at 12 quarters for a deficit-financed tax cut, when the multiplier is calculated as the ratio of the present value of the impulse response functions. In order to compare their results to Blanchard and Perotti, they also calculate "impact multipliers," meaning the value of the GDP response at a certain quarter to the initial shock impact on the fiscal variable. They find that whereas the Blanchard and Perotti method implies a peak-to- 
impact multiplier of -1.3 at quarter 7, Mountford and Uhlig's results imply a peak-to-impact multiplier of -3.6.

In the context of the Blanchard and Perotti (2002) model, Caldara and Kamps (2012) demonstrate how the estimated multiplier depends crucially on their assumption about the elasticity of net tax revenue to GDP. Particularly important is their demonstration of how a small change in the assumed cyclical elasticity parameter can result in large changes in the estimated tax multiplier; to wit, this seems to be a case of a "multiplier multiplier" on the assumed elasticity. Caldara and Kamps (2012) propose a new method, which involves imposing probability restrictions on the output elasticities of taxes and spending. When they implement this method, they find peak-to-impact multipliers of -0.65 for tax shocks and peak-to-impact multipliers greater than unity for government spending shocks.

Barro and Redlick (2011) construct a new series of average marginal tax rates using IRS data and analyze its effects in a system that also considers government spending in annual data extending back to 1917. In their baseline specification, they find that an increase in the average marginal tax rate of one percentage point lowers GDP by 0.5 percent. Their calculations indicate a tax multiplier of -1.1 .

Romer and Romer (2010) (R\&R) use narrative methods to identify tax shocks. Based on presidential speeches and congressional reports, they construct several series of legislated tax changes and distinguish those series based on the motivation for enacting them. They argue that tax changes motivated by a desire to pay down the deficit or long-run growth considerations can be used to establish the causal effect of tax changes on output. When they estimate their standard dynamic single equation regression of output growth on its lags and on current and lagged values of the "exogenous" tax changes, they obtain estimates implying tax multipliers of -2.5 to -3 at three years. Leigh et al. (2010) use a similar narrative method to study fiscal consolidations across countries. ${ }^{31}$ Cloyne (2013) uses this method to identify exogenous tax shocks in the U.K.

Favero and Giavazzi (2012) embed the R\&R series in a somewhat restricted VAR and find smaller multipliers. In a series of papers, Mertens and Ravn (2011b, 2012, 2013, 2014) exploit the $R \& R$ narrative tax information in a way that significantly expands our understanding of the effects of tax shocks on the economy. I will focus on several of their contributions in this

31 The Leigh et al attempts to address measurement concerns in the very large literature on the effects of fiscal consolidations across countries, perhaps best exemplified by Giavazzi and Pagano (1990, 1996), Alesina and Perotti (1995, 1997), and Alesina and Ardagna (1998, 2010). 
subsection and discuss the others in the next subsection. First, Mertens and Ravn (2011b, 2012) split the Romer and Romer series into anticipated versus unanticipated shocks based on the delay between the passing of the legislation and the implementation of the legislation. $R \& R$ had timed all of their shocks to coincide with the implementation rather the legislation. I will discuss the findings using unanticipated shocks here and discuss the findings using anticipated shocks below. Second, in their 2013 paper, Mertens and Ravn (2013) decomposed the unanticipated parts of the R\&R series into personal income tax changes and corporate income tax changes and showed the differences in the two types of cuts on the economy. In their 2014 paper, Mertens and Ravn (2014) reconciled the Blanchard and Perotti SVAR estimates with the narrative estimates by introducing the proxy SVAR method discussed in detail in previous sections.

As discussed in Section 2.3.5, Mertens and Ravn's (2014) proxy SVAR provides a new method for identifying shocks using external instruments. In particular, they regress the reduced form residual of GDP, $\eta_{3 t}$, from equation (4.4) above on the reduced form residual of taxes, $\eta_{1 t}$, using the R\&R shock as an instrument. This leads to an unbiased estimate of $b_{31}$ (since it is assumed that $\eta_{2 t}$ is the structural shock to government spending, which is uncorrelated with the other structural shocks). We can then use the estimated residual from that regression as one of the instruments in the regression of $\eta_{1 t}$ on $\eta_{2 t}$ and $\eta_{3 t}$. This regression identifies $b_{12}$ and $b_{13}$. When they implement their method, they estimate $b_{13}=3.13$ with a $95 \%$ confidence band of $(2.73$, 3.55). Thus, their results suggest that Blanchard and Perotti's preset estimate of $b_{13}=2.08$ is too low. Setting the output elasticity of tax revenue too low results in estimated tax shocks that include a reverse causality component (i.e. there is a positive correlation between the cyclical components of taxes and output because of the positive causal effect of output on tax revenues). This is also an excellent illustration of Caldara and Kamps' (2012) insight on the link between the assumed structural tax elasticity and the estimated multipliers. Table 4.4 shows various tax multiplier estimates from the literature.

Mertens and Ravn (2013) split the unanticipated Romer shocks into changes in personal income tax rates versus corporate income tax rates. They find that cuts in either tax rate have positive effects on output, employment, hours, and the tax base. Interestingly, a cut in the corporate tax rate does not decrease corporate tax revenues because the corporate income tax base responds so robustly. Personal income tax cuts tend to raise consumption and investment 
more than corporate income tax cuts do. See Figures 2, 9, and 10 of Mertens and Ravn (2013) for more detail.

Oh and Reiss (2012) highlight the importance of transfers in the stimulus packages adopted in response to the Great Recession. They formulate a heterogeneous agent model and explore the predicted multipliers on transfers. There has been, however, very little empirical work on the multipliers associated with government transfers. ${ }^{32}$ A major challenge has been identifying exogenous movements in transfers. Hausman (forthcoming) studied the large veteran's bonus of 1936, equaling two percent of GDP, and found that it led to immediate effects on consumption spending. His calculations suggest that it led to faster GDP growth in 1936, but followed by a quick reversal in growth in 1937. Romer and Romer (2015) study the effects of changes in Social Security benefit payments in aggregate U.S. data. They find very rapid responses consumption to permanent changes in benefit, but the results dissipate within a few months. Moreover, there is no clear evidence of effects on aggregate output or employment.

Gechert (forthcoming) conducts a meta-analysis of various types of multipliers. He finds that tax and transfer multiplier tend to be around 0.6 to 0.7 .

\subsubsection{Further Explorations}

I now investigate the Mertens and Ravn (2014) reconciliation of the tax results in more detail. To do this, I first use Mertens and Ravn (2014) specification, data, and sample. The specification is a trivariate SVAR with federal government spending, output, and federal tax revenue, all in real per capita logarithms. ${ }^{33}$ The SVAR includes four lags of the variables in addition to a quadratic trend and a dummy variable for the second quarter of 1975 (following Blanchard and Perotti (2002)). The tax shock is Mertens and Ravn's unanticipated shocks extracted from the R\&R narrative, demeaned as they describe.

Figure 4.3A shows the impulse responses for tax revenue and output from their proxy SVAR using their programs. ${ }^{34}$ The results show that a positive R\&R tax shock that has an impact

\footnotetext{
${ }^{32}$ There is a large literature on the effects of various transfers on individual household consumption and saving. However, these estimates do not translate directly to aggregate mutlipliers.

${ }_{33}$ Blanchard and Perotti actually used net taxes, meaning taxes less transfers. I follow Mertens and Ravn and use taxes. One could augment the system to include transfers as a fourth variable and use Romer and Romer's (2014) narrative-based transfer shock series as an external instrument.

${ }^{34}$ This is the same as Mertens and Ravn's (2014) Figure 4 with the signs reversed to examine the effect of a tax increase.
} 
effect on tax revenues equal to one percent of GDP raises tax revenue for several quarters, and then lowers it below zero (though not statistically different). Output falls significantly on impact and troughs around -3 after a year. The magnitude of the results are similar to those found by R\&R (2010) with their entire exogenous series.

My further investigation reveals some potentially problems with instrument relevance, though. The first-stage regression of tax revenue on the unanticipated tax shock (controlling for the lags of the other variables in the VAR) has an F-statistic of 1.6 (based on robust standard errors), which suggests a possible problem with instrument relevance. ${ }^{35}$ Stock and Watson (2012) also noticed problems with first-stage F-statistics of some of these external instruments in their dynamic factor model. ${ }^{36}$ Of course, the feedback from GDP to tax revenues is a potential complication. An exogenous tax increase should raise revenue, holding GDP constant; however, the decline in GDP exerts a downward effect on tax revenues. Thus, perhaps it is better to think of the R\&R tax shock as an instrument for tax rates. Ideally, one would use statutory rates, since the actual rate paid is partly endogenous (since a change in income can push an entity into a different tax bracket). I do not have those data, so I simply construct an average tax rate as federal tax revenues divided by nominal GDP. I then estimate the first-stage regression described above with the average tax rate substituted for the log of taxes. The F-statistic on the R\&R shock in this regression is 3.2, twice as high as the previous case but still well below the threshold for instrument relevance.

With the caveats about instrument relevance in mind, I further explore the robustness of Mertens and Ravn's (2014) results by estimating impulse responses using the Jordà local projection method and the Romer tax shock. I first estimate the reduced forms. As discussed earlier, this involves regressing the dependent variable at $\mathrm{t}+\mathrm{h}$ on the shock at $\mathrm{t}$, controlling for lags of other variables. To be consistent with Mertens and Ravn's specification, I use the same lags and variables in their proxy SVAR. Figure 4.3B shows the impulse responses from the reduced form. Tax revenue increases in response to the shock initially and then falls below normal. In response to the tax shock, output falls on impact and then declines further to about -2 at two years, before beginning to recover. The confidence bands are wider, both because the Jordà method imposes fewer restrictions on the dynamics and because they incorporate the

\footnotetext{
35 These additional results are based on the same data definitions and specification as Mertens and Ravn (2014), but on revised data. The results are similar if I use their original data.

36 See Lunsford (2015) and Montiel Olea, Stock, and Watson (2015) for discussions of instrument relevance in the external instruments framework.
} 
uncertainty about the impact of the tax shock on tax revenue. However, the point estimates for output for the first few years are broadly consistent with both Romer and Romer's (2010) original results and Mertens and Ravn's (2014) proxy SVAR. ${ }^{37}$ Table 4.5 shows the forecast error variance decomposition based on a standard VAR. ${ }^{38}$ Unanticipated tax shocks appear to account for very little of the forecast error variance of output.

As Mertens and Ravn (2014) note, however, external instruments tend to have measurement error, so they should not be used directly in an SVAR. A natural way to adjust for this in the Jordà set-up is to estimate things as an instrumental variables regression, as discussed in Section 2. Thus, in a second specification I regress output at $t+h$ on the change in tax revenue at $t$, instrumented with the unanticipated part of the Romer tax shock, also controlling for the same variables as in the proxy SVAR (four lags of output, tax revenue, and government spending, as well as the deterministic terms). Figure 4.3C shows the estimated impulse response of output for this specification. The point estimates for these results look very similar to those for output in panel B. The difference is that the confidence intervals are very wide, always encompassing zero. Moreover, when I test whether the integral of the response for the first 12 quarters is different from zero, I cannot reject that it is zero. ${ }^{39}$

To summarize, the literature on the effects of tax shocks has employed numerous methods, such as SVARs with calibrated elasticities, narrative approaches, and sign restrictions. Mertens and Ravn's (2014) reconciliation of some of the various approaches tends to support Romer and Romer's (2010) large estimated elasticities. My robustness checks suggest that while there might be a problem with instrument relevance, less restrictive ways to estimate impulse responses also generally support Romer and Romer’s (2010) estimates of tax multipliers of -2 to $-3$.

\subsubsection{News About Future Tax Changes}

\subsubsection{Summary of the Literature}

\footnotetext{
${ }^{37}$ If I use the Jordà method on Romer and Romer's original specification and tax shock, I obtain results that are very close to theirs. This is as one would expect since the do not calculate impulses from a VAR. ${ }_{38}$ As discussed in Section 4.1.3, although one can calculate forecast error variances using the estimated local projection coefficients, I found that the shares sometimes exceeded 100 percent. Thus, for present purposes I calculate the forecast error variance in a standard VAR with the shock, log government spending, log real GDP, and log taxes. The shock is ordered first and four lags are included, along with a quadratic trend.

${ }^{39}$ Reducing the number of lags or control variables changes the results little.
} 
Theory predicts that anticipated tax changes should have very different effects from unanticipated tax shocks (e.g. Yang (2005)). If agents know that tax rates will increase in the future, they should respond by intertemporally substituting taxable activity into the present. Moreover, as discussed in Section 2, foresight about future tax changes can lead to identification problems in a standard SVAR. I will now review some recent results on the effects of anticipated tax changes on aggregate outcomes and provide some new results.

Mertens and Ravn (2011b, 2012) explore the effects of anticipated tax changes by splitting the Romers' narrative tax shock series into anticipated versus unanticipated shocks based on the delay between the passing of the legislation and the implementation of the legislation. Romer and Romer had timed all of their shocks to coincide with the implementation rather the legislation. Mertens and Ravn argue that the response of macroeconomic variables should be very different for anticipated versus unanticipated shocks.

Mertens and Ravn separate out the tax changes that were legislated more than 90 days before they were implemented. Because there are not a large number of these kinds of tax changes and because the lags between legislation and implementation vary significantly, Mertens and Ravn preserve the degrees of freedom in their estimation by combining various anticipated tax shocks according to the number of quarters left before implementation. Thus, their study does not trace out the effect of "news" per se; rather, it is more similar to an event study of the behavior of variables before and after the tax changes are implemented. Mertens and Ravn (2011) estimate that anticipated and unanticipated tax shocks together account for 20 percent of the historical variation in output at business cycle frequencies. Particularly interesting is their finding that the so-called "Volcker" recession was in fact mostly caused by the Reagan tax cuts. The legislation was passed in summer 1981 but the actual tax cuts were phased in between 1982 and 1984. Mertens and Ravn's estimates imply that most of the decline in output from the second half of 1981 through 1982 was due to the negative output effects of anticipated future tax cuts.

Leeper, Richter and Walker (2011) (LRW) construct an alternative measure of expected tax changes based on the spread between federal bonds and municipal bonds. They use their new series to inform their theoretical model, but do not estimate effects of shocks to their series directly from the data. In the unpublished supplement to their 2013 Econometrica paper, Leeper, 
Walker, Yang (2013) investigate the effect of their measure on output and show that expectations of a future tax increase raise output when the news arrives.

\subsubsection{Further Explorations}

I now explore the effects of several of the leading identified tax news shocks. Figure 4.4 reproduces Mertens and Ravn's (2011) estimates of the effects of Romer tax shocks that were anticipated. Quarter 0 is the date of the implementation, negative quarters are quarters between the arrival of the news and before the implementation, and positive quarters are after the implementation. The graphs show clear evidence of anticipation effects and intertemporal substitution. Most variables, including output, hours, investment, and durable goods consumption expenditures, are higher than average in the interval between the announcement of a tax increase and its actual implementation. After implementation, all variables fall below normal, including nondurable consumption. Thus, the behavior of the data is very consistent with the theory.

To see how the results compare to Mertens and Ravn's results, I analyze the effects of Leeper, Richter and Walker's (2011) measure of average expected future tax rates from one to five years forward (AFTR15). Using a Jordà local projection, I estimate several sets of regressions at each horizon. In particular, I regress the endogenous variable of interest at $t+h$ on AFTR15 in period t, as well as on four lags of AFTR15, four lags of the endogenous variable and four lags of the average federal tax rate (total federal receipts divided by GDP). Because I do not orthogonalize the shock with respect to current values of any of the other variables, this identification scheme is similar to the one used by Leeper, Walker, Yang (2013), where they order the tax news first in the Cholesky decomposition.

Figure 4.5 shows the estimated responses to "news" that future tax rates will rise. The results are quite similar to those of Mertens and Ravn's results, even though the tax news variable is from a completely difference source and the model is estimated as responses to news rather than as an event study around the implementation. Output, hours and investment start rising when news arrives at period 0 that tax rates will increase in the interval between one and five years. The variables remain high for a while and then fall below normal after a year or so. 
Table 4.5 shows the forecast error variance decomposition for the LRW measure of expected tax changes. These shocks appear to account for more of the variance of output than the unanticipated tax changes, but still less than six percent.

In sum, some of the strongest and most robust findings in the fiscal literature are those associated with news about future tax changes. Expectations that future tax rates will increase lead to boom now followed by "busts." This is perhaps some of the strongest evidence that "news” can drive economic fluctuations.

\subsection{Summary of Fiscal Results}

In this section, I have summarized some of the main methods and findings concerning the effects of fiscal shocks. For both government spending and taxes, the methods that use external narrative series tend to find bigger effects on output than the more traditional SVAR method. For both government spending and taxes, anticipation effects are found to be very important.

Some of the literature has studied the effects of government spending and tax shocks jointly and made statements about "which" multiplier is larger. Some find larger government spending multipliers, others find larger tax multipliers. My assessment is that the existing methods do not yield precise enough and robust enough estimates to be able to make this comparison.

\section{Technology Shocks}

I now review the evidence on the leading non-policy shock: technology shocks. This section reviews the literature on technology shocks and presents some new results comparing various shocks from the literature. I will discuss both the classic unanticipated technology shocks as well as news about future changes in technology. I will also distinguish between neutral and investment-specific technology shocks.

\subsection{Neutral Technology Shocks}


In 1982, Kydland and Prescott (1982) demonstrated the (then) surprising result that one could produce business cycle movements of key variables from a dynamic stochastic general equilibrium growth model beset by only one type of shock: variations in the growth rate of exogenous total factor productivity (TFP). To be concrete, consider the following aggregate production function:

$$
Y_{t}=A_{t} F\left(L_{t}, K_{t}\right) \text {, }
$$

where $Y_{t}$ is output, $A_{t}$ is total factor productivity (TFP), $L_{t}$ is labor, and $K_{t}$ is the capital stock at the beginning of period t. Neutral technology shocks, or TFP shocks, are shocks to the process driving $A_{t}$.

Several empirical regularities supported Kydland and Prescott’s (1982) hypothesis. First, Solow (1957) showed that 87 percent of the growth in average labor productivity from 1909 to 1949 was due to TFP growth. If TFP growth was so important for growth, why not also for business cycles? Second, at the time that Kydland and Prescott published their article, a longstanding stylzed fact was the procyclicality of labor productivity. In fact, this stylized fact was a problem for Keynesian "aggregate demand" explanations of business cycles, since diminishing returns would predict countercyclical labor productivity. Typically, the aggregate demand drivenbusiness cycle literature had to resort to stories of labor hoarding or increasing returns to explain the procyclicality of labor productivity.

In follow-up work, Prescott (1986) used the Solow residual as his measure of exogenous TFP and used the standard deviation of that series along with his model to argue that the bulk of business cycle fluctuations could be explained by technology shocks. Beginning in the 1990s, though, several new results emerged that cast doubt on using the Solow residual as an exogenous technological progress for the purpose of business cycle analysis. First, Evans (1992) showed that variables such as money, interest rates, and government spending Granger-caused the Solow residual. Second, Hall $(1988,1990)$ developed a generalization of the Solow residual framework that relaxed the assumptions of competition and constant returns to scale. This framework demonstrated how endogenous components could enter the Solow Residual. Third, a number of papers, such as Shapiro (1993), Burnside, Eichenbaum, and Rebelo (1995), Basu and Kimball, (1997) used proxies such as the workweek of capital, electricity, or average hours to adjust the 
Solow residual for variations in utilization of labor and/or capital. They found that much of the procyclicality of the Solow residual disappeared once it was adjusted.

Two approaches called into question whether technology shocks even led to businesscycle like movements. Galí (1999) and Basu, Fernald, Kimball (2006) used different methods but both found results suggesting that a positive technology shock led to a decline in labor inputs, such as hours. Both of these analyses assumed that all technology shocks were neutral technology shocks. I will discuss each of the approaches with the follow-up work in turn.

Galí (1999) used long-run restrictions to identify neutral technology shocks. He argued that a standard real business cycle (RBC) model predicted that technology shocks were the only shocks that could have permanent effects on labor productivity. As discussed in Section 2.3.6, Galí (1999) estimated a bivariate VAR with labor productivity and hours (or employment) and imposed the long-run restriction that technology shocks were the only shocks that could have a permanent effect on labor productivity. Francis and Ramey (2005) derived additional long-run restrictions from the theory and used them as an overidentification test and found that one could not reject the over-identifying restrictions. Francis and Ramey (2004) constructed new historical data for the U.S. and extended the analysis back to 1889. They found that a positive technology shock raised hours in the pre-WWII period but lowered them in the post-WWII period. They explained the switch with the difference in the serial correlation properties of productivity. In the early period, an identified technology shock raised productivity immediately, whereas in the later period an identified technology shock raised productivity more gradually. This gradual rise in the later period provides an incentive to reduce hours worked in the short-run in anticipation of higher productivity in the long-run.

Galí (1999) and Francis and Ramey (2005) both assumed that both (log) labor productivity and hours had a unit root and that their first differences were stationary. As Section 2.3.6 above demonstrated, imposing long-run restrictions also requires the imposition of assumptions on stationarity. Christiano, Eichenbaum and Vigfusson (2003) argued that it makes no sense to model hours per capita as having a unit root since it is bounded above and below. They showed that if instead one assumes that hours are stationary and then impose the Galí longrun restriction, a positive technology shock leads to a rise in hours worked. Fernald (2007) noted the structural break in labor productivity growth, and when he allowed for that feature of the data, he found that hours fell after a positive technology shock. Francis and Ramey (2009) 
argued that the baby boom led to low frequency movements in both labor productivity growth and hours worked per capita and that failure to correct for these led to the positive correlations found by Christiano et al. When they corrected for demographics, they found that a positive technology shock led to a decrease in hours. Gospodinov, Maynard and Pesavento (2011) discuss various econometric issues that arise in this setting with low frequency movements.

Building on ideas of Uhlig (2003), Francis, Owyang, Rousch, DiCecio (2014) introduced a new method of imposing long-run restrictions that overcame many of these problems. They identify the technology shock as the shock that maximizes the forecast error variance share of labor productivity at some finite horizon $h$. Using that scheme, they find that their identified technology leads to a fall in hours worked. They estimate that technology shocks contribute 15 to 40 percent of the forecast error variance of output at business cycle horizons. A variation by Barsky and Sims (2011) identifies the technology shock as the one that maximizes the sum of the forecast error variances up to some horizon $h$.

Several papers have questioned Galís (1999) basic identifying assumption that technology shocks are the only shocks that have a long-run effect on labor productivity. Uhlig (2004) argues that capital taxation and shifts in preferences involving "leisure in the workplace" can also have long-run effects on labor productivity. He also introduces a "medium run" identification procedure that anticipates the procedures discussed above. He finds that the impact effect on hours is zero and that there is a small rise afterward. Mertens and Ravn (2010) include the Romer and Romer (2010) exogenous tax shocks in a vector error correction model and find that once taxes are controlled and cointegration is allowed, a positive TFP shock raises hours in the short-run. They also find that technology shocks account for $50-55$ percent of the forecast error variance of output.

Basu, Fernald and Kimball (2006) found that technology shocks were contractionary using a completely different method. Employing theoretical insights from Basu and Kimball (1997), they adjusted the annual Solow residual for utilization using hours per worker as a proxy. When they examined shocks to this purged Solow residual, they found that positive shocks to technology led to a decline in hours worked. Fernald (2014) has now constructed a quarterly version of this utilization-adjusted TFP series. ${ }^{40}$

\footnotetext{
${ }^{40}$ The series is regularly updated and made available by John Fernald at http://www.frbsf.org/economicresearch/economists/jfernald/quarterly'tfp.xls .
} 
Alexopoulos (2011) identified technology shocks by creating an entirely new data series for measuring technology. Meticulously collecting and counting book publications for several types of technologies, she constructed several annual series on new technologies. She found that these series were not Granger-caused by standard macroeconomic variables. Using her new series in VARs, she found that a positive technology raises output and productivity. Contrary to the findings of Galí (1999) and Basu, Fernald and Kimball (2006), she estimated that a positive shock to technology raises output, though the effect is weak.

Table 5.1 summarizes some of the estimates of the contribution of TFP shocks to output fluctuations at business cycle frequencies, based on approaches that identify technology shocks in time series models.

Numerous papers have identified technology shocks through estimated DSGE models. McGrattan (1994) estimated a neoclassical DSGE model with technology and fiscal shocks. Smets and Wouters (2007) estimated a New Keynesian DSGE model using Bayesian methods in order to explore the effects of various shocks. They incorporate a number of different shocks in the model, including neutral technology shocks, investment-specific technology shocks (discussed in the next section), monetary shocks, government spending shocks, mark-up shocks, and risk premium shocks. Their estimates imply that a positive neutral technology shock lowers hours worked. Justiniano, Primiceri, and Tambalotti $(2010,2011)$ also estimate a New Keynesian model, but incorporate also investment-specific shocks and marginal efficiency of investment shocks. Schmitt-Grohe and Uribe (2012) estimate a DSGE model which allows all oftheir shocks to have an unanticipated component and a "news," or unanticipated, component. Miyamoto and Nguyen (2015) extend their estimation method by including series on survey expectations in the estimation. I will discuss these papers in more detail in the sections on investment-specific technology shocks and news. Blanchard, L'Huillier, and Lorenzoni (2013) estimate a DSGE model allowing for both "news" and "noise." Table 5.2 summarizes the estimates from DSGE models of the contribution of various types of technology shocks to output fluctuations at business cycle frequencies.

\subsection{Investment-Related Technology Shocks}


Greenwood, Hercowitz and Huffman (1988) were the first to examine in a DSGE model Keynes' idea that shocks to the marginal efficiency of investment could be a source of business cycle volatility. In follow-up work, Greenwood, Hercowitz, and Krusell (2000) used a calibrated DSGE model to examine the importance of investment-specific technological change in business cycles. They used the relative price of new equipment to identify the process driving investmentspecific technology shocks and concluded that these shocks could account for 30 percent of business cycle volatility.

Fisher (2006) extended Galís (1999) analysis of neutral technology shocks by incorporating additional data and restrictions that separately identify neutral and investmentspecific technology (IST) shocks. In particular, he assumed that only IST shocks affect the relative price of investment goods in the long-run and only neutral technology and IST technology shocks affect labor productivity in the long-run. Because of some sample instability, he estimated his model over two periods: 1955q1 - 1979q2 and 1982q3 - 2000q4. He found that both technology shocks together accounted for a substantial shared of the forecast error variance of output, 60 percent at 12 quarters in the early sample, 83 percent in the later sample.

Justiniano, Primiceri, Tambalotti $(2010,2011)$ estimate a New Keynesian DSGE model with a variety of unanticipated shocks. Justiniano, Primiceri, and Tambolotti (2011) distinguish between investment-specific technology shocks and marginal efficiency of investment shocks. To be concrete, consider simplified versions of two equations from their DSGE model:

$$
\begin{aligned}
& I_{t}=Y_{t} Y_{t}^{I} \\
& K_{t+1}=(1-\delta) K_{t}+\mu_{t} I_{t}
\end{aligned}
$$

$I_{t}$ is the production of investment goods and $Y_{t}$ denotes the rate of transformation of final goods, $Y_{t}^{I}$, into investment goods. $Y_{t}$ is investment-specific technology (IST) which, according to their model, should be equal to the inverse of the relative price of investment goods to consumption goods. $K_{t+1}$ is the level of capital at the beginning of period $t+1, \delta$ is the depreciation rate, and $\mu_{t}$ is the rate of transformation between investment goods and installed capital, or the marginal efficiency of investment (MEI). Previous research, such as by Greenwood, Hercowitz, and Krusell (2000) and Fisher (2006), had not distinguished IST from MEI and had assumed their product was equal to the inverse of the relative price of investment goods. Justiniano, Primaceri 
and Tambolotti (2011) estimate that (unanticipated) MEI shocks contribute to 60 percent of the variance of output at business cycle frequencies.

Schmitt-Grohe and Uribe (2012), Khan and Tsoukalas (2012), and Miyamoto and Nguyen (2015) estimate DSGE models that incorporate both TFP and IST shocks. An important focus of their estimation is the distinction between unanticipated technology changes and news about future changes, so I will discuss their work in the next section on news.

Although there is a wide range of results, a general pattern that emerges is that when models include IST and/or MEI shocks, they tend to explain a significant portion of the variation in output at business cycle frequencies.

\subsection{News about Future Technology Changes}

Both Pigou (1927) and Keynes (1936) suggested that changes in expectations about the future may be an important driver of economic fluctuations. Beaudry and Portier (2006) reignited interest in the idea by providing time series evidence that news about future productivity could explain half of output fluctuations over the business cycle. Furthermore, their estimates implied that hours and output rose when the news arrived, thus creating business-cycle type comovements. They identified news shocks using two methods; both involved identifying shocks that moved stock prices immediately, but affected productivity only with a lag. Beaudry and Lucke (2009) and Kurmann and Otrok (2013) used other techniques to reach similar conclusions. More recently, however, Barsky and Sims (2011) and Barsky, Basu and Lee (2014) have used medium run restrictions and series on consumer confidence to identify news shocks and found that news shocks did not generate business cycle fluctuations. In particular, hours fell when news arrived. Fisher (2010), Kurmann and Mertens (2014), and Forni, Gambetti, and Sala (2014) have highlighted problems with Beaudry and Portier's identification method. For example, Kurmann and Mertens (2014) show that the larger VECM in Beaudry and Portier's (2006) paper is not identified. Forni, Gambetti and Sala (2014) argue that the small-scale SVARs are affected by the “non-fundamentalness" problem discussed in Section 2.5. Thus, the empirical work based on time series identification is in flux. Beaudry and Portier (2014) present a comprehensive summary of the literature. 
I would add that another potential problem with Beaudry and Portier's (2006) method for identifying TFP news shocks is the implicit assumption they make about stock prices. They assume that the future profits from the TFP shock will show up in current stock prices. It is not clear that this assumption holds for major innovations. Greenwood and Jovanovic (1999) and Hobijn and Jovanovic (2001) present theory and evidence that major technological innovations (such as information technology) actually lead to a temporary decline in stock market values because they lower the value of the existing technology. Revolutionary innovations usually arise in private companies and claims to future dividend streams only show up in stock prices after the initial public offerings. Thus, we should not necessarily see positive effects of news about future TFP on stock prices.

Ben Zeev and Khan (2015) identify both unanticipated investment-specific technology (IST) shocks and IST news shocks. To do this, they extend Barsky and Sims (2011) medium horizon restriction method for identifying news and employ Fisher's (2006) assumptions linking IST and the relative price of investment goods. They find that IST news shocks explain 73\% of the forecast error variance of output at a horizon of 8 quarters. They show that the IST shocks originally identified by Fisher (2006) were a combination of the unanticipated IST shocks and news about IST. Ben Zeev and Khan's paper thus corroborates Fisher's finding that IST shocks are the major source of fluctuations, but goes on to show that it is the news part that is the most important.

Another strategy for identifying news is through estimation of a DSGE model, as pioneered by Schmitt-Grohe and Uribe (2012). This approach achieves part of its identification by assuming particular lags between the arrival of news and the realization of the change. Schmitt-Grohe and Uribe (2012) allow for a variety of unanticipated and news shocks for variables such as TFP, investment-specific technology, and wage markups. They estimate that all news variables combined (including nontechnology shocks such as wage markup shocks) account for 50 percent of output fluctuations according to their estimates. An extension by Miyamoto and Nguyen (2015) uses actual survey forecasts for the expectations variables.

Khan and Tsoukalas (2012) estimate a New Keynesian DSGE model with both investment-specific technology and marginal efficiency of investment shocks, and allow for both unanticipated changes and news shocks. They find that unanticipated marginal efficiency of investment shocks contribute an important part of the variance of output (47\%), but that 
technology news shocks are not important at all. Nontechnology news shocks do, however, contribute to the variance decomposition of hours. In particular, wage markup shocks account for over 40 percent of the variance of hours. Thus, their results on the importance of unanticipated technology shocks contrast with those of Schmitt-Grohe and Uribe (2012), but their results on the importance of news about wage markups is consistent with their findings. The estimates of the importance of technology news are summarized in Table 5.2.

\subsection{Explorations with Estimated Technology Shocks}

I now study the relationship between some of the leading shocks and explore the effects of a few of them in the Jordà local projection framework. I re-estimate the Galí (1999), Christiano, Eichenbaum, Vigfusson (2004) (CEV), and Beaudry and Portier (2006) systems using updated data. In each case, I used a simple bivariate system. Both the Galí and CEV shocks use long-run restrictions, with the former assuming a unit root in hours per capita and the latter assuming a quadratic trend in hours. I use Beaudry and Portier's shock estimated with the shortrun restriction, i.e., it is the shock to stock prices that does not affect TFP on impact; the correlation of this shock with their shock estimated using long-run restrictions is 0.97. The Fernald shocks are simply the growth rate of Fernald's (2014) utilization-adjusted TFP for the aggregate economy or for the investment goods sector. The rest of the estimated shocks were kindly provided by Francis, Owyang, Roush, and DiCecio (2014) (medium-horizon restrictions), Barsky and Sims (2011) (medium-run restrictions, consumer confidence), Justiniano, Primiceri, and Tambolotti (2011) (estimated DSGE model), Ben Zeev and Khan (2015) (SVAR with medium-run restrictions), and Miyamoto and Nguyen (2015) (estimated DSGE model with forecast data). The joint sample is 1955q2 - 2006q4, except for the TFP news sample, which is limited to 1961q1 - 2006q4 by the Barsky and Sims shock availability. Correlations between subsets of shocks that are available over longer samples are similar to those reported for the joint sample. Table 5.3 shows the correlations, broken down according to whether the shock is to TFP or IST (or MEI) and whether it is unanticipated or is news.

Table 5.3, Panel A shows the results for unanticipated TFP shocks, which have received the most attention. Most of the shocks have a correlation above 0.6 with the shock estimated using Galí’s (1999) method. The exception is the Miyamoto and Nguyen (2015) permanent TFP 
shock. It is surprising that the Miyamoto and Nguyen stationary TFP shock has a higher correlation than the permanent TFP shock, since the Galí method only identifies permanent TFP shocks.

Panel B shows news shocks about TFP. The correlation between Beaudry and Portier's (2006) shock estimated using short-run restrictions and Barksy and Sims’ (2011) shock estimated using medium horizon restrictions is only 0.25. The correlations of both of those SVAR-based shocks with the Miyamoto and Nguyen (2015) DSGE-based shocks are essentially 0.

Panel C shows correlations of various estimates of unanticipated investment-specific technology (IST) or marginal efficiency of investment (MEI) shocks. The correlations between the various estimates are quite low. For example, the correlation between Fernald's utilizationadjusted TFP for the investment goods sector and Justiniano et al.'s (2011) IST shock is only 0.19 and is -0.27 for Justianiano et al.s’ MEI shock. The highest correlation of 0.49 is between Justiniano et al.’s IST shock and Ben Zeev and Khan’s (2015) IST shock. The higher correlation is not surprising since both methods associate the IST shock with the inverse of the relative price of equipment.

Panel D shows correlations of various estimates of IST news shocks. There is essentially no correlation between Ben Zeev and Khan's (2015) SVAR-based estimates and Miyamoto and Nguyen's (2015) DSGE-estimated shocks.

If we were simply trying to develop instruments for estimating structural parameters, it would not matter if various instruments had low correlation. ${ }^{41}$ If, however, we are trying to estimate shocks in order to determine their importance for macroeconomic fluctuations, a low correlation across various estimates is troubling. The large number of low correlations across methods and the widely-varying results reported across papers suggest that we are still far from a consensus on the nature and importance of technology shocks. The problem is not one of lack of consensus of estimated DSGE vs. SVAR methods. Even within each class of method, the results vary widely, as evidenced in Tables 5.1 and 5.2.

Moreover, many of the estimated shocks do not satisfy the property that they are unanticipated or news. Table 5.4 shows the p-values from two sets of tests. The first one tests for serially correlation of the shock by regressing the shock on its own two lags and testing their joint significance. The SVAR estimated shocks do well on this test, but quite a few of the DSGE-

\footnotetext{
${ }^{41}$ Sims (1998) made this argument in his discussion of Rudebusch's (1998) monetary shock critique.
} 
estimated shocks fail this test. The second set of tests is for Granger-Causality (Granger (1969)). To conduct these tests, I augment this regression with two lags each of log real GDP, log real consumption and log real stock prices. I chose consumption and stock prices because those variables have forward-looking components to them. Half of the shocks fail this test. Of course, the Galí and CEV shocks were estimated using a simple bivariate model. Had I augmented those systems with these variables, the shocks would have passed the tests by construction. The Francis et al., Beaudry and Portier, and Ben Zeev and Kahn shocks pass this test, as do about half of the DSGE-estimated shocks.

I explore the effects of a few of the estimated shocks on several macroeconomic variables in a Jordà local projection framework. To do this, I estimate the following series of regressions:

$$
z_{t+h}=\alpha_{h}+\theta_{h} \text { shock }_{t}+\varphi_{h}(L) y_{t-1}+\text { quadratic trend }+\varepsilon_{t+h}
$$

The $z$ is the variable of interest. The control variables include two lags each of the shock (to mop up any serial correlation in the shocks), log real GDP per capita, log real stock prices per capita, log labor productivity (equal to real GDP divided by total hours worked), and the dependent variable. The coefficient $\theta_{h}$ gives the response of $z$ at time $t+h$ to a shock at time $t$. As discussed in Section 2, $t+h$ will be serially correlated, so the standard errors must incorporate a correction, such as Newey-West.

Figure 5.1 shows the responses of real GDP, labor productivity hours, stock prices, consumption and nonresidential investment to three different measures of unanticipated TFP shocks: the Francis, Owyang, Roush, and DiCecio (2014) (FORD) measure, which uses medium run restrictions; Fernald's (2014) utilization-adjusted TFP growth, and Justiniano, Primiceri, and Tambalotti's (2011) (JPT) estimate from their DSGE model. The responses to the FORD and JPT shocks are quite similar: GDP, labor productivity, stock prices, and consumption all jump immediately and significantly. Hours fall for a few quarters before rising. The Fernald shock implies a more hump-shaped response of GDP, hours, stock prices, consumption and investment. Labor productivity rises immediately but then returns to normal at around 16 quarters. The Fernald shock also shows an initial decline in hours before they rise.

Figure 5.2 shows the effects of the Ben Zeev and Khan (2015) investment-specific technology (IST) news shock. Recall that this shock is an extension of Fisher's (2006) method, 
estimated using the Barsky-Sims (2011) medium-horizon method combined with information on relative prices of investment. This shock appears to generate a classic business cycle pattern. GDP, hours, stock prices, consumption, and nonresidential investment increase with a prolonged hump shape. Labor productivity does nothing for about 6 quarters, falls around 9 quarters, and then rises.

Figure 5.3 shows the effects of JPT’s marginal efficiency of investment shock, estimated from their DSGE model. While this shock leads to temporary rises (for a year or less) in real GDP, labor productivity, consumption, and nonresidential investment, it leads to a fall in stock prices, which is puzzling.

Table 5.5 shows the forecast error variance decompositions for these five shocks for both output and hours. The decompositions are calculated from a standard VAR with the shock, and log per capita values of real GDP, hours, stock prices, consumption, and nonresidential investment. Although some of the unanticipated TFP shocks can account for up to 16 percent of output, none accounts for much of the variance of hours. In contrast, the Ben Zeev and Khan investment-specific technology news shock accounts for well over a third of the forecast error variance of both output and hours. Justiniano, Primiceri, and Tambalotti's marginal efficiency of investment shock accounts for large fractions on impact, 50 percent for output and 26 percent for hours, but the effects dissipate fairly quickly.

\subsection{Summary of Technology Shocks}

The literature investigating the effects of technology shocks has moved far beyond the simple Solow residual. Various methods have been introduced to deal with changes in measured TFP that are due to variable utilization. Moreover, the literature has moved beyond neutral technology shocks to recognize the potential importance of investment-specific technology shocks and marginal efficiency of investment shocks. In addition, recent contributions have investigated the importance of news shocks.

My analysis shows, however, that some of the estimated shocks are not highly correlated with other versions. Moreover, many of the shocks are serially correlated or Granger-caused by other variables. This suggests that more research needs to be done to refine these shock measures. One of the shocks that seems to be promising both for generating business-cycle 
comovement and for contributing significant amounts to the variance of output is the shock that captures news about investment-specific technological change.

\section{Additional Shocks}

So far, this chapter has focused on only three types of shocks - monetary, fiscal, and technology shocks. There are numerous other candidates for potentially important macroeconomic shocks. Here I will briefly review a few.

One obvious additional candidate for a macroeconomic shock is oil shocks. Hamilton (1983) argued that oil supply shocks were a major driver of economic fluctuations. Since then a large literature has examined the effects of oil supply shocks. One of the major themes of the literature is the changing estimated effects of oil price shocks, identified by ordering oil prices first in a linear VAR. In particular, after the 1970s oil price changes seemed to have smaller effects. One potential explanation is asymmetries. Several analyses, such as by Davis and Haltiwanger (2001) and Hamilton (2003), argued that oil price increases have larger effects than oil price decreases. Subsequent research, however, found that there was not strong evidence of asymmetry (e.g. Kilian and Vigfusson (2011)). A second potential explanation for the changing effects of oil supply shocks is that the oil price increases in earlier periods were accompanied by price controls, which led to many distortions (Ramey and Vine (2011)). When they constructed an implicit cost of oil that incorporated a proxy for the distortion costs, they did not find much evidence of changing effects. A third explanation was by Kilian (2009), and was a critique of standard identification methods. He argued that many of the changes in oil prices are driven now driven by demand shocks, not supply shocks, so a standard Cholesky decomposition with oil prices ordered first does not properly identify oil supply shocks. Stock and Watson's (forthcoming) chapter in this Handbook uses oil shocks as a case study of their methods. They

find that oil supply shocks, identified using Kilian's (2009) method, do not account for a significant fraction of the forecast error variance of output.

Credit shocks are another possible candidate for a macroeconomic shock. There is huge literature analyzing the importance of credit and credit imperfections in economic fluctuations and growth. Most of this literature focuses on credit as an important propagation and amplification mechanism (e.g. "the credit channel" of monetary policy), rather than as an 
important independent source of shocks. Gilchrist and Zakrajsek's (2012) recent analysis of the effects of innovations to their new excess bond premium variable can be interpreted as an analysis of credit market shocks. They showed that innovations to the excess bond premium that were orthogonal to the current state of the economy had significant effects on macroeconomic variables. They interpret a negative "shock" to this variable as signaling a reduction in the effective risk-bearing capacity of the financial sector.

The role of uncertainty in the business cycle has received heightened attention recently. In addition to standard firm-level uncertainty and financial uncertainty, recent work has suggested a possible role for policy uncertainty. More research needs to be done to untangle uncertainty as an endogenous propagation mechanism versus uncertainty as an independent source of macroeconomic shocks. Bloom and Davis' (forthcoming) chapter in this Handbook reviews the literature on the role of uncertainty in the macroeconomy.

Labor supply shocks are yet another possible source of macroeconomic shocks. It is wellknown that cyclical variations in the "labor wedge" are an important component of business cycles. Shapiro and Watson (1988) estimated an SVAR with long-run restrictions and found that labor supply shocks were the dominant driver of business cycles. In estimated DSGE models with many shocks, wage markup shocks are often found to play an important role. This is particularly the case for news about wage markups. For example, both Kahn and Tsoukalas (2012) and Schmitt-Grohé and Uribe (2012) find that wage markup news shocks account for 60 percent of the variance share of hours. A key question is whether exogenous shocks to the labor market are an important part of fluctuations or whether we are accidentally identifying an internal propagation mechanism as an exogenous shock.

\section{Summary and Conclusions}

This chapter has summarized the new methods and new findings concerning macroeconomic shocks and their propagation. Identification is particularly challenging in macroeconomics because researchers ask questions for which dynamics are all-important, general equilibrium effects are crucial, and expectations have powerful effects.

The literature has made substantial progress in thinking seriously about identification of shocks since the early days of Cholesky decompositions. It now exploits new data sources, such 
as narrative records, survey expectations, and high frequency financial data, and combines theory with extra data series (e.g. the relative price of investment goods), and incorporates that information in estimated DSGE models and structural vector autoregressions.

The introduction to this chapter posed the question: Are we destined to remain forever ignorant of the fundamental causes of economic fluctuations? I would argue "no." Although we still have far to go, substantial progress has been made since Cochrane (1994) asked that question.

In support of my answer, I offer the following forecast error variance decomposition that combines some of the leading shocks I have discussed in this chapter. I specify a VAR that contains the shocks as well as some macroeconomic variables. In particular, it contains (in this order) Ben Zeev and Pappa’s (forthcoming) military news shock, Leeper, Richter, and Yang (2012) news about future taxes from bond prices, the Romer and Romer's (2010) unanticipated tax shocks (as constructed by Mertens and Ravn (2012)), Francis et al.’s (2014) medium-horizon restriction TFP shock, Ben Zeev and Khan’s (2015) investment-specific technology news shock, and Justiniano et al.'s (2011) marginal efficiency of investment shock. The macroeconomic variables include the logs real per capita values of GDP and total hours, as well as the log of commodity prices and the GDP deflator. Ordered last is the federal funds rate. Four lags are used and a quadratic trend is included.

Table 6.1 shows the forecast error variance decomposition of log real GDP per capita and $\log$ hours per capita. Because of data limitations on some of the shocks, the sample starts after the Korean War. It should not be surprising, then, that the government spending shocks are not very important. The tax news shocks contribute a small amount, less than ten percent. The unanticipated tax shocks are unimportant.

Which shocks are important? The most important, both for output and hours is Ben Zeev and Khan's (2015) news about investment-specific technology change. This variable contributes an important part of the forecast error variance of both output and hours. For example, at 8 quarters the contribution to hours is 40 percent. The 90 percent confidence interval (not shown in the table) is (25, 54). Justiniano, Primiceri, and Tambalotti's (2011) marginal efficiency of investment shock contributes 42 percent on impact, with a 90 percent confidence interval of $(34,50)$, but this falls to 24 percent by one year. If we associate the innovations to the federal 
funds rate with monetary policy shocks, then monetary policy shocks contribute up to 8 percent of the variance of output, but up to 18 percent of the variance in hours.

In sum, the three fiscal shocks, the three technology shocks, and the federal funds rate shock contribute 63 to 79 percent of the variances of output and hours at horizons of 4 to 20 quarters. While much more work should be done exploring the plausibility of the identifying assumptions, testing the robustness of these shock estimates, and making sure that they do satisfy the properties a shock should satisfy, these results suggest that we are indeed closer to understanding Slutsky's random shocks that drive macroeconomic fluctuations. 


\section{References}

Alesina, Alberto, and Silvia Ardagna, 1998, “Tales of Fiscal Adjustment,” Economic Policy, Vol. 13, No. 27, pp. 487-545.

Alesina, Alberto, and Silvia Ardagna, 2010, "Large Changes in Fiscal Policy: Taxes versus Spending,” Tax Policy and the Economy, Vol. 24, ed. by Jeffrey R. Brown (Cambridge, Massachusetts: National Bureau of Economic Research).

Alesina, Alberto, and Roberto Perotti, 1995, "Fiscal Expansions and Fiscal Adjustments in OECD Countries,” Economic Policy, Vol. 10, No. 21, pp. 205-248.

Alesina, Alberto, and Roberto Perotti, 1997, "Fiscal Adjustments in OECD Countries: Composition and Macroeconomic Effects,” IMF Staff Papers, Vol. 44 (June), pp. 210-48.

Alexopoulos, Michelle. "Read all about it!! What happens following a technology shock?." The American Economic Review 101.4 (2011): 1144-1179.

Amir Ahmadi, Pooyan and Harald Uhlig, "Sign Restrictions in Bayesian FAVARs with an Application to Monetary Policy Shocks,” NBER Working paper 21738, November 2015.

Angrist, Joshua D. and Jorn-Steffen Pischke, "The Credibility Revolution in Empirical Economics: How Better Research Design is Taking the Con out of Econometrics," Journal of Economic Perspectives, 24 (Spring 2010): 3-30.

Angrist, Joshua D., Òscar Jordà, and Guido Kuersteiner (2013), “Semiparametric Estimates of Monetary Policy Effects: String Theory Revisited,” NBER working paper 19355.

Arias, Jonas E., Diego Caldara, and Juan F. Rubio-Ramirez, "The Systematic Component of Monetary Policy in SVARS: An Agnostic Identification Procedure,” January 2015 working paper.

Arias, Jonas E., Juan F. Rubio-Ramirez, and Daniel F. Waggoner, “Inference Based on SVARs Identified with Sign and Zero Restrictions: Theory and Applications, November 2015 working paper.

Auerbach, Alan and Yuriy Gorodnichenko. 2012. "Measuring the Output Responses to Fiscal Policy.” American Economic Journal: Economic Policy 4 (2): 1-27.

Auerbach, Alan and Yuriy Gorodnichenko. 2013. "Fiscal Multipliers in Recession and Expansion” Fiscal Policy After the Financial Crisis, eds. Alberto Alesina and Francesco Giavazzi, University of Chicago Press.

Bagliano, Fabio C., and Carlo A. Favero. 1999. "Information from Financial Markets and VAR Measures of Monetary Policy.” European Economic Review 43 (4-6): 825-37. 
Barakchian, S. Mahdi and Christopher Crowe, "Monetary Policy Matters: Evidence from New Shocks,” Journal of Monetary Economics, Volume 60, Issue 8, November 2013, Pages 950-966.

Barro, Robert J., “Unanticipated Money Growth and Unemployment in the United States.” The American Economic Review Vol. 67, No. 2 (Mar., 1977), pp. 101-115.

Barro, Robert J., "Unanticipated Money, Output, and the Price Level in the United States." Journal of Political Economy Vol. 86, No. 4 (Aug., 1978), pp. 549-580.

Barro, Robert J., and Charles J. Redlick. 2011. "Macroeconomic Effects from Government Purchases and Taxes.” Quarterly Journal of Economics 126 (1): 51-102.

Barsky, R. B., and E. R. Sims (2011): "News shocks and business cycles," Journal of Monetary Economics, 58(3), 273-289.

Barsky, Robert. B. and Eric Sims, "Information, Animal Spirits, and the Meaning of Innovations in Consumer Confidence," American Economic Review, 102(4), 2012.

Barsky, Robert B., Susanto Basu, and Keyoung Lee. 2014. "Whither News Shocks?" NBER Working Paper 20666. November.

Barth III, Marvin J., and Valerie A. Ramey. "The cost channel of monetary transmission." NBER Macroeconomics Annual 2001, Volume 16. MIT Press, 2002. 199-256.

Basu, Susanto, and Miles S. Kimball. Cyclical productivity with unobserved input variation. No. w5915. National Bureau of Economic Research, 1997.

Basu, Susanto, John G. Fernald, and Miles S. Kimball. "Are Technology Improvements Contractionary?." The American Economic Review (2006): 1418-1448.

Baumeister, Christiane and James D. Hamilton, "Sign Restrictions, Structural Vector Autoregressions, and Useful Prior Information,” Econometrica 83 (September 2015): 1963-1999.

Beaudry, Paul and Frank Portier, "Stock Prices, News, and Economic Fluctuations," American Economic Review, 2006, 96(4), 1293-1307.

Beaudry, Paul and Frank Portier, "News Driven Business Cycles: Insights and Challenges," Journal of Economic Literature 2014, 52(4), 993-1074.

Beaudry, Paul, and Bernd Lucke. 2010. "Letting Different Views about Business Cycles Compete." NBER Macroeconomics Annual 2009, 24: 413-455. University of Chicago Press. 
Beaudry, Paul, Patrick Fève, and Alain Guay. When is Nonfundamentalness in VARs a Real Problem? An Application to News Shocks. No. W21466. National Bureau of Economic Research, 2015.

Ben Zeev, Nadav and Hashmat Khan, "Investment-Specific News Shocks and U.S. Business Cycles,” Journal of Money, Credit and Banking 47 (October 2015): 1443-1464.

Ben Zeev, Nadav and Evi Pappa, "Chronicle of a War Foretold: The Macroeconomic Effects of Anticipated Defense Spending Shocks,” forthcoming Economic Journal.

Bernanke, Ben S. "Alternative explanations of the money-income correlation" CarnegieRochester Conference Series on Public Policy, Volume 25, Autumn 1986, Pages 49-99.

Bernanke, Ben S. and Alan S. Blinder, "The Federal Funds Rate and the Channels of Monetary Transmission,” The American Economic Review Vol. 82, No. 4 (Sep., 1992), pp. 901921.

Bernanke, Ben S. and Ilian Mihov, "Measuring Monetary Policy," The Quarterly Journal of Economics Vol. 113, No. 3 (Aug., 1998), pp. 869-902.

Bernanke, Ben S., Jean Boivin and Piotr Eliasz, "Measuring the Effects of Monetary Policy: A Factor-Augmented Vector Autoregressive (FAVAR) Approach,” Quarterly Journal of Economics, Volume 120, Issue 1, 2002, Pp. 387-422.

Blanchard, Olivier and Mark W. Watson, “Are All Business Cycles Alike?” in The American Business Cycle: Continuity and Change, ed. Robert J. Gordon, NBER 1986.

Blanchard, Olivier and Danny Quah, "The Dynamic Effects of Aggregate Demand and Supply Disturbances,” American Economic Review, 79 (4): September 1989, 655-673.

Blanchard, Olivier, and Roberto Perotti, "An Empirical Characterization of the Dynamic Effects of Changes in Government Spending and Taxes on Output," Quarterly Journal of Economics, 117 (2002), 1329-1368.

Blanchard, Olivier J., and Daniel Leigh. 2013. "Growth Forecast Errors and Fiscal Multipliers." American Economic Review, 103(3): 117-20.

Blanchard, Olivier J., Jean-Paul L'Huillier, Guido Lorenzoni, 2013. "News, Noise, and Fluctuations: An Empirical Exploration," American Economic Review, vol. 103(7), pages 3045-70, December.

Bloom, Nicholas and Steven Davis, "Measuring Risk and Uncertainty ,” forthcoming Handbook of Macroeconomics, eds. John B. Taylor and Harald Uhlig.

Boivin, Jean. 2006. "Has U.S. Monetary Policy Changed? Evidence from Drifting Coefficients and Real-Time Data.” Journal of Money, Credit, and Banking 38 (5): 1149-73. 
Boivin, Jean, and Marc P. Giannoni. "Has monetary policy become more effective?" The Review of Economics and Statistics 88.3 (2006): 445-462.

Boivin, Jean, Michael T. Kiley, and Frederick S. Mishkin, “How Has the Monetary Transmission Mechanism Evolved Over Time?” Handbook of Monetary Economics. 2010.

Boschen, John F. and Leonard O. Mills (1995). “The Relation between Narrative and Money Market Indicators of Monetary Policy,” Economic Inquiry, Volume 33, Issue 1, pages 24 44.

Brückner, Markus, and Evi Pappa. "Fiscal Expansions, Unemployment, and Labor Force Participation: Theory and Evidence,” International Economic Review 53.4 (2012): 12051228.

Burnside, Craig, Martin Eichenbaum, and Sergio Rebelo. "Capital utilization and returns to scale." In NBER Macroeconomics Annual 1995, Volume 10, pp. 67-124. MIT Press, 1995.

Burnside, Craig, Martin Eichenbaum, and Jonas Fisher, "Fiscal Shocks and their Consequences,” Journal of Economic Theory, 115 (2004), 89-117.

Caldara, Dario and Christophe Kamps, "The Analytics of SVARs: A Unified Framework to Measure Fiscal Multipliers," Finance and Economics Discussion Series Divisions of Research \& Statistics and Monetary Affairs Federal Reserve Board, Washington, D.C., 2012-20.

Campbell, Jeffrey R., Charles L. Evans, Jonas DM Fisher, and Alejandro Justiniano. "Macroeconomic effects of federal reserve forward guidance." Brookings Papers on Economic Activity (2012): 1-80.

Canova, Fabio, and Gianni De Nicolo. "Monetary disturbances matter for business fluctuations in the G-7." Journal of Monetary Economics 49, no. 6 (2002): 1131-1159.

Canova, Fabio, and Joaquim Pires Pina. "What VAR Tell us about DSGE Models?." In New Trends in Macroeconomics, pp. 89-123. Springer Berlin Heidelberg, 2005.

Canova, Fabio and Luca Sala, "Back to Square One: Identification Issues in DSGE Models," Journal of Monetary Economics 56 (May 2009): 431-449.

Chang, Pao Li, and Shinichi Sakata. "Estimation of impulse response functions using long autoregression." The Econometrics Journal 10.2 (2007): 453-469.

Chari, VV, Patrick J. Kehoe, and Ellen R. McGrattan, “Are Structural VARs with Long-Run Restrictions Useful in Developing Business Cycle Theory?” Journal of Monetary Economics, 2008. 
Christiano, Lawrence J., and Martin Eichenbaum. "Liquidity Effects and the Monetary Transmission Mechanism." The American Economic Review 82.2 (1992): 346.

Christiano, Lawrence J, Martin Eichenbaum, Charles L. Evans, "What Have We Learned and To What End?" in Handbook of Macroeconomics, ed. Michael Woodford and John D. Taylor, 1999.

Christiano, Lawrence J, Martin Eichenbaum, Charles L. Evans, "Nominal Rigidities and the Dynamic Effects of a Shock to Monetary Policy,” Journal of Political Economy, Vol. 113, No. 1, February 2005.

Christiano, Lawrence J., Martin Eichenbaum, and Robert Vigfusson. 2003. "What Happens after a Technology Shock?" NBER Working Paper Series 9819. Cambridge, MA: National Bureau of Economic Research.

Christiano, Lawrence J., Martin Eichenbaum, and Robert Vigfusson (2007). "Assessing Structural VARs," in NBER Macroeconomics Annual 2006. Cambridge and London: MIT Press, pp. 1-72.

Cloyne, James, "Discretionary Tax Changes and the Macroeconomy: New Narrative Evidence from the United Kingdom,” The American Economic Review, Volume 103, Number 4, June 2013, pp. 1507-1528(22).

Cochrane, John, "Shocks," Carnegie-Rochester Conference Series on Public Policy, 41 (December 1994): 295-364.

Cochrane, John, "Comments on 'A new measure of monetary shocks: Derivation and implications’ By Christina Romer and David Romer.” July 17 2004, presented at NBER EFG meeting .

http://faculty.chicagobooth.edu/john.cochrane/research/papers/talk_notes_new_measure_2.pdf

Cochrane, John and Monika Piazzesi, 2002. "The Fed and Interest Rates - A High-Frequency Identification." American Economic Review, 92(2): 90-95.

Cogan, John F., Tobias Cwik, John B. Taylor, and Volker Wieland. "New Keynesian versus old Keynesian government spending multipliers." Journal of Economic dynamics and control 34, no. 3 (2010): 281-295.

Coibion, Olivier, and Yuriy Gorodnichenko. 2011. "Monetary Policy, Trend Inflation, and the Great Moderation: An Alternative Interpretation.” American Economic Review 101 (1): $341-70$.

Coibion, Olivier, “Are the Effects of Monetary Policy Shocks Big or Small?” American Economic Journal: Macroeconomics, Volume 4, Number 2, April 2012, pp. 1-32(32). 
Cook, Timothy., (1989). "Deterrminants of the Federal Funds Rate: 1979-1982," Federal Reserve Bank of Richmond Economic Review, 75: 3-19.

Cook, Timothy. and T.Hahn (1989). "The Effect of Changes in the Federal Funds Rate Target on Market Interest Rates in the 1970s, Journal of Monetary Economics, 24: 331-351.

Cover, James Peery, “Asymmetric Effects of Positive and Negative Money-Supply Shocks,” The Quarterly Journal of Economics Vol. 107, No. 4 (Nov., 1992), pp. 1261-1282 .

Crafts, Nicholas and Terence C. Mills. 2012. "Rearmament to the Rescue? New Estimates of the Impact of ‘Keynesian’ Policies in 1930s’ Britain.” October Working Paper.

Crouzet, Nicolas and Oh, Hyunseung, "What Do Inventories tell us about News-Driven Business Cycles?” Columbia University, November 2013.

D’Amico, Stefania and Thomas B. King, “What Does Anticipated Monetary Policy Do?” Federal Reserve Bank of Chicago Working Paper 2015-10, November 2015.

Davis, Steven J., and John Haltiwanger. "Sectoral job creation and destruction responses to oil price changes." Journal of monetary economics 48.3 (2001): 465-512.

Eichenbaum, Martin S. (1992) "Comment on Interpreting the Macroeconomic Time Series Facts: The Effects of Monetary Policy,” European Economic Review 36(5): 1001-1011.

Elliott, Graham. "On the robustness of cointegration methods when regressors almost have unit roots." Econometrica (1998): 149-158.

Erceg, Christopher J., Luca Guerrieri, and Christopher Gust, "Can Long-Run Restrictions Identify Technology Shocks?” Journal of the European Economic Association, Volume 3, Issue 6, pages 1237-1278, December 2005.

Evans, Charles L. "Productivity shocks and real business cycles." Journal of Monetary Economics 29.2 (1992): 191-208.

Evans, Charles L. and David A. Marshall, "Fundamental Economic Shocks and the Macroeconomy," Journal of Money, Credit and Banking, Vol. 41, No. 8 (December 2009).

Farhi,, Emmanuel and Iván Werning, "Fiscal Multipliers: Liquidity Traps and Currency Unions,” NBER Working Paper No. 18381, September 2012.

Faust, Jon and Eric M. Leeper, "When Do Long-Run Identifying Restrictions Give Reliable Results?” Journal of Business \& Economic Statistics Volume 15, Issue 3, 1997 .

Faust, Jon. (1998). "The Robustness of Identified VAR Conclusions about Money. CarnegieRochester Conference Series on Public Policy 49:207-244. 
Faust, Jon, Eric T. Swanson, and Jonathan H. Wright (2004), "Identifying VARS based on high frequency futures data,” Journal of Monetary Economics, Volume 51, Issue 6, September 2004, Pages 1107-113.

Favero, Carlo and Francesco Giavazzi, 2012.”Measuring Tax Multipliers: The Narrative Method in Fiscal VARs,” American Economic Journal: Economic Policy 4(2), 69-94.

Fernald, John G. "Roads to prosperity? Assessing the link between public capital and productivity." American Economic Review (1999): 619-638.

Fernald, John G. "Trend breaks, long-run restrictions, and contractionary technology improvements." Journal of Monetary Economics 54.8 (2007): 2467-2485.

Fernald, John G. “A Quarterly, Utilization-Adjusted Series on Total Factor Productivity,” Federal Reserve Bank of San Francisco Working Paper 2012-19, April 2014.

Fernandez-Villaverde, Jesus, Juan Rubio-Ramirez, Thomas J. Sargent, and Mark W. Watson. "A, B, Cs (and Ds) of Understanding VARs." American Economic Review 97, no. 3 (2007).

Fisher, Jonas DM. "The dynamic effects of neutral and investment specific technology shocks." Journal of political Economy 114.3 (2006): 413-451.

Fisher, Jonas D.M. 2010. “Comment on 'Letting Different Views of the Business Cycle Compete’” NBER Macroeconomics Annual 2009, Vol. 4, 457-474.

Fisher, Jonas D.M., and Ryan Peters, "Using Stock Returns to Identify Government Spending Shocks,” The Economic Journal, 120 (May 2010): 414-436.

Forni, Mario, Luca Gambetti, Luca Sala, "No News in Business Cycles,” The Economic Journal 124 (December 2014): 1168-1191.

Francis, Neville and Valerie A. Ramey, "The Source of Historical Fluctuations: An Analysis using Long-Run Restrictions," with Neville Francis, NBER International Seminar on Macroeconomics 2004, eds. Richard Clarida, Jeffrey Frankel, Francesco Giavazzi, and Kenneth West, pp. 17-49

Francis, Neville, and Valerie A. Ramey. "Is the technology-driven real business cycle hypothesis dead? Shocks and aggregate fluctuations revisited." Journal of Monetary Economics 52.8 (2005): 1379-1399.

Francis, Neville, and Valerie A. Ramey. "Measures of per Capita Hours and Their Implications for the Technology Hours Debate." Journal of Money, credit and Banking 41.6 (2009): 1071-1097. 
Francis, Neville, Michael T. Owyang, Jennifer E. Rousch, and Ricardo DiCecio , “A Flexible Finite-Horizon Alternative to Long-Run Restrictions with an Application to Technology Shocks,” The Review of Economics and Statistics, October 2014, 96(4): 638-647.

Friedman, Milton and Anna Schwartz, A Monetary History of the United States: 1867-1960, National Bureau of Economic Research, 1963.

Friedman, Milton, “The Role of Monetary Policy, ”American Economic Review, 58(1): (March 1968).

Frisch, Ragnar, "Propagation Problems and Impulse Problems in Dynamic Economics," Economic essays in honor of Gustav Cassel (1933), pp. 171-205 (London).

Galí, J., 1999. Technology, employment, and the business cycle: Do technology shocks explain aggregate fluctuations, American Economic Review 89, 249-271.

Galí, Jordi, J. David López Salido, and Javier Vallés. "Understanding the effects of government spending on consumption." Journal of the European Economic Association 5.1 (2007): 227-270.

Gechert, Sebastian, "What Fiscal Policy is Most Effective? A Meta Regression Analysis," forthcoming Oxford Economic Papers.

Gertler, Mark and Peter Karadi, "Monetary Policy Surprises, Credit Costs, and Economic Activity,” American Economic Journal: Macroeconomics, 7(1) (January 2015) 44-76.

Giavazzi, Francesco, and Marco Pagano, 1990, "Can Severe Fiscal Consolidations Be Expansionary? Tales of Two Small European Countries," NBER Macroeconomics Annual, Vol. 5 (Cambridge, Massachusetts: National Bureau of Economic Research).

Giavazzi, Francesco, and Marco Pagano, 1996, "Non-Keynesian Effects of Fiscal Policy Changes: International Evidence and the Swedish Experience,” Swedish Economic Policy Review, Vol. 3, No. 1, pp. 67-103.

Gilchrist, Simon, and Egon Zakrajšek. 2012. "Credit spreads and business cycle fluctuations." American Economic Review 102 (4): 1692-1720.

Gospodinov, Nikolay, Ana María Herrera, and Elena Pesavento. "Unit Roots, Cointegration, and Pretesting in Var Models." VAR Models in Macroeconomics-New Developments and Applications: Essays in Honor of Christopher A. Sims. Emerald Group Publishing Limited, 2013. 81-115.

Gordon, Robert J. and Robert Krenn. 2010. “The End of the Great Depression: VAR Insight on the Roles of Monetary and Fiscal Policy,” NBER Working Paper 16380, September. 
Granger, C.W.J., "Investigating Causal Relations by Econometric Models and Cross-spectral Methods,” Econometrica Vol. 37, No. 3 (Aug., 1969), pp. 424-438 .

Greenwood, Jeremy, Zvi Hercowitz, and Gregory W. Huffman. "Investment, capacity utilization, and the real business cycle." The American Economic Review (1988): 402-417.

Greenwood, Jeremy, Zvi Hercowitz, and Per Krusell. "Long-run implications of investmentspecific technological change." The American Economic Review (1997): 342-362.

Greenwood, Jeremy, Zvi Hercowitz, and Per Krusell. "The role of investment-specific technological change in the business cycle." European Economic Review 44.1 (2000): 91115.

Greenwood, Jeremy, and Boyan Jovanovic. "The Information-Technology Revolution and the Stock Market." American Economic Review (1999): 116-122.

Gürkaynak, Refet S., Brian Sack and Eric Swanson, "The Sensitivity of Long-Term Interest Rates to Economic News: Evidence and Implications for Macroeconomic Models,” American Economic Review, Vol. 95, No. 1 (Mar., 2005), pp. 425-436.

Hall, Robert E. "Labor supply and aggregate fluctuations." Carnegie-Rochester Conference Series on Public Policy. Vol. 12. North-Holland, 1980.

Hall, Robert E. "The role of consumption in economic fluctuations." The American business cycle: Continuity and change. University of Chicago Press, 1986. 237-266.

Hall, Robert E., “The Relation between Price and Marginal Cost in U.S. Industry,” JPE, October 1988, 96(5), 921-947.

Hall, Robert E., “Invariance Properties of Solow’s Productivity Residual,” in Peter Diamond (ed.), Growth/ Productivity/Unemployment: Essays to Celebrate Bob Solow's Birthday, MIT Press, 71-112, 1990.

Hall, Robert E. 2009. “By How Much Does GDP Rise If the Government Buys More Output?” Brookings Papers on Economic Activity, 2 (2009): 183-231.

Hamilton, James D., "Oil and the Macroeconomy Since World War II," Journal of Political Economy, April 1983, pp. 228-248.

Hamilton, James D., "Historical Causes of Postwar Oil Shocks and Recessions," Energy Journal, January 1985, pp. 97-116.

Hamilton, James D. “What Is an Oil Shock?” Journal of Econometrics, April 2003, vol. 113, pp. 363-398. 
Hamilton, James D. "Macroeconomics and ARCH." In Volatility and Time Series Econometrics: Essays in Honor of Robert Engle, edited by Tim Bollerslev, Jeffrey Russell, and Mark Watson, 79-96, Oxford: Oxford University Press.

Hansen, Lars Peter and Thomas J. Sargent, "Two Difficulties in Interpreting Vector Autoregressions," in Rational Expectations Econometrics, ed. Lars Peter Hansen and Thomas J. Sargent. Boulder, CO: Westview Press, 1991, 77-119.

Hanson, Samuel G., and Jeremy C. Stein. "Monetary policy and long-term real rates." Journal of Financial Economics 115.3 (2015): 429-448.

Hausman, Joshua K., "Fiscal Policy and Economic Recovery: The Case of the 1936 Veterans' Bonus" forthcoming American Economic Review.

Hobijn, Bart, and Boyan Jovanovic. "The Information-Technology Revolution and the Stock Market: Evidence." American Economic Review 91.5 (2001): 1203-1220.

Hoover, Kevin D. and Stephen J. Perez, "Post hoc ergo propter once more an evaluation of 'does monetary policy matter?' in the spirit of James Tobin,” Journal of Monetary Economics, Volume 34, Issue 1, August 1994, Pages 47-74.

House, Christopher L., and Matthew D. Shapiro. 2006. "Phased-In Tax Cuts and Economic Activity." American Economic Review, 96(5): 1835-1849.

Ilzetski, Ethan, Enrique G. Mendoza, Carlos A. Végh, "How Big (Small?) are Fiscal Multipliers?" 2013. "How big (small?) are fiscal multipliers?," Journal of Monetary Economics, Elsevier, vol. 60(2), pages 239-254.

Jaimovich, Nir and Sergio Rebelo, "Can News about the Future Drive the Business Cycle?" American Economic Review, 99(4) 2009, 1097-1118.

Jordà, Òscar. 2005. "Estimation and Inference of Impulse Responses by Local Projections.” American Economic Review 95 (1): 161-82.

Justiniano, Alejandro, Giorgio E. Primiceri, and Andrea Tambalotti, "Investment shocks and business cycles,” Journal of Monetary Economics, Volume 57, Issue 2, March 2010, Pages 132-145.

Justiniano, Alejandro, Giorgio E. Primiceri, and Andrea Tambalotti, "Investment shocks and the relative price of investment," Review of Economic Dynamics, Volume 14, Issue 1, January 2011, Pages 102-121.

Keynes, John Maynard. 1936. The General Theory of Employment, Interest and Money. London: Macmillan. 
Khan, Hashmat and John Tsoukalas, 2012, The quantitative importance of news shocks in estimated dsge models, Journal of Money, Credit and Banking 44(8), 1535-1561.

Kilian, Lutz. "Not All Oil Price Shocks Are Alike: Disentangling Demand and Supply Shocks in the Crude Oil Market." The American Economic Review (2009): 1053-1069.

Kilian, Lutz, and Robert J. Vigfusson. "Are the responses of the US economy asymmetric in energy price increases and decreases?." Quantitative Economics 2.3 (2011): 419-453.

King, Robert, Charles Plosser, James Stock and Mark W. Watson (1991), "Stochastic Trends and Economic Fluctuations,” American Economic Review, 81 (4) September 1991, 819-840.

Kliem, Martin, and Alexander Kriwoluzky. "Reconciling narrative monetary policy disturbances with structural VAR model shocks?" Economics Letters 121.2 (2013): 247-251.

Komunjer, Ivana and Serena Ng, “Dynamic Identification of DSGE Models,”Econometrica, Vol. 79, No. 6 (November, 2011), 1995-2032.

Koop, Gary, M. Hashem Pesaran, and Simon M. Potter. "Impulse response analysis in nonlinear multivariate models." Journal of econometrics 74.1 (1996): 119-147.

Krishnamurthy, Arvind and Annette Vissing-Jorgensen, “The Effects of Quantitative Easing on Interest Rates,’Brookings Papers on Economic Activity, Fall 2011.

Kurmann, André and Elmar Mertens, "Stock Prices, News, and Economic Fluctuations: Comment,” American Economic Review " 104.4 (2014): 1439-1445.

Kuttner, Kenneth N., "Monetary policy surprises and interest rates: Evidence from the Fed funds futures market,” Journal of Monetary Economics Volume 47, Issue 3, June 2001, Pages 523-544.

Kydland, Finn E. and Edward C. Prescott, "Time to Build and Aggregate Fluctuations," Econometrica Vol. 50, No. 6 (Nov., 1982), pp. 1345-1370.

Lakdawala, Aeimit, "Changes in Federal Reserve Preferences," Michigan State University working paper, April 2015.

Leduc, Sylvain and Daniel Wilson. "Roads to Prosperity or Bridges to Nowhere? Theory and Evidence on the Impact of Public Infrastructure Investment," (NBER Macroeconomics Annual 27, no. 1 (2012), pp. 89-142..

Leeper, Eric M., "Narrative and VAR Approaches to Monetary Policy: Common Identification Problems,” Journal of Monetary Economics 40 (1997): 641-657.

Leeper, Eric M., Alexander Richter, and Shu-Chun Susan Yang, "Quantitative Effects of Fiscal Foresight,” American Economic Journal: Economic Policy 4 (2): 1-27. 
Leeper, Eric M., Todd B. Walker, Shu-Chun Susan Yang, "Fiscal Foresight and Information Flows,” Econometrica 81 (3) May 2013: 1115-1145. (Also, unpublished supplement at: https://www.econometricsociety.org/sites/default/files/8337_extensions_0.pdf .

Leigh, Daniel, P.Devries, C.Freedman, Jaime.Guajardo, D.Laxton, Andrea.Pescatori "Will It Hurt? Macroeconomic Effects of Fiscal Consolidation" Chapter 3, World Economic Outlook, IMF, October 2010.

Litterman, Robert B. and Laurence Weiss, “Money, Real Interest Rates, and Output: A Reinterpretation of Post-War Data,” Econometrica, Vol. 53, No. 1 (Jan., 1985), pp. 129156.

Lundsford, Kurt G., "Identifying Structural VARs with a Proxy Variable and a Test for a Weak Proxy,” Federal Reserve Bank of Cleveland Working Paper, 15-28, December 2015.

Marcellino, Massimo, James H. Stock, and Mark W. Watson, “A comparison of direct and iterated multistep AR methods for forecasting macroeconomic time series,” Journal of Econometrics, 2006.

McCallum, Bennett T., "A Reconsideration of Sims' Evidence Concerning Monetarism," Economics Letters, 1983, 13 (2-3), 167-71.

McGrattan, Ellen R. "The macroeconomic effects of distortionary taxation." Journal of Monetary Economics 33.3 (1994): 573-601.

Mertens, Karel, and Morten O. Ravn, 2011a "Technology-Hours Redux: Tax Changes and the Measurement of Technology Shocks,” NBER International Seminar on Macroeconomics 2010.

Mertens, Karel, and Morten O. Ravn, 2011b, "Understanding the Aggregate Effects of Anticipated and Unanticipated Tax Policy Shocks," Review of Economic Dynamics, Volume 14:1, January 2011.

Mertens, Karel, and Morten O. Ravn. 2012. "Empirical Evidence on the Aggregate Effects of Anticipated and Unanticipated US Tax Policy Shocks." American Economic Journal: Economic Policy, 4(2): 145-81.

Mertens, Karel, and Morten O. Ravn. 2013. "The Dynamic Effects of Personal and Corporate Income Tax Changes in the United States." American Economic Review, 103(4): 1212-47.

Mertens, Karel, and Morten O. Ravn., “A Reconciliation of SVAR and Narrative Estimates of Tax Multipliers,” Journal of Monetary Economics 68 (2014): S1-S19.

Miyamoto, Wataru and Nguyen, Thuy Lan, "News Shocks and Business Cycles: Evidence from Forecast Data,” Columbia University, Nov. 2013. 
Montiel Olea, Jose Luis and Carolin Pflueger, 2013. "A Robust Test for Weak Instruments.” Journal of Business \& Economic Statistics 31(3): 358-369.

Montiel Olea, Jose Luis, James H. Stock, and Mark W. Watson, “Uniform Inference in SVARs with External Instruments,” December 2015 manuscript.

Mountford, Andrew and Harald Uhlig, "What are the Effects of Fiscal Policy Shocks? Journal of Applied Econometrics 24 (September/October 2009): 960-992.

Nakamura, Emi, and Steinsson, Jón. (2014). Fiscal Stimulus in a Monetary Union: Evidence from US Regions. The American Economic Review, 104(3), 753-792.

Nakamura, Emi, and Steinsson, Jón, "High Frequency Identification of Monetary NonNeutrality,” October 2015 working paper.

Newey, Whitney K. and Kenneth D. West, “A simple, positive semi-definite, heteroskedasticity and autocorrelation consistent covariance matrix,” Econometrica, 1987, vol. 55, 3, pp. 703-708.

Oh, Hyunseung, and Ricardo Reis. "Targeted transfers and the fiscal response to the great recession." Journal of Monetary Economics 59 (2012): S50-S64.

Olivei, Giovanni, and Silvana Tenreyro. "The timing of monetary policy shocks." The American Economic Review (2007): 636-663.

Owyang, Michael and Garey Ramey, "Regime switching and monetary policy measurement," Journal of Monetary Economics, Volume 51, Issue 8, November 2004, Pages 1577-1597.

Owyang, Michael T., Valerie A. Ramey, and Sarah Zubairy. "Are Government Spending Multipliers Greater during Periods of Slack? Evidence from Twentieth-Century Historical Data." The American Economic Review 103.3 (2013): 129-134.

Pappa, Evi. "The Effects of Fiscal Shocks on Employment and the Real Wage," International Economic Review 50.1 (2009): 217-244.

Perotti, Roberto, “Expectations and Fiscal Policy: An Empirical Investigation,” 2011 Bocconi working paper.

Perron, Pierre. "The great crash, the oil price shock, and the unit root hypothesis." Econometrica: Journal of the Econometric Society (1989): 1361-1401.

Pflueger, Carolin E., and Su Wang. "A robust test for weak instruments in Stata." Stata Journal 15, no. 1 (2015): 216-225. 
Piazzesi, Monika and Eric T. Swanson (2008), "Futures prices as risk-adjusted forecasts of monetary policy,” Journal of Monetary Economics, Volume 55, Issue 4, May 2008, Pages 677-691.

Pigou, Arthur C. 1927. Industrial fluctuations. London: Macmillan.

Poterba, James M. "Explaining the yield spread between taxable and tax-exempt bonds: The role of expected tax policy." Studies in state and local public finance. University of Chicago Press, 1986. 5-52.

Prescott, Edward C., "Theory Ahead of Business-Cycle Measurement," Carnegie-Rochester Conference Series on Public Policy, Volume 25, Autumn 1986, Pages 11-44.

Primiceri, Giorgio, “Time Varying Structural Vector Autoregressions and Monetary Policy," Review of Economic Studies (2005) 72 (3): 821-852.

Ramey, Valerie A. and Matthew Shapiro, "Costly Capital Reallocation and the Effects of Government Spending,” Carnegie Rochester Conference on Public Policy (1998).

Ramey, Valerie A., “Defense News Shocks, 1939-2008: An Analysis Based on News Sources,” UCSD manuscript, 2009a. http://econ.ucsd.edu/ vramey/research/Defense_News_Narrative.pdf .

Ramey, Valerie A., “Identifying Government Spending Shocks: It’s All in the Timing,” NBER Working Paper No. 15464, October 2009. 2009b.

Ramey, Valerie A., “Identifying Government Spending Shocks: It's All in the Timing,” Quarterly Journal of Economics, 126 (February 2011a): 1-50.

Ramey, Valerie A. "Can government purchases stimulate the economy?." Journal of Economic Literature 49, no. 3 (2011b): 673-685.

Ramey, Valerie A. "Government Spending and Private Activity," Fiscal Policy After the Financial Crisis eds. Alberto Alesina and Francesco Giavazzi, University of Chicago Press. 2013a.

Ramey, Valerie A., "Discussion of 'Roads to Prosperity or Bridges to Nowhere? Theory and Evidence on the Impact of Public Infrastructure Investment'” by Sylvain Leduc and Daniel Wilson 2012 NBER Macroeconomics Annual Conference, 2013b.

Ramey, Valerie A., and Daniel J. Vine. "Oil, Automobiles, and the US Economy: How Much Have Things Really Changed?." NBER Macroeconomics Annual 2010, Volume 25. University of Chicago Press, 2011. 333-367.

Ramey, Valerie A. and Sarah Zubairy, "Government Spending Multipliers in Good Times and in Bad: Evidence from $20^{\text {th }}$ Century Historical Data,” November 2014 working paper. 
Romer, Christina D. and David H. Romer, "Does Monetary Policy Matter? A New Test in the Spirit of Friedman and Schwartz,” NBER Macroeconomic Annual 1989.

Romer, Christina D. and David H. Romer, “Identification and the Narrative Approach: A Reply to Leeper,” Journal of Monetary Economics 40 (1997): 659-665.

Romer, Christina D., and David H. Romer, "Federal Reserve Information and the Behavior of Interest Rates.” American Economic Review, June 2000, 90(3), pp. 429-57.

Romer, Christina D., and David H. Romer, "A New Measure of Monetary Policy Shocks: Derivation and Implications,” American Economic Review, 94(4) (September 2004): 1055-84.

Romer, Christina D., and David H. Romer, "The Macroeconomic Effects of Tax Changes: Estimates Based on a New Measure of Fiscal Shocks,” American Economic Review, 100 (June 2010): 763-801 .

Rotemberg, Julio, and Woodford, Michael, "Oligopolistic Pricing and the Effects of Aggregate Demand on Economic Activity,” Journal of Political Economy, 100 (1992), 1153-1297.

Rudebusch, Glenn, “Do Measures of Monetary Policy in a VAR Make Sense?” International Economic Review, Vol. 39, No. 4, Symposium on Forecasting and Empirical Methods in Macroeconomics and Finance (Nov., 1998), pp. 907-931.

Schmitt-Grohe, Stephanie and Martin Uribe (2012), "What's News in Business Cycles?" Econometrica, Volume 80, Issue 6, pages 2733-2764, November 2012.

Shapiro, Matthew D. and Mark W. Watson (1988), "The Sources of Business Cycle Fluctuations,” NBER Macroeconomics Annual 1988.

Shapiro, Matthew D. "Cyclical productivity and the workweek of capital." The American Economic Review (1993): 229-233.

Shapiro, Matthew D., "Federal Reserve Policy: Cause and Effect," in Monetary Policy ed. N. Gregory Mankiw, National Bureau of Economic Research, 1994.

Sims, Christopher A. “Money, Income, and Causality,” American Economic Review, Vol. 62, No. 4 (Sep., 1972), pp. 540-552.

Sims, Christopher A. 1980a. “Macroeconomics and Reality,” Econometrica. 48, pp. 1-48.

Sims, Christopher A. 1980b. "Comparison of Interwar and Postwar Business Cycles: Monetarism Reconsidered,” The American Economic Review Vol. 70, No. 2, (May, 1980), pp. 250257. 
Sims, Christopher A. "Interpreting the macroeconomic time series facts: The effects of monetary policy." European Economic Review 36.5 (1992): 975-1000.

Sims, Christopher A., James H. Stock, and Mark W. Watson. "Inference in linear time series models with some unit roots." Econometrica: Journal of the Econometric Society (1990): 113-144.

Sims, Christopher A., "Discussion of Glenn Rudebusch, 'Do Measures of Monetary Policy in a VAR Make Sense?”’ International Economic Review , Vol. 39, No. 4, Symposium on Forecasting and Empirical Methods in Macroeconomics and Finance (Nov., 1998), pp. 907-931

Sims, Christopher A. and Tao Zha, (2006a) "Were there Regime Switches in U.S. Monetary Policy?” American Economic Review, Vol. 96, No. 1 (Mar., 2006), pp. 54-81.

Sims, Christopher A. and Tao Zha, (2006b), "Does Monetary Policy Generate Recessions?" Macroeconomic Dynamics, 10 (2) April 2006: 231-272.

Slutzky, Eugen, "The Summation of Random Causes as the Source of Cyclic Processes," Econometrica, Vol. 5, No. (2) (April 1937), pp. 105-146.

Smets, Frank and Raf Wouters, “An Estimated Dynamic Stochastic General Equilibrium Model of the Euro Area," Journal of the European Economics Association, Volume 1, Issue 5, pages 1123-1175, September 2003.

Smets, Frank and Raf Wouters, "Shocks and Frictions in U.S. Business Cycles: A Bayesian DSGE Approach,” American Economic Review, 97(3) June 2007: 586-606.

Solow, Robert M., "Technical Change and the Aggregate Production Function," The Review of Economics and Statistics Vol. 39, No. 3 (Aug., 1957), pp. 312-320.

Stock, James H. and Mark W. Watson, "Forecasting Using Principal Components From a Large Number of Predictors," Journal of the American Statistical Association Volume 97, Issue 460, 2002.

Stock, James H. and Mark W. Watson, NBER Summer Institute Minicourse 2008: What's New in Econometrics-Time Series, Lecture 7: Structural VARs,” Cambridge, Mass.: National Institute for Economic Research. www.nber.org/minicourse_2008.html.

Stock, James H. and Mark W. Watson, "Disentangling the Channels of the 2007-09 Recession,” Brookings Papers on Economic Activity, Spring 2012.

Stock, James H. and Mark W. Watson, "Factor Models and Structural Vector Autoregressions in Macroeconomics," forthcoming Handbook of Macroeconomics, eds. John B. Taylor and Harald Uhlig. 
Stock, James H., Jonathan H. Wright, and Motohiro Yogo. 2002. "A survey of weak instruments and weak identification in generalized method of moments." Journal of Business \& Economic Statistics 20 (4): 518-29.

Stock, James H., and Motohiro Yogo. "Testing for weak instruments in linear IV regression." Identification and inference for econometric models: Essays in honor of Thomas Rothenberg (2005).

Strongin, Steven, "The identification of monetary policy disturbances explaining the liquidity puzzle,” Journal of Monetary Economics, Volume 35, Issue 3, June 1995, Pages 463497.

Tenreyro, Silvana and Gregory Thwaites, Gregory (2013) "Pushing on a string: US monetary policy is less powerful in recessions,” CEP Discussion Papers, CEPDP1218. Centre for Economic Performance, London School of Economics and Political Science, London, UK.

Thoma, Mark A., "Subsample instability and asymmetries in money-income causality," Journal of Econometrics, Volume 64, Issues 1-2, September-October 1994, Pages 279-306.

Uhlig, Harald. 1997. "What are the effects of monetary policy on output? Results from an agnostic identification procedure." Tillburg University Manuscript.

Uhlig, H., 2003. What drives GNP? Unpublished manuscript, Euro Area Business Cycle Network.

Uhlig, Harald. "Do technology shocks lead to a fall in total hours worked?." Journal of the European Economic Association (2004): 361-371.

Uhlig, Harald. "What are the effects of monetary policy on output? Results from an agnostic identification procedure." Journal of Monetary Economics 52.2 (2005): 381-419.

Uhlig, Harald. "Some fiscal calculus." The American Economic Review (2010): 30-34.

Uhlig, Harald, “Economics and Reality,” Journal of Macroeconomics 34 (March 2012): 29-41.

Velde, François R. "Chronicle of a Deflation Unforetold." Journal of Political Economy 117.4 (2009): 591-634.

Weise, Charles L., "The Asymmetric Effects of Monetary Policy: A Nonlinear Vector Autoregression Approach,” Journal of Money, Credit and Banking, Vol. 31, No. 1 (Feb., 1999), pp. 85-108.

Wieland, Johannes and Mu-Jeung Yang, "Financial Dampening," September 2015 working paper. 
Wu, Jing Cynthia and Fan Dora Xia, "Measuring the Macroeconomic Impact of Monetary Policy at the Zero Lower Bound,” forthcoming Journal of Money, Credit, and Banking.

Yang, Shu-Chun Susan. "Quantifying tax effects under policy foresight." Journal of Monetary Economics 52.8 (2005): 1557-1568. 
Table 3.1. Summary of Monetary Policy Shock Effects on Output and Prices

\begin{tabular}{|c|c|c|c|c|}
\hline Paper & Method, sample & $\begin{array}{l}\text { Trough effect of } \\
100 \text { basis point } \\
\text { funds peak }\end{array}$ & $\begin{array}{l}\text { \% of output } \\
\text { explained by } \\
\text { shock }\end{array}$ & Price Puzzle? \\
\hline $\begin{array}{l}\text { Christiano, } \\
\text { Eichenbaum, } \\
\text { Evans (1999) - } \\
\text { FFR identification } \\
\end{array}$ & $\begin{array}{l}\text { SVAR, 1965q3 - } \\
1995 q 3\end{array}$ & $-0.7 \%$ at 8 quarters. & $4.4 \%$ at 2 years & $\begin{array}{l}\text { Yes, but very } \\
\text { small }\end{array}$ \\
\hline $\begin{array}{l}\text { Faust, Swanson, } \\
\text { Wright (2004) }\end{array}$ & $\begin{array}{l}\text { HFI, 1991m2 - } \\
\text { 2001m7 }\end{array}$ & $-0.6 \%$ at 10 months & & \\
\hline $\begin{array}{l}\text { Romer and } \\
\text { Romer (2004) }\end{array}$ & $\begin{array}{l}\text { Narrative/Greenbook } \\
\text { 1970m1 - 1996m12 }\end{array}$ & $-4.3 \%$ at 24 months & Major part & $\begin{array}{l}\text { No, but prices } \\
\text { don't change for } \\
22 \text { months }\end{array}$ \\
\hline Uhlig (2005) & $\begin{array}{l}\text { Sign restrictions, } \\
1965 \mathrm{~m} 1-1996 \mathrm{~m} 12\end{array}$ & $\begin{array}{l}\text { Positive, but not } \\
\text { statistically different } \\
\text { from } 0\end{array}$ & $\begin{array}{l}5-10 \% \text { at all } \\
\text { horizons. }\end{array}$ & $\begin{array}{l}\text { No (by } \\
\text { construction) }\end{array}$ \\
\hline $\begin{array}{l}\text { Bernanke, Boivin, } \\
\text { and Eliasz (2005) }\end{array}$ & $\begin{array}{l}\text { FAVAR, 1959m1 - } \\
\text { 2001m7 }\end{array}$ & $-0.6 \%$ at 18 months & $5 \%$ at 5 years & Yes \\
\hline $\begin{array}{l}\text { Smets-Wouters } \\
\text { (2007) }\end{array}$ & $\begin{array}{l}\text { Estimated DSGE } \\
\text { model } \\
\text { 1966Q1 - 2004Q4 }\end{array}$ & $\begin{array}{l}-1.8 \text { at } 4 \text { quarter } \\
\text { trough }\end{array}$ & $\begin{array}{l}10 \% \text { at } 1 \text { year } \\
\text { (trough) }\end{array}$ & No \\
\hline $\begin{array}{l}\text { Boivin, Kiley, } \\
\text { Mishkin (2010) }\end{array}$ & $\begin{array}{l}\text { FAVAR, 1962m1- } \\
\text { 79m9, 1984m1- } \\
\text { 2008m12 }\end{array}$ & $\begin{array}{l}-1.6 \% \text { at } 8 \text { months in } \\
\text { early period, } \\
-0.7 \% \text { at } 24 \text { months } \\
\text { in later period }\end{array}$ & & $\begin{array}{l}\text { Only in the early } \\
\text { period. }\end{array}$ \\
\hline Coibion (2012) & $\begin{array}{l}\text { "Robust” Romer- } \\
\text { Romer methods, } \\
\text { 1970m1 - 1996m12 }\end{array}$ & $-2 \%$ at 18 months & "Medium" part & Yes, sometimes \\
\hline $\begin{array}{l}\text { Barakchian- } \\
\text { Crowe (2013) }\end{array}$ & $\begin{array}{l}\text { HFI, Romer hybrid } \\
\text { VAR, 1988m12- } \\
\text { 2008m6 }\end{array}$ & $-5 \%$ at 23 months & $50 \%$ at 3 years & Yes \\
\hline $\begin{array}{l}\text { Gertler-Karadi } \\
\text { (2015) }\end{array}$ & $\begin{array}{l}\text { HFI-Proxy SVAR, } \\
\text { 1979m7 - 2012m6 } \\
\text { (1991m1-2012m6 } \\
\text { for instruments) }\end{array}$ & $-2.2 \%$ at 18 months & ? & No \\
\hline $\begin{array}{l}\text { Amir-Uhlig } \\
\text { (2015) }\end{array}$ & $\begin{array}{l}\text { Bayesian FAVAR } \\
\text { with sign } \\
\text { restrictions, 1960m2- } \\
\text { 2010m6 }\end{array}$ & $-1.3 \%$ at 9 months & $7 \%$ at 24 months & $\begin{array}{l}\text { No (by } \\
\text { construction) }\end{array}$ \\
\hline
\end{tabular}


Table 3.2. Effects of Monetary Policy Shocks on Industrial Production: My Estimates

\begin{tabular}{|l|l|l|}
\hline Method \& sample & $\begin{array}{l}\text { Trough effect of } \mathbf{1 0 0} \\
\text { basis point funds peak } \\
\mathbf{( \% )}\end{array}$ & $\begin{array}{l}\text { Forecast Error Variance } \\
\text { Decompositions } \\
\text { (percentages) 24 months }\end{array}$ \\
\hline & & \\
\hline CEE: $1965 \mathrm{~m} 1-1996 \mathrm{~m} 6$ & -0.48 & 6.6 \\
\hline CEE: $1959 \mathrm{~m} 1-2007 \mathrm{~m} 12$ & -0.20 & 0.5 \\
\hline R\&R VAR: $1969 \mathrm{~m} 3-1996 \mathrm{~m} 12$ & -1.38 & 8.8 \\
\hline R\&R VAR: $1969 \mathrm{~m} 3-2007 \mathrm{~m} 12$ & -0.83 & 2.7 \\
\hline R\&R, Jordà method: $1969 \mathrm{~m} 3-1996 \mathrm{~m} 12$ & -0.83 & \\
\hline $\begin{array}{l}\text { R\&R, Jordà method, no recursiveness } \\
\text { assumption: } 1969 m 3-1996 \mathrm{~m} 12\end{array}$ & -0.90 & \\
\hline Gertler-Karadi, proxy SVAR: $1990 \mathrm{~m} 1-2012 \mathrm{~m} 6$ & -2.2 & \\
\hline Gertler_Karadi Jordà method: $1990 \mathrm{~m} 1-2012 \mathrm{~m} 6$ & -1, but then rises to +4 & \\
\hline
\end{tabular}

Notes: See text for the description of the CEE (Christiano, Eichenbaum, and Evans (1999)), R\&R (Romer and Romer (2004)) VARs, and Gertler-Karadi proxy SVARs. 
Table 4.1. Summary of Government Spending Multiplier Estimates for the Aggregate U.S.

\begin{tabular}{|c|c|c|c|}
\hline Study & Sample & Identification & $\begin{array}{l}\text { Implied spending } \\
\text { multiplier }\end{array}$ \\
\hline $\begin{array}{l}\text { Barro (1981), Hall (1986), } \\
\text { Hall (2009), Barro-Redlick } \\
\text { (2011) }\end{array}$ & $\begin{array}{l}\text { Annual } \\
\text { historical } \\
\text { samples. }\end{array}$ & $\begin{array}{l}\text { Use military spending as } \\
\text { instrument for government } \\
\text { spending. }\end{array}$ & $0.6-1$ \\
\hline $\begin{array}{l}\text { Rotemberg-Woodford } \\
\text { (1992) }\end{array}$ & $\begin{array}{l}\text { Quarterly, } 1947 \\
\text { - } 1989\end{array}$ & $\begin{array}{l}\text { Residuals from regression of } \\
\text { military spending on own lags } \\
\text { and lags of military } \\
\text { employment }\end{array}$ & 1.25 \\
\hline $\begin{array}{l}\text { Ramey-Shapiro (1998), } \\
\text { Edelberg, Eichenbaum, } \\
\text { and Fisher (1999), } \\
\text { Eichenbaum-Fisher (2005), } \\
\text { Cavallo (2005) }\end{array}$ & $\begin{array}{l}\text { Quarterly, } 1947 \\
\text { - late 1990s or } \\
\text { 2000s }\end{array}$ & $\begin{array}{l}\text { Ramey-Shapiro dates, which } \\
\text { are based on narrative } \\
\text { evidence of anticipated } \\
\text { military buildups }\end{array}$ & $\begin{array}{l}0.6-1.2 \text {, depending } \\
\text { on sample \& } \\
\text { whether calculated } \\
\text { as cumulative or } \\
\text { peak. }\end{array}$ \\
\hline Blanchard-Perotti (2002) & $\begin{array}{l}\text { Quarterly, } 1960 \\
\text { - } 1997\end{array}$ & $\begin{array}{l}\text { SVARS, Choleski } \\
\text { decomposition with G ordered } \\
\text { first }\end{array}$ & $\begin{array}{l}0.9 \text { to } 1.29 \text {, } \\
\text { calculated as peak } \\
\text { multipliers. }\end{array}$ \\
\hline Mountford-Uhlig (2009) & $\begin{array}{l}\text { Quarterly, } 1955 \\
\text { - } 2000\end{array}$ & Sign restrictions on an SVAR & $\begin{array}{l}0.65 \text { for a deficit- } \\
\text { financed increase in } \\
\text { spending. }\end{array}$ \\
\hline Romer-Bernstein (2009) & Quarterly & $\begin{array}{l}\text { Average multipliers from } \\
\text { FRB/US model and a private } \\
\text { forecasting firm model }\end{array}$ & $\begin{array}{l}\text { Rising to } 1.57 \text { by the } \\
8^{\text {th }} \text { quarter }\end{array}$ \\
\hline $\begin{array}{l}\text { Cogan, Cwik, Taylor, } \\
\text { Wieland (2010) }\end{array}$ & $\begin{array}{l}\text { Quarterly, } 1966 \\
-2004\end{array}$ & $\begin{array}{l}\text { Estimated Smets-Wouters } \\
\text { Model }\end{array}$ & 0.64 at peak \\
\hline Ramey (2011) & $\begin{array}{l}\text { Quarterly, } 1939 \\
\text { - } 2008 \text { and } \\
\text { subsamples }\end{array}$ & $\begin{array}{l}\text { VAR using shocks to the } \\
\text { expected present discounted } \\
\text { value of government spending } \\
\text { caused by military events, } \\
\text { based on narrative evidence }\end{array}$ & $\begin{array}{l}0.6 \text { to } 1.2 \text {, depending } \\
\text { on sample. }\end{array}$ \\
\hline Fisher-Peters (2010) & $\begin{array}{l}\text { Quarterly, } 1960 \\
-2007\end{array}$ & $\begin{array}{l}\text { VAR using shocks to the } \\
\text { excess stock returns of military } \\
\text { contractors }\end{array}$ & $\begin{array}{l}1.5 \text { based on } \\
\text { cumulative effects. }\end{array}$ \\
\hline $\begin{array}{l}\text { Auerbach-Gorodnichenko } \\
\text { (2011) }\end{array}$ & $\begin{array}{l}\text { Quarterly, } 1947 \\
\text { - } 2008\end{array}$ & $\begin{array}{l}\text { SVAR that controls for } \\
\text { professional forecasts, Ramey } \\
\text { news. } \\
\text { Key innovation is regime } \\
\text { switching model }\end{array}$ & $\begin{array}{l}\text { Expansion: }-0.3 \text { to } \\
0.8 \\
\text { Recession: } 1 \text { to } 3.6 \\
\text { (uses a variety of } \\
\text { ways to calculate } \\
\text { multipliers) }\end{array}$ \\
\hline $\begin{array}{l}\text { Ben Zeev and Pappa } \\
\text { (forthcoming }\end{array}$ & $\begin{array}{l}\text { Quarterly, 1947- } \\
2007\end{array}$ & $\begin{array}{l}\text { Shock that (i) is orthogonal to } \\
\text { current defense spending; and } \\
\text { (ii) best explains future } \\
\text { movements in defense } \\
\text { spending over a horizon of } \\
\text { five years. }\end{array}$ & $\begin{array}{l}2.1 \text { based on integral } \\
\text { multiplier at } 6 \\
\text { quarters. }\end{array}$ \\
\hline
\end{tabular}


Table 4.2. Multiplier Estimates (HAC standard errors in parenthesis)

\begin{tabular}{|l|l|l|l|}
\hline Horizon (in quarters) & Blanchard-Perotti & Ramey news & Ben Zeev-Pappa news \\
\hline 0 & $0.65(0.24)$ & $-7.53(7.26)$ & $-7.37(5.85)$ \\
\hline 4 & $0.37(0.23)$ & $1.37(0.33)$ & $2.91(1.13)$ \\
\hline 8 & $0.39(0.32)$ & $0.80(0.25)$ & $1.41(0.61)$ \\
\hline 12 & $0.39(0.44)$ & $0.77(0.27)$ & $1.24(0.71)$ \\
\hline 16 & $0.40(0.58)$ & $0.60(0.36)$ & $1.10(1.01)$ \\
\hline 20 & $0.44(0.63)$ & $0.69(0.48)$ & $1.17(1.46)$ \\
\hline
\end{tabular}

Notes: Multipliers estimated using equation (4.2). All regressions also include two lags of the shock (to mop up any serial correlation), real GDP (divided by potential GDP), real government purchases (divided by potential GDP), the tax rate, and a quadratic trend.

Table 4.3. Shock Contribution to the Forecast Error Variance of Government Spending and Output

\begin{tabular}{|c|c|c|c|c|c|c|}
\hline \multirow[b]{2}{*}{$\begin{array}{l}\text { Horizon } \\
\text { (in quarters) }\end{array}$} & \multicolumn{2}{|c|}{ Blanchard-Perotti } & \multicolumn{2}{|l|}{ Ramey news } & \multicolumn{2}{|c|}{ Ben Zeev-Pappa news } \\
\hline & $\begin{array}{l}\text { Government } \\
\text { Spending }\end{array}$ & Output & $\begin{array}{l}\text { Government } \\
\text { Spending }\end{array}$ & Output & $\begin{array}{l}\text { Government } \\
\text { Spending }\end{array}$ & Output \\
\hline 0 & 100.0 & 5.5 & 1.0 & 2.2 & 1.4 & 5.6 \\
\hline 4 & 96.2 & 3.3 & 31.8 & 2.6 & 14.0 & 10.1 \\
\hline 8 & 90.5 & 2.9 & 50.2 & 2.9 & 27.0 & 12.6 \\
\hline 12 & 86.5 & 2.5 & 50.5 & 2.5 & 29.8 & 12.1 \\
\hline 16 & 83.1 & 2.4 & 46.7 & 2.4 & 29.4 & 11.8 \\
\hline 20 & 80.2 & 2.3 & 43.0 & 2.2 & 28.7 & 11.7 \\
\hline
\end{tabular}

Notes: Based on standard VAR with the shock, log output, log government spending, log taxes, and a quadratic trend. The shock is ordered first and 4 lags of the variables are included. 
Table 4.4. Summary of Some Tax Multiplier Estimates for the Aggregate U.S.

\begin{tabular}{|c|c|c|c|}
\hline Study & Main sample & Identification & Implied tax multiplier \\
\hline Evans (1969) & $\begin{array}{l}\text { Quarterly, 1966- } \\
1974\end{array}$ & $\begin{array}{l}\text { Based on estimates of } \\
\text { equations of Wharton, Klein- } \\
\text { Goldberger, and Brookings } \\
\text { models }\end{array}$ & $\begin{array}{l}-0.5 \text { to }-1.7 \text {, depending } \\
\text { on horizon, type of tax, } \\
\text { and model }\end{array}$ \\
\hline $\begin{array}{l}\text { Blanchard-Perotti } \\
\text { (2002) }\end{array}$ & $\begin{array}{l}\text { Quarterly, } 1960 \text { - } \\
1997\end{array}$ & $\begin{array}{l}\text { Assumed output elasticities in } \\
\text { an SVAR. “Taxes” are actually } \\
\text { taxes less transfers. }\end{array}$ & $\begin{array}{l}-0.78 \text { to }-1.33 \text { (peak to } \\
\text { impact) }\end{array}$ \\
\hline $\begin{array}{l}\text { Mountford-Uhlig } \\
(2009)\end{array}$ & $\begin{array}{l}\text { Quarterly, } 1955 \text { - } \\
2000\end{array}$ & $\begin{array}{l}\text { Sign restrictions on a VAR. } \\
\text { Use same variables as BP. }\end{array}$ & $\begin{array}{l}-5 \text { for a tax increase that } \\
\text { reduces the deficit. }\end{array}$ \\
\hline Romer-Romer (2010) & $\begin{array}{l}\text { Quarterly, } 1947 \text { - } \\
2007\end{array}$ & $\begin{array}{l}\text { Legislated tax changes driven } \\
\text { by an inherited government } \\
\text { budget deficit or to promote } \\
\text { future growth, based on } \\
\text { narrative evidence. }\end{array}$ & $\begin{array}{l}\text {-3, based on peak effect. } \\
\text { Romer-Romer (2009) } \\
\text { show that these tax } \\
\text { shocks do not raise } \\
\text { government spending } \\
\text { significantly, so these are } \\
\text { close to pure tax shocks. }\end{array}$ \\
\hline Barro-Redlick (2011) & $\begin{array}{l}\text { Annual, } 1917 \text { - } \\
2006 \text { and } \\
\text { subsamples }\end{array}$ & $\begin{array}{l}\text { Average marginal income tax } \\
\text { rate }\end{array}$ & -1.1 \\
\hline $\begin{array}{l}\text { Favero-Giavazzi } \\
\text { (2011) }\end{array}$ & $\begin{array}{l}\text { Quarterly, 1950- } \\
2006\end{array}$ & $\begin{array}{l}\text { Romer-Romer shocks } \\
\text { embedded in an SVAR }\end{array}$ & -0.5 \\
\hline $\begin{array}{l}\text { Caldara and Kamps } \\
\text { (2012) }\end{array}$ & $\begin{array}{l}\text { Quarterly, 1947- } \\
2006\end{array}$ & $\begin{array}{l}\text { SVAR using outside } \\
\text { elasticities }\end{array}$ & -0.65 (peak to impact) \\
\hline Mertens-Ravn (2014) & $\begin{array}{l}\text { Quarterly, } 1950 \text { - } \\
2006\end{array}$ & $\begin{array}{l}\text { Proxy SVAR using Romer- } \\
\text { Romer unanticipated shocks }\end{array}$ & -3 at 6 quarters \\
\hline
\end{tabular}

Table 4.5. Tax Shock Contribution to the Forecast Error Variance of Output

\begin{tabular}{|l|l|l|}
\hline Horizon (in quarters) & Romer-Romer unanticipated & $\begin{array}{l}\text { Leeper, Richter, Walker (2012) } \\
\text { anticipated tax series }\end{array}$ \\
\hline 0 & 1.6 & 0.4 \\
\hline 4 & 0.4 & 5.7 \\
\hline 8 & 0.5 & 4.8 \\
\hline 12 & 1.1 & 4.4 \\
\hline 16 & 1.8 & 4.3 \\
\hline 20 & 2.1 & 4.3 \\
\hline
\end{tabular}

Notes: Based on standard VAR with the shock, log output, log government spending, log taxes, and a quadratic trend. The shock is ordered first and 4 lags of the variables are included. 
Table 5.1. Estimated Importance of Technology Shocks in SVAR Models

\begin{tabular}{|c|c|c|c|c|}
\hline Study & Method & Type & News? & $\begin{array}{l}\text { \% of output } \\
\text { explained }\end{array}$ \\
\hline $\begin{array}{l}\text { Galí (1999), Francis- } \\
\text { Ramey (2005) }\end{array}$ & $\begin{array}{l}\text { Long-run restrictions, hours in first } \\
\text { differences }\end{array}$ & TFP & No & Very little \\
\hline $\begin{array}{l}\text { Christiano, } \\
\text { Eichenbaum, Vigfusson } \\
\text { (2004) }\end{array}$ & $\begin{array}{l}\text { Long-run restrictions, hours in } \\
\text { levels }\end{array}$ & TFP & No & $\begin{array}{l}31-45 \% \text { for horizons } \\
\text { up to } 20 \text { quarters }\end{array}$ \\
\hline $\begin{array}{l}\text { Christiano, } \\
\text { Eichenbaum, Vigfusson } \\
\text { (2004) }\end{array}$ & $\begin{array}{l}\text { Long-run restrictions, hours in first } \\
\text { differences }\end{array}$ & TFP & No & $\begin{array}{l}1-17 \% \text { for horizons } \\
\text { up to } 20 \text { quarters }\end{array}$ \\
\hline $\begin{array}{l}\text { Basu, Fernald, Kimball } \\
\text { (2006) }\end{array}$ & Utilization and effort adjusted TFP & TFP & No & $\begin{array}{l}17 \text { to } 40 \% \text { from } 1 \text { to } 3 \\
\text { years }\end{array}$ \\
\hline $\begin{array}{l}\text { Beaudry and Portier } \\
\text { (2006) }\end{array}$ & Short-run or long-run restrictions & TFP & Yes & $50 \%$ \\
\hline Fisher (2006) & $\begin{array}{l}\text { Long-run restrictions involving both } \\
\text { labor productivity and investment } \\
\text { goods prices }\end{array}$ & TFP & No & $\begin{array}{l}32 \% \text { at } 12 \text { quarters (see } \\
\text { papers for more } \\
\text { details) }\end{array}$ \\
\hline Fisher (2006) & $\begin{array}{l}\text { Long-run restrictions involving both } \\
\text { labor productivity and investment } \\
\text { goods prices }\end{array}$ & IST & No & $\begin{array}{l}26 \%(49 \%) \text { at } 12 \\
\text { quarters in early (late) } \\
\text { sample }\end{array}$ \\
\hline $\begin{array}{l}\text { Mertens and Ravn } \\
\text { (2010) }\end{array}$ & $\begin{array}{l}\text { Long-run restrictions, cointegration, } \\
\text { include taxes }\end{array}$ & TFP & No & $\begin{array}{l}50-55 \% \text { at business } \\
\text { cycle frequencies }\end{array}$ \\
\hline $\begin{array}{l}\text { Barsky and Sims } \\
\text { (2011) }\end{array}$ & Medium horizon restrictions & TFP & Yes & $\begin{array}{l}9-43 \% \text { for horizons } \\
\text { up to } 24 \text { quarters. }\end{array}$ \\
\hline $\begin{array}{l}\text { Barsky and Sims } \\
\text { (2011) }\end{array}$ & Medium horizon restrictions & TFP & No & $\begin{array}{l}6-20 \% \text { for horizons } \\
\text { up to } 24 \text { quarters }\end{array}$ \\
\hline $\begin{array}{l}\text { Francis, Owyang, } \\
\text { Roush, and DiCecio } \\
\text { (2014) }\end{array}$ & Medium horizon restrictions & TFP & No & $\begin{array}{l}15-40 \% \text { for horizons } \\
\text { up to } 32 \text { quarters. }\end{array}$ \\
\hline $\begin{array}{l}\text { Francis, Owyang, } \\
\text { Roush, and DiCecio } \\
\text { (2014) }\end{array}$ & Long-run restrictions & TFP & No & $\begin{array}{l}40-55 \% \text { for horizons } \\
\text { up to } 32 \text { quarters }\end{array}$ \\
\hline $\begin{array}{l}\text { Ben Zeev and Khan } \\
\text { (2015) }\end{array}$ & Medium horizon restrictions & IST & Yes & $73 \%$ at 8 quarters \\
\hline $\begin{array}{l}\text { Ben Zeev and Khan } \\
\text { (2015) }\end{array}$ & Medium horizon restrictions & IST & No & Very little \\
\hline $\begin{array}{l}\text { Ben Zeev and Khan } \\
\text { (2015) }\end{array}$ & Medium horizon restrictions & TFP & No & $10 \%$ at 8 quarters \\
\hline
\end{tabular}

Notes: TFP denotes neutral total factor productivity technology, IST denotes investment-specific technology, MEI denotes marginal efficiency of investment. 
Table 5.2. Estimated Importance of Technology Shocks in DSGE Models

\begin{tabular}{|c|c|c|c|c|}
\hline Study & Model Features & Type & News? & $\begin{array}{l}\% \text { of output explained } \\
\text { at business cycle } \\
\text { frequencies }\end{array}$ \\
\hline Prescott (1986) & $\begin{array}{l}\begin{array}{l}\text { Calibrated neoclassical DSGE } \\
\text { model }\end{array} \\
\end{array}$ & TFP & No & $75 \%$ \\
\hline McGrattan (1994) & $\begin{array}{l}\text { Neoclassical model with } \\
\text { distortionary taxes and government } \\
\text { spending }\end{array}$ & TFP & No & $41 \%$ \\
\hline $\begin{array}{l}\text { Greenwood, } \\
\text { Hercowitz, Krusell } \\
\text { (2000) }\end{array}$ & $\begin{array}{l}\text { Calibrated DSGE model, } \\
\text { technology identified with relative } \\
\text { price of investment }\end{array}$ & IST & No & $30 \%$ \\
\hline $\begin{array}{l}\text { Smets and Wouters } \\
\text { (2007) }\end{array}$ & $\begin{array}{l}\text { New Keynesian model with many } \\
\text { types of shocks }\end{array}$ & TFP & No & $\begin{array}{l}15 \%-30 \% \text { from } \\
\text { horizon } 1-10 \text { quarters }\end{array}$ \\
\hline $\begin{array}{l}\text { Justiniano, } \\
\text { Primiceri, } \\
\text { Tambalotti (2011) }\end{array}$ & $\begin{array}{l}\text { New Keynesian model with many } \\
\text { types of shocks }\end{array}$ & TFP & No & $25 \%$ \\
\hline $\begin{array}{l}\text { Justiniano, } \\
\text { Primiceri, } \\
\text { Tambalotti (2011) }\end{array}$ & $\begin{array}{l}\text { New Keynesian model with many } \\
\text { types of shocks }\end{array}$ & IST & No & $0 \%$ \\
\hline $\begin{array}{l}\text { Justiniano, } \\
\text { Primiceri, } \\
\text { Tambalotti (2011) }\end{array}$ & $\begin{array}{l}\text { New Keynesian model with many } \\
\text { types of shocks }\end{array}$ & MEI & No & $60 \%$ \\
\hline $\begin{array}{l}\text { Schmitt-Grohe and } \\
\text { Uribe (2012) }\end{array}$ & $\begin{array}{l}\text { Distinguishes unanticipated vs. } \\
\text { anticipated, TFP versus investment } \\
\text { specific, no sticky prices }\end{array}$ & TFP & No & $25 \%$ \\
\hline $\begin{array}{l}\text { Schmitt-Grohe and } \\
\text { Uribe (2012) }\end{array}$ & $\begin{array}{l}\text { Distinguishes unanticipated vs. } \\
\text { anticipated, TFP versus investment } \\
\text { specific, no sticky prices }\end{array}$ & TFP & Yes & $3 \%$ \\
\hline $\begin{array}{l}\text { Schmitt-Grohe and } \\
\text { Uribe (2012) }\end{array}$ & $\begin{array}{l}\text { Distinguishes unanticipated vs. } \\
\text { anticipated, TFP versus investment } \\
\text { specific, no sticky prices }\end{array}$ & IST & No & $21 \%$ \\
\hline $\begin{array}{l}\text { Schmitt-Grohe and } \\
\text { Uribe (2012) }\end{array}$ & $\begin{array}{l}\text { Distinguishes unanticipated vs. } \\
\text { anticipated, TFP versus investment } \\
\text { specific, no sticky prices }\end{array}$ & IST & Yes & $7 \%$ \\
\hline $\begin{array}{l}\text { Khan and Tsoukalas } \\
\text { (2012) }\end{array}$ & $\begin{array}{l}\text { New Keynesian model, } \\
\text { distinguishes unanticipated vs. } \\
\text { anticipated }\end{array}$ & TFP & No & $24 \%$ \\
\hline $\begin{array}{l}\text { Khan and Tsoukalas } \\
\text { (2012) }\end{array}$ & $\begin{array}{l}\text { New Keynesian model, } \\
\text { distinguishes unanticipated vs. } \\
\text { anticipated }\end{array}$ & MEI & No & $47 \%$ \\
\hline $\begin{array}{l}\text { Khan and Tsoukalas } \\
\text { (2012) }\end{array}$ & $\begin{array}{l}\text { New Keynesian model, } \\
\text { distinguishes unanticipated vs. } \\
\text { anticipated }\end{array}$ & IST & No & $1.2 \%$ \\
\hline $\begin{array}{l}\text { Khan and Tsoukalas } \\
\text { (2012) }\end{array}$ & $\begin{array}{l}\text { New Keynesian model, } \\
\text { distinguishes unanticipated vs. } \\
\text { anticipated }\end{array}$ & $\begin{array}{l}\text { TFP + } \\
\text { MEI + } \\
\text { IST }\end{array}$ & Yes & $1.4 \%$ \\
\hline
\end{tabular}




\begin{tabular}{|l|l|l|l|l|}
\hline $\begin{array}{l}\text { Miyamoto and } \\
\text { Nguyen (2015) }\end{array}$ & $\begin{array}{l}\text { Extends Schmitt-Grohe-Uribe } \\
\text { analysis by using data on } \\
\text { expectations }\end{array}$ & TFP & No & $19 \%$ \\
\hline $\begin{array}{l}\text { Miyamoto and } \\
\text { Nguyen (2015) }\end{array}$ & $\begin{array}{l}\text { Extends Schmitt-Grohe-Uribe } \\
\text { analysis by using data on } \\
\text { expectations }\end{array}$ & TFP & Yes & $7 \%$ \\
\hline $\begin{array}{l}\text { Miyamoto and } \\
\text { Nguyen (2015) }\end{array}$ & $\begin{array}{l}\text { Extends Schmitt-Grohe-Uribe } \\
\text { analysis by using data on } \\
\text { expectations }\end{array}$ & IST & No & $27 \%$ \\
\hline $\begin{array}{l}\text { Miyamoto and } \\
\text { Nguyen (2015) }\end{array}$ & $\begin{array}{l}\text { Extends Schmitt-Grohe-Uribe } \\
\text { analysis by using data on } \\
\text { expectations }\end{array}$ & IST & Yes & $12 \%$ \\
\hline
\end{tabular}

Notes: TFP denotes neutral total factor productivity technology, IST denotes investment-specific technology, MEI denotes marginal efficiency of investment. 
Table 5.3. Correlation of Various Estimated Technology Shocks (Sample is 1955q2 - 2006q4)

\section{A. Unanticipated TFP Shocks}

\begin{tabular}{|l|rrrrrrrr|}
\hline & gali-tfp & cev-tfp & jf-tfp & ford-tfp & bzk-tfp & jpt-tfp & mn-tfp-p & mn-tfp-s \\
\hline gali-tfp & 1.00 & & & & & & & \\
cev-tfp & 0.62 & 1.00 & & & & & & \\
jf-tfp & 0.68 & 0.42 & 1.00 & & & & & \\
ford-tfp & 0.75 & 0.62 & 0.62 & 1.00 & & & & \\
bzk-tfp & 0.67 & 0.78 & 0.54 & 0.63 & 1.00 & & & \\
jpt-tfp & 0.68 & 0.69 & 0.53 & 0.54 & 0.63 & 1.00 & & \\
mn-tfp-p & 0.17 & 0.16 & 0.20 & 0.28 & 0.08 & 0.16 & 1.00 & \\
mn-tfp-s & 0.52 & 0.59 & 0.47 & 0.52 & 0.58 & 0.62 & 0.10 & 1.00 \\
\hline
\end{tabular}

\section{B. TFP News Shocks}

\begin{tabular}{|l|rrrrrr|}
\hline & bp-news & bs-news & mn-p-n4 & mn-p-n8 & mn-s-n4 & mn-p-n8 \\
\hline bp-news & 1.00 & & & & & \\
bs-news & 0.25 & 1.00 & & & & \\
mn-p-n4 & 0.08 & 0.12 & 1.00 & & & \\
mn-p-n8 & 0.05 & 0.00 & 0.29 & 1.00 & & \\
mn-s-n4 & 0.04 & -0.04 & 0.53 & -0.14 & 1.00 & \\
mn-p-n8 & 0.05 & 0.00 & 0.29 & 1.00 & -0.14 & 1.00 \\
\hline
\end{tabular}

\section{Unanticipated IST or MEI Shocks}

\begin{tabular}{|l|rrrrrr|}
\hline & jf-ist & bzk-ist & jpt-mei & jpt-ist & mn-ist-p & mn-ist-s \\
\hline jf-ist & 1.00 & & & & & \\
bzk-ist & 0.17 & 1.00 & & & & \\
jpt-mei & -0.27 & 0.05 & 1.00 & & & \\
jpt-ist & 0.19 & 0.49 & -0.01 & 1.00 & & \\
mn-ist-p & 0.03 & 0.31 & 0.17 & 0.20 & 1.00 & \\
mn-ist-s & -0.13 & 0.11 & 0.27 & 0.14 & -0.06 & 1.00 \\
\hline
\end{tabular}

\section{IST News Shocks}

\begin{tabular}{|l|rrrrr|}
\hline & bzk-news & mn-p-n4 & mn-p-n8 & mn-s-n4 & mn-s-n8 \\
\hline bzk-news & 1.00 & & & & \\
mn-p-n4 & 0.15 & 1.00 & & & \\
mn-p-n8 & 0.02 & 0.18 & 1.00 & & \\
mn-s-n4 & 0.12 & 0.07 & 0.12 & 1.00 & \\
mn-s-n8 & 0.08 & 0.01 & 0.02 & 0.28 & 1.00 \\
\hline
\end{tabular}

Abbreviations:

$\begin{array}{lll}\text { ist = investment-specific technology } & \text { tfp = total factor productivity } & \mathrm{mn}=\text { Miyamoto and Nguyen } \\ \text { mei = marginal efficiency of invest. } & \text { gali = Gali } & \mathrm{p}=\text { permanent } \\ \text { jpt = Justiniano, Primiceri, Tambolotti } & \text { bzk = Ben Zeev and Khan } & \mathrm{s}=\text { stationary } \\ \text { cev= Christiano, Eichenbaum, Vigfusson } & \text { bp = Beaudry-Portier } & \mathrm{n} 4=\text { news with 4 quarter lead } \\ \text { ford = Francis, Owyang, Roush, DiCecio } & \text { bs = Barsky Sims } & \text { n8 = news with 8 quarter lead } \\ & \text { jf = John Fernald } & \end{array}$


Table 5.4 Tests for Serial Correlation and Granger Causality

\begin{tabular}{|l|cc|}
\hline & P-value & \multicolumn{2}{|c|}{$\begin{array}{l}\text { P-value } \\
\text { Test for significance of own lags }\end{array}$} \\
Test for Granger Causality
\end{tabular}

Notes: The tests for serial correlation are conducted by regressing the shock on its own two lags and testing the joint significance. The tests for Granger Causality are conducted by regressing the shock on its own two lags, as well as two lags of log real GDP, log real consumption, and log real stock prices. The test is on the joint significance of the lags of the three additional variables.

Abbreviations:

\begin{tabular}{|lll|}
\hline ist = investment-specific technology & tfp = total factor productivity & $\mathrm{mn}=$ Miyamoto and Nguyen \\
mei = marginal efficiency of invest. & gali = Gali & $\mathrm{p}=$ permanent \\
jpt = Justiniano, Primiceri, Tambolotti & bzk = Ben Zeev and Khan & $\mathrm{s}=$ stationary \\
cev= Christiano, Eichenbaum, Vigfusson & bp = Beaudry-Portier & n4 = news with 4 quarter lead \\
ford = Francis, Owyang, Roush, DiCecio & bs = Barsky Sims & n8 = news with 8 quarter lead \\
& jf = John Fernald & \\
\hline
\end{tabular}


Table 5.5 A. TFP Shock Contribution to the Forecast Error Variance of Output and Hours

\begin{tabular}{|r|r|r|r|r|r|r|}
\hline & \multicolumn{2}{|c|}{ FORD TFP } & \multicolumn{2}{c|}{ Fernald TFP } & \multicolumn{2}{|c|}{ JPT TFP } \\
\hline $\begin{array}{l}\text { Horizon } \\
\text { (in } \\
\text { quarters) }\end{array}$ & Output & Hours & \multicolumn{2}{|c|}{ Output } & Hours & \multicolumn{2}{|l|}{ Output } & Hours \\
\hline 0 & 16.2 & 10.5 & 6.1 & 10.5 & 28.2 & 1.0 \\
\hline 4 & 13.1 & 2.0 & 2.0 & 2.4 & 15.1 & 0.9 \\
\hline 8 & 14.3 & 1.9 & 2.8 & 1.3 & 15.9 & 1.6 \\
\hline 12 & 14.3 & 1.6 & 3.1 & 1.2 & 16.3 & 1.6 \\
\hline 16 & 14.0 & 1.5 & 3.1 & 1.5 & 16.0 & 1.6 \\
\hline 20 & 13.7 & 1.5 & 3.0 & 2.0 & 15.7 & 1.9 \\
\hline
\end{tabular}

Notes: Based on standard VAR with the shock, output, hours stock prices, consumption, and nonresidential investment. The shock is ordered first. 4 lags are included, along with a quadratic trend.

Table 5.5 B. Investment-Related Technology Shock Contribution to the Forecast Error Variance of Output and Hours

\begin{tabular}{|c|c|c|c|c|}
\hline & \multicolumn{2}{|c|}{ Ben Zeev-Khan IST News } & \multicolumn{2}{|c|}{ JPT MEI } \\
\hline $\begin{array}{l}\text { Horizon } \\
\text { (in quarters) }\end{array}$ & Output & Hours & Output & Hours \\
\hline$x^{2}-7=0$ & 7.8 & 6.9 & 49.6 & 26.4 \\
\hline 4 & 33.2 & 31.3 & 19.8 & 20.9 \\
\hline 8 & 36.8 & 38.5 & 11.9 & 12.1 \\
\hline 12 & 36.8 & 38.8 & 11.4 & 10.5 \\
\hline 16 & 36.4 & 37.9 & 11.3 & 10.1 \\
\hline 20 & 35.9 & 36.8 & 11.1 & 9.8 \\
\hline
\end{tabular}

Notes: Based on standard VAR with the shock, output, hours stock prices, consumption, and nonresidential investment. The shock is ordered first. 4 lags are included, along with a quadratic trend. 
Table 6.1 Combined VAR

Shock Contribution to the Forecast Error Variance of Output and Hours: 1954q3 - 2005q4.

\section{A. Output}

\begin{tabular}{|l|l|l|l|l|l|l|l|}
\hline Horizon & bzp-gov & lrw & rrtaxu & ford-tfp & bzk-ist-news & jpt-mei & ffr \\
\hline 0 & 5.5 & 0.1 & 2.4 & 15.8 & 11.8 & 42.1 & 0.0 \\
\hline 4 & 1.6 & 5.6 & 1.6 & 15.1 & 28.8 & 23.9 & 2.0 \\
\hline 8 & 1.4 & 4.8 & 1.5 & 13.9 & 26.9 & 16.3 & 6.1 \\
\hline 12 & 3.0 & 4.8 & 1.2 & 12.6 & 22.1 & 13.6 & 8.1 \\
\hline 16 & 4.4 & 6.9 & 1.2 & 11.2 & 19.6 & 12.5 & 7.8 \\
\hline 20 & 4.9 & 8.5 & 1.2 & 10.7 & 18.6 & 11.9 & 7.4 \\
\hline
\end{tabular}

\section{B. Hours}

\begin{tabular}{|l|l|l|l|l|l|l|l|}
\hline Horizon & bzp-gov & lrw & rrtaxu & ford-tfp & bzk-ist-news & jpt-mei & ffr \\
\hline 0 & 2.3 & 0.8 & 0.3 & 17.6 & 13.2 & 20.5 & 0.0 \\
\hline 4 & 0.5 & 6.6 & 0.8 & 3.7 & 38.3 & 22.1 & 3.2 \\
\hline 8 & 0.9 & 6.3 & 0.9 & 2.4 & 39.5 & 14.2 & 10.9 \\
\hline 12 & 4.1 & 5.2 & 0.7 & 1.8 & 33.4 & 11.5 & 16.8 \\
\hline 16 & 7.3 & 6.0 & 0.7 & 1.7 & 28.6 & 10.6 & 18.3 \\
\hline 20 & 8.9 & 7.0 & 0.8 & 2.0 & 26.7 & 10.2 & 18.1 \\
\hline
\end{tabular}

Notes: These results are from a standard VAR with 4 lags and a quadratic trend estimated from $1954 q 3-2005 q 4$. The variables are as follows, in this order: Bzp-gov, lrw, rrtaxu, ford-tfp, bzk-ist-news, jpt-mei, log real GDP per capita, log total hours per capita, log commodity prices, log GDP deflator, federal funds rate.

\section{Abbreviations:}

\begin{tabular}{|l|l|}
\hline lrw = Leeper, Richter, Walker anticipated future tax & ford = Francis, Owyang, Roush, DiCecio \\
\hline rrtaxu = Romer-Romer unanticipated tax & bzk = Ben Zeev and Khan \\
\hline tfp = total factor productivity & Jpt = Justiniano, Primiceri, Tambolotti \\
\hline ist = investment-specific technology & bzp = Ben Zeev and Pappa \\
\hline mei = marginal efficiency of invest. & ffr = federal funds rate \\
\hline
\end{tabular}




\section{Figures}

All confidence bands shown on impulse responses are $90 \%$ confidence bands. 
Figure 3.1. Christiano, Eichenbaum, and Evans (1999) Identification

1965m1-1995m6 full specification: solid black lines; 1983m1-2007m12 full specification: short dashed blue lines; 1983m1-2007m12, omits money and reserves: long dashed red lines)
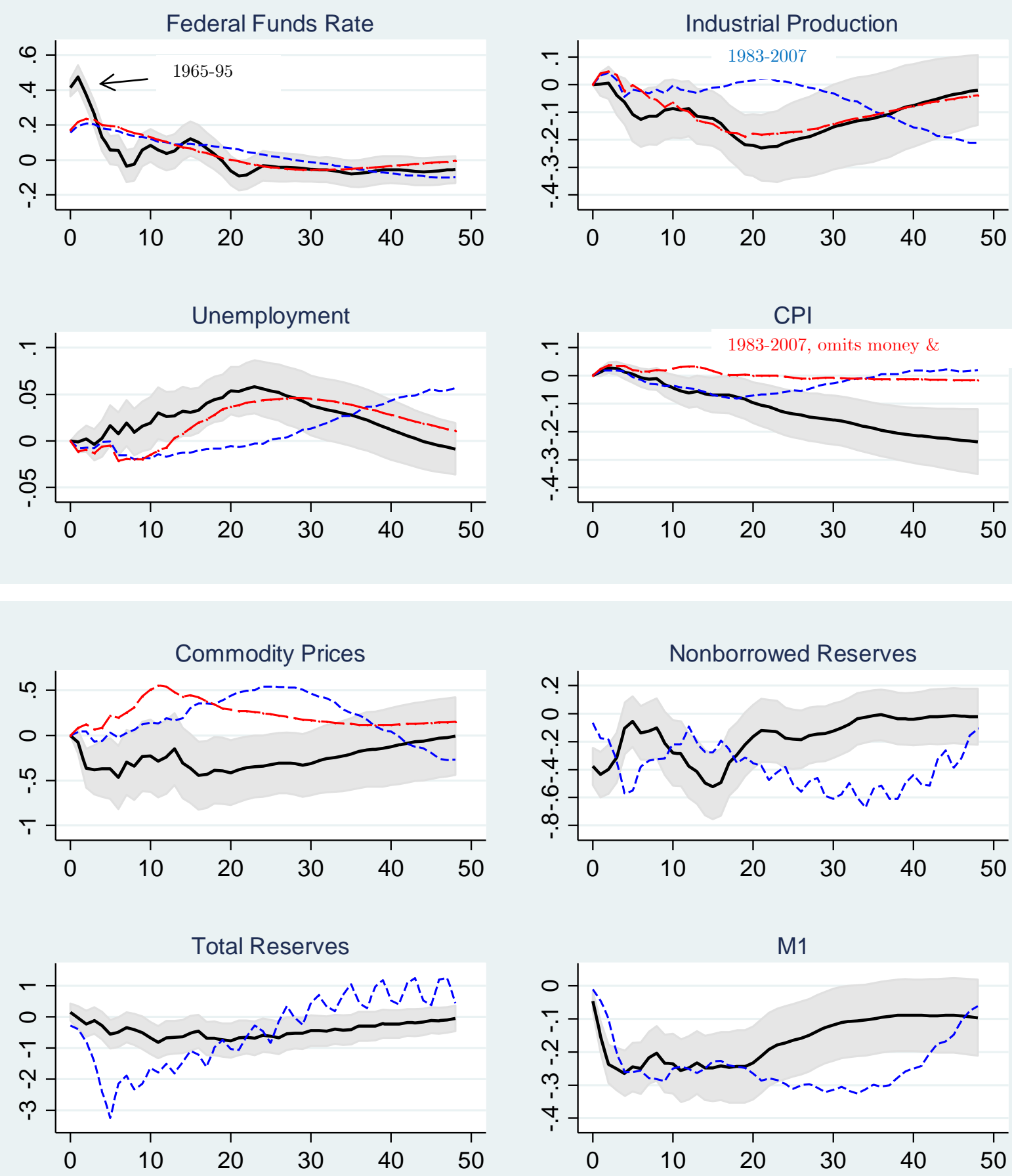


\section{Figure 3.2. Romer \& Romer Monetary Shock}

A. Coibion VAR 1969m3-1996m12: solid black lines; 1983m1-2007m12: short dashed blue lines; 1969m3-2007m12: long dashed red lines.
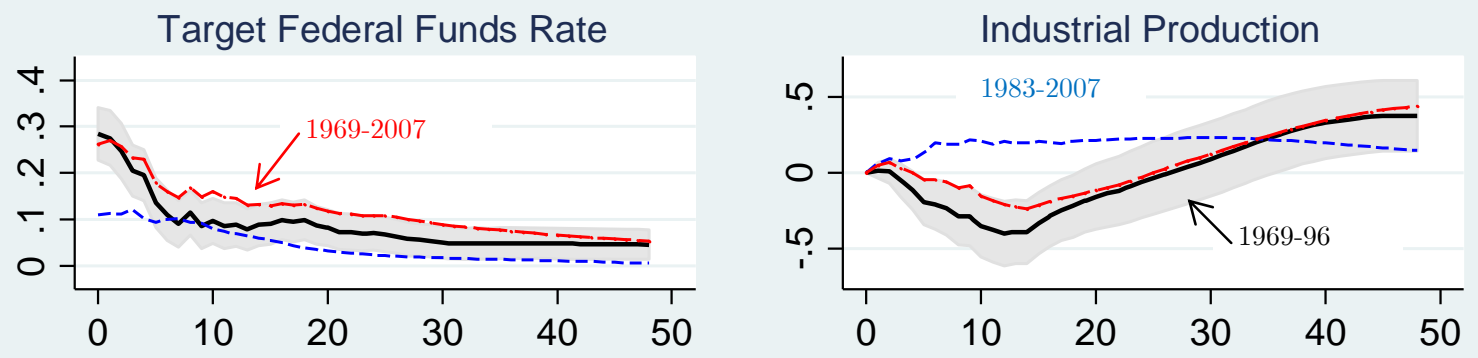

Unemployment
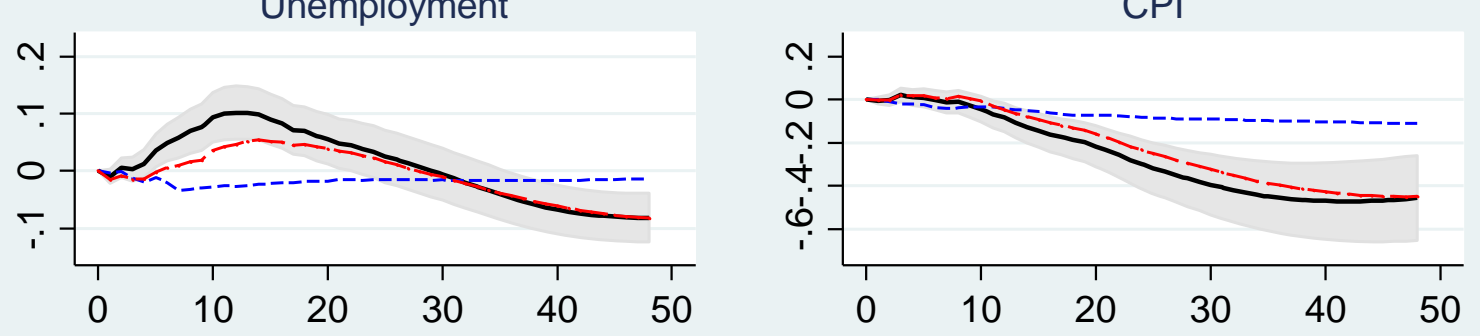

B. Jordà Local Projection Method, 1969m3-1996m12 Recursiveness assumption: solid black lines; No recursiveness assumption: dashed green lines; No recursiveness assumption, FAVAR controls: dashed purple lines.

Federal Funds Rate

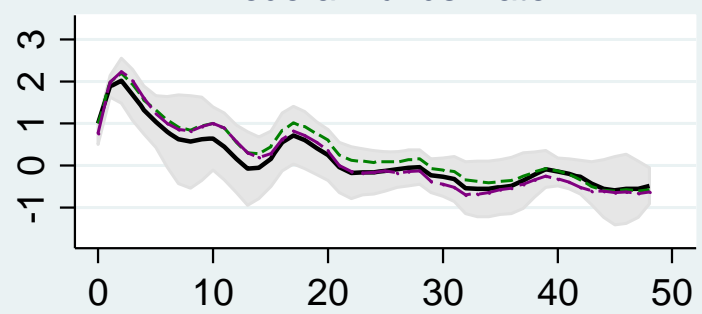

Unemployment

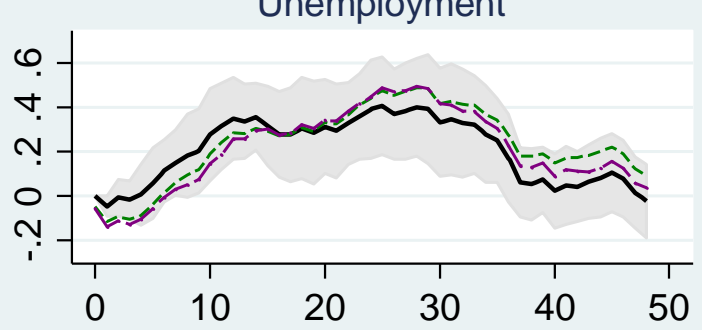

Industrial Production

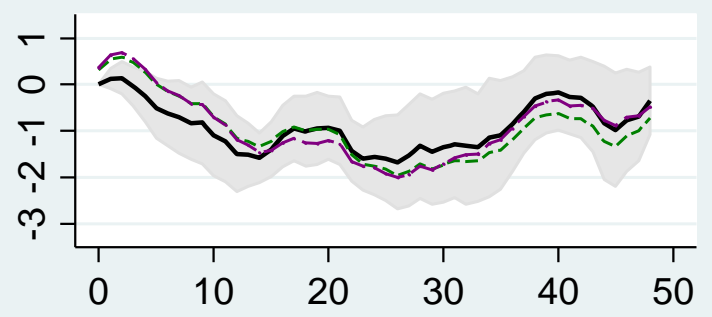

CPI

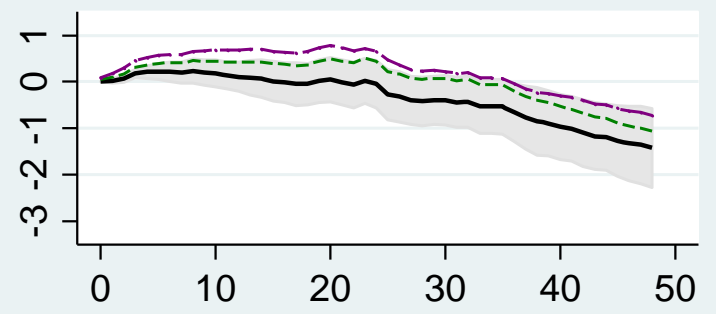


C. Proxy SVAR 1969m3-1996m12: solid black lines; 1969m3-2007m12: long dashed red lines.
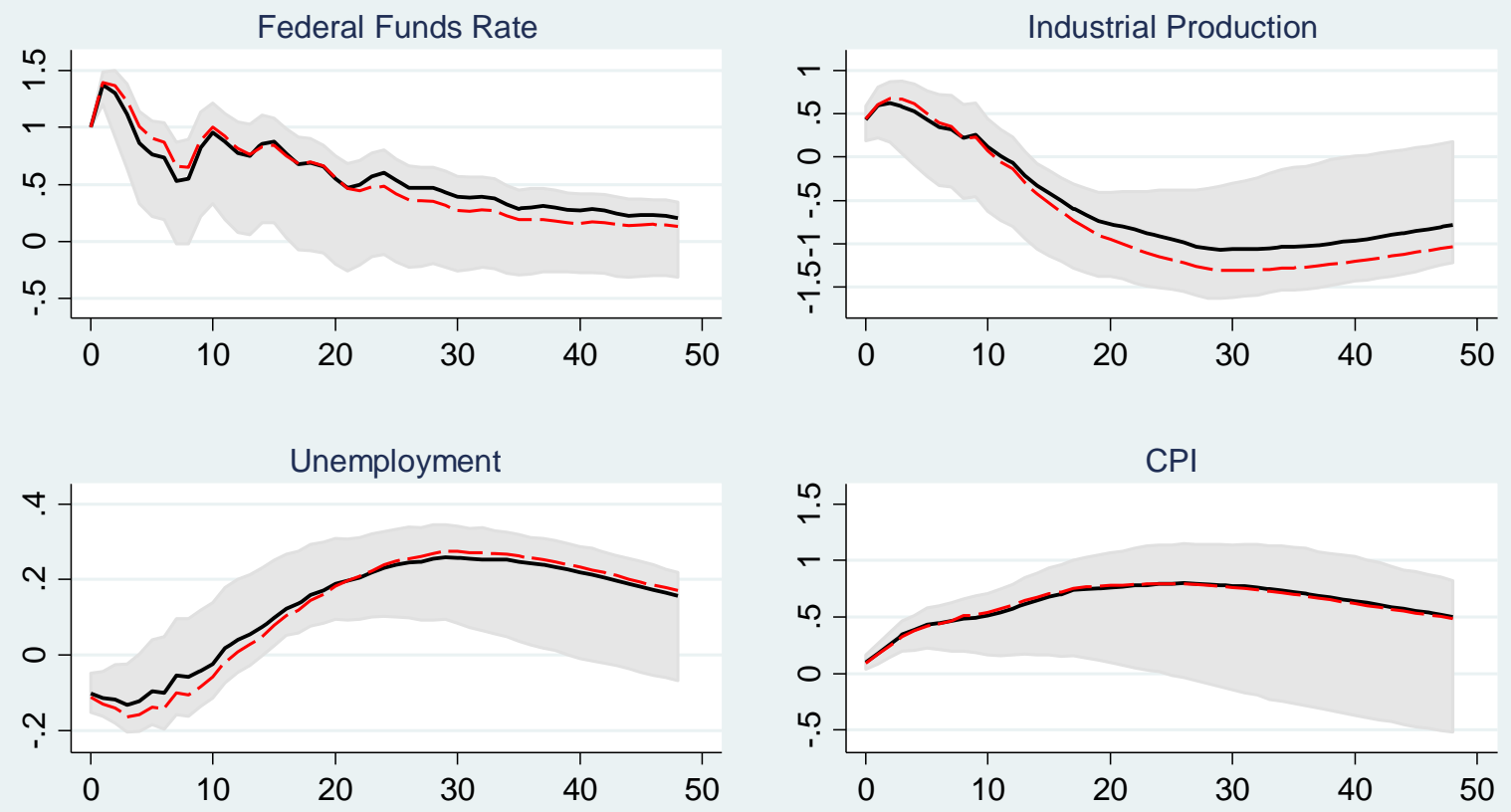
Figure 3.3 Gertler-Karadi’s Monetary Shock

A. Gertler-Karadi's Monetary Proxy SVAR, VAR from 1979m7-2012m6, instrument from 1991m1-2012m6
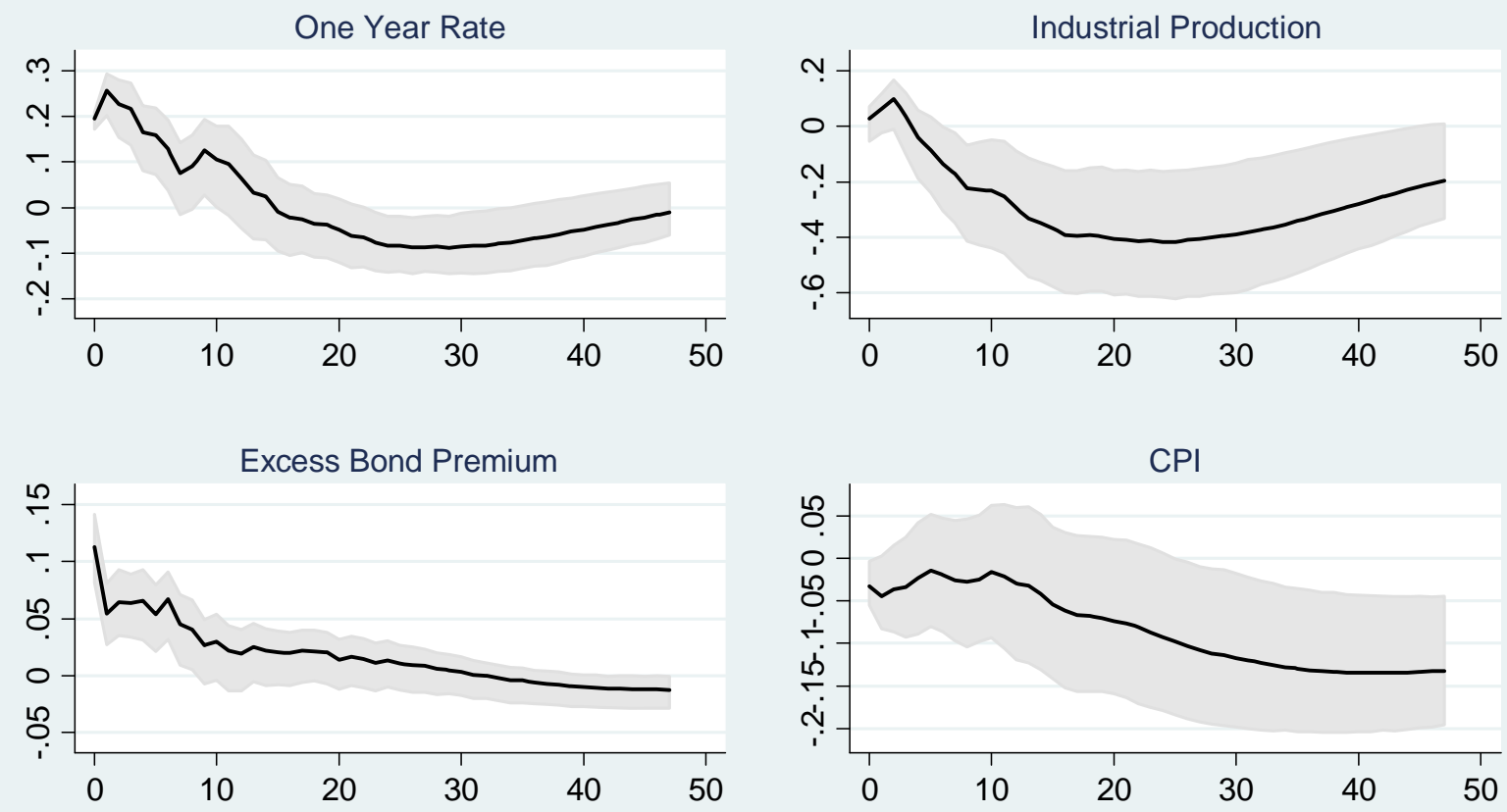

Figure 3.3B Gertler-Karadi Monetary Shock, Jordà 1990m1-2012m6
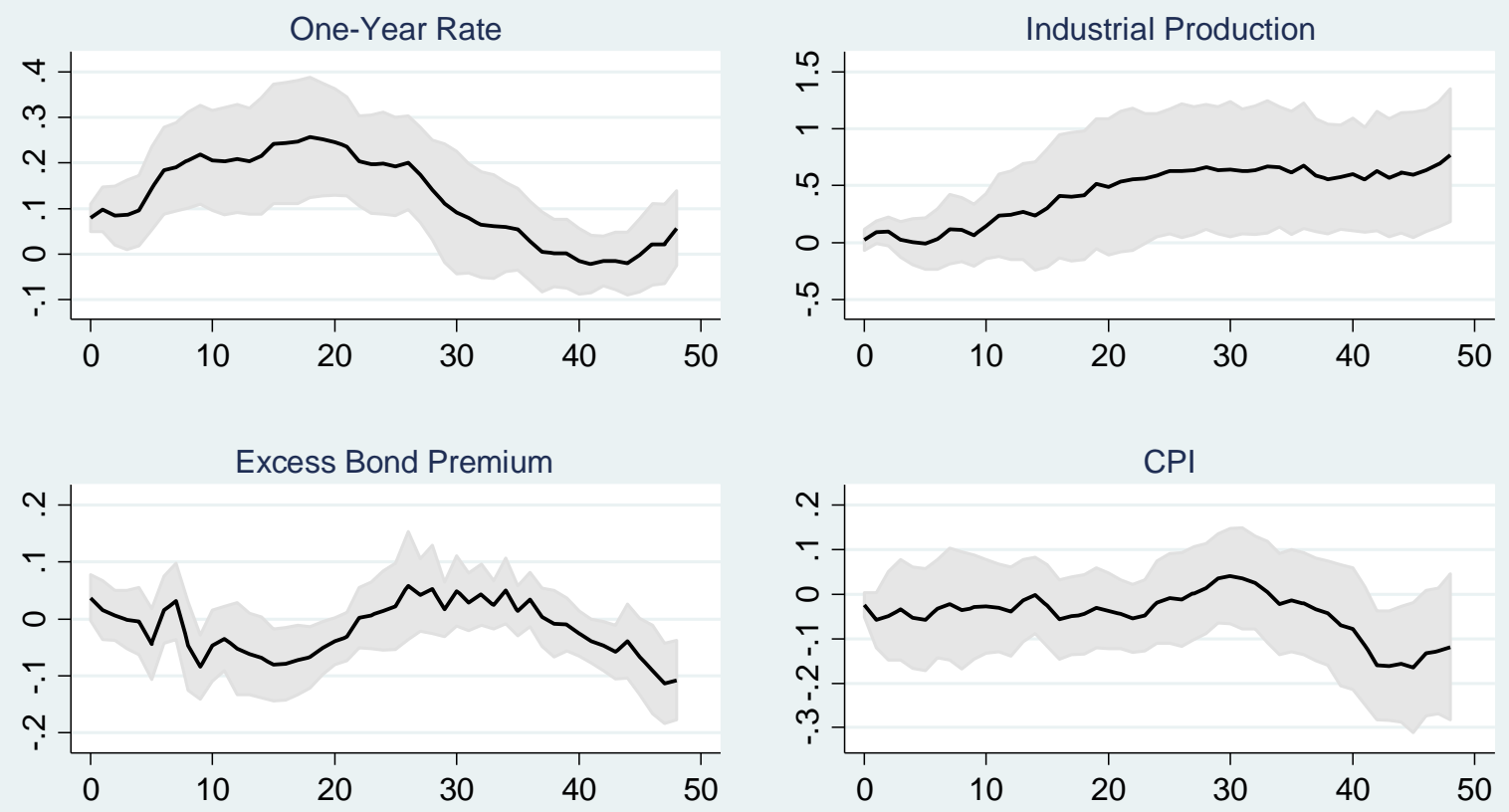
Figure 4.1. First-Stage F-Statistics for Government Spending Shocks

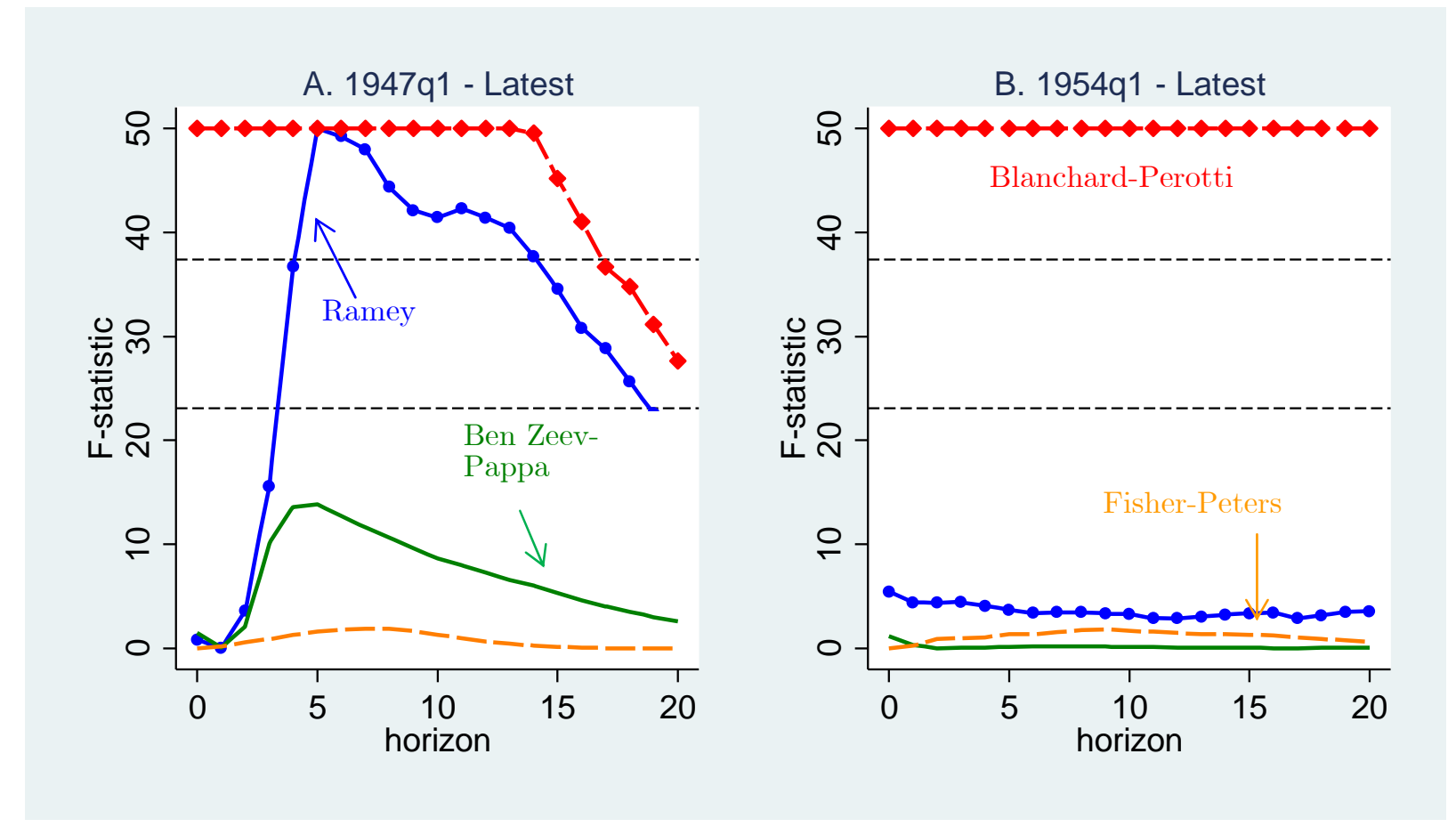

Note: The F-statistics are based on the regression of the sum of government spending from $t$ to $\mathrm{t}+\mathrm{h}$ on the shock at $\mathrm{t}$, plus the lagged control variables. Values above 50 have been capped at 50 . The horizontal dashed lines are the Montiel-Pflueger (2013) 5 \% (upper line) and 10\% (lower line) thresholds. 
Figure 4.2 Comparison of the Effects of Government Spending Shocks

(BP: Blanchard-Perotti; BZP: Ben Zeev-Pappa)
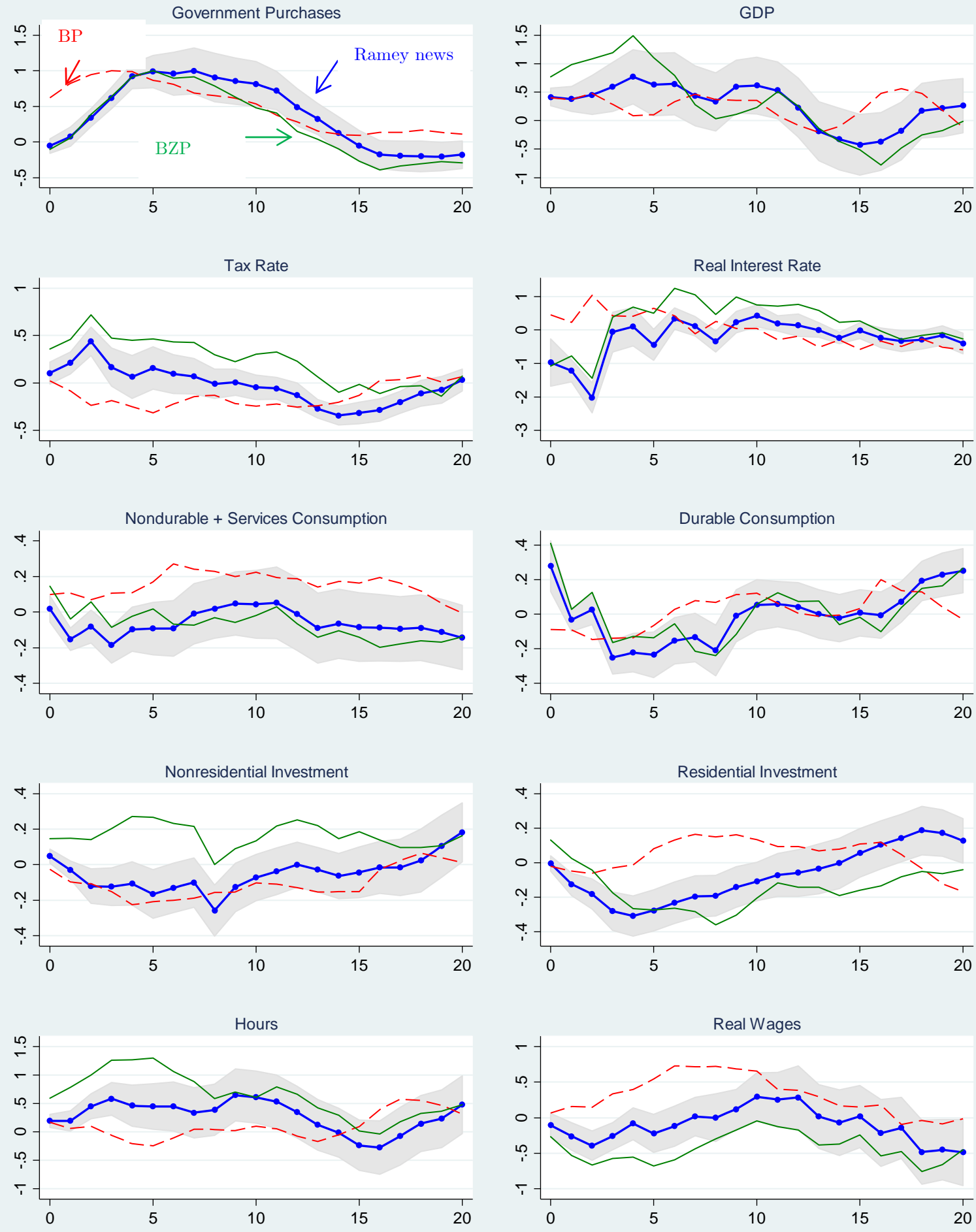
Figure 4.3 Effects of Unanticipated Romer Tax Shock, Trivariate VAR, 1950q1 - 2006q4

A. Mertens-Ravn (2014) Proxy SVAR
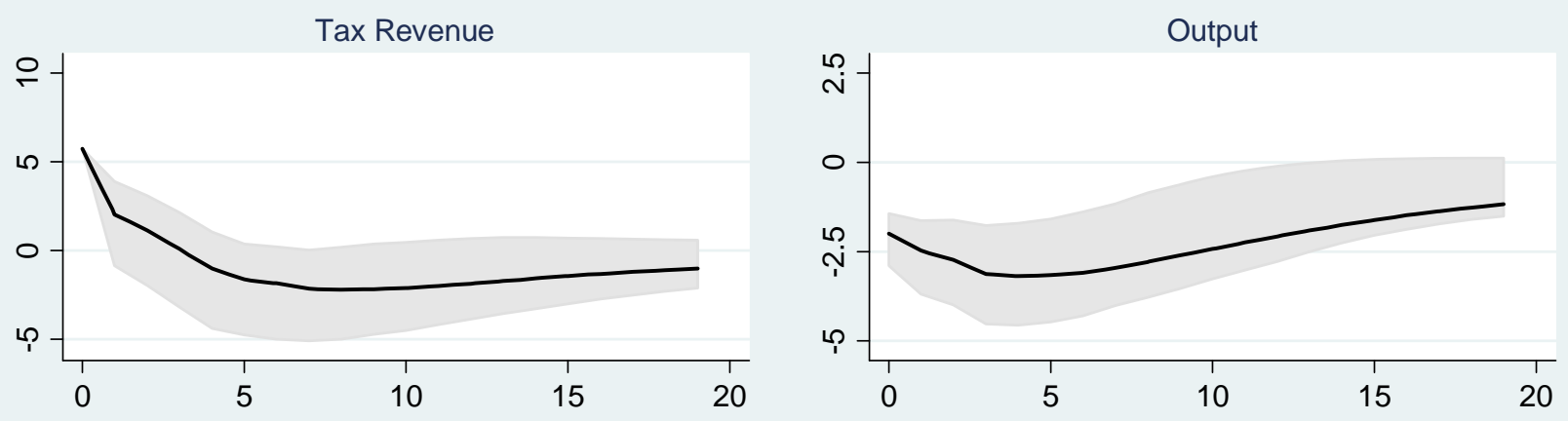

B. Jordá Local Projection, Reduced Form
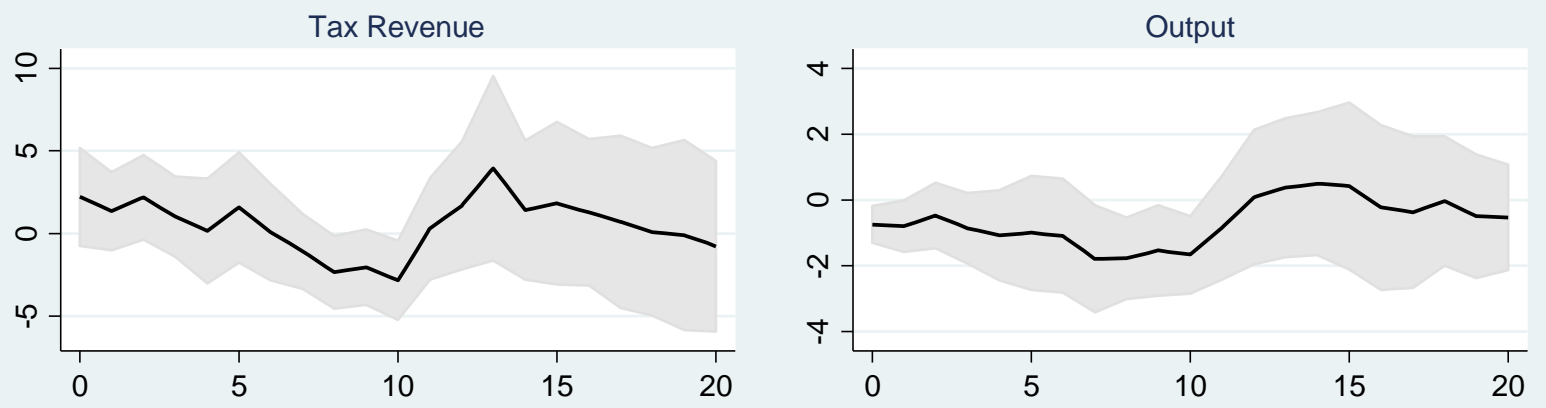

C. Jordá Local Projection, IV Regression of Output on Tax Revenue

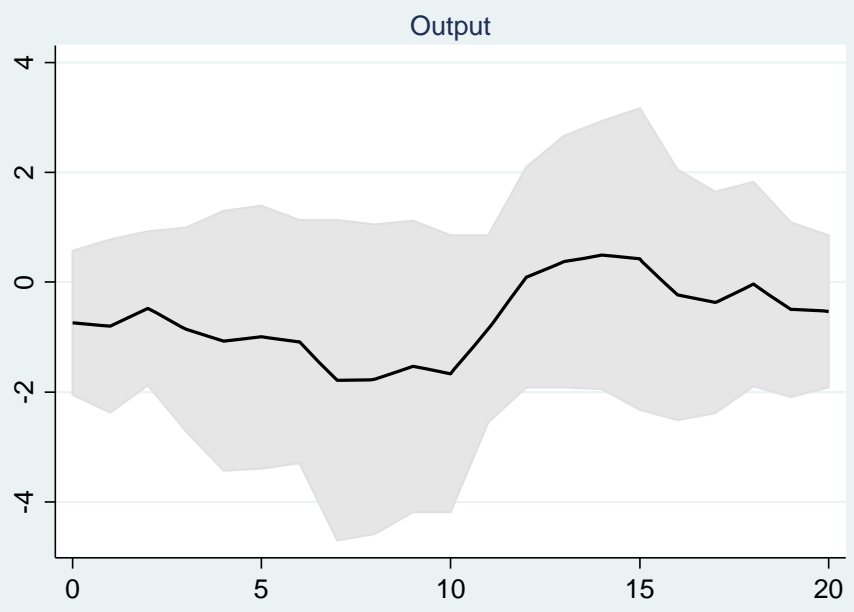


Figure 4.4 Effects of News of Future Tax Increases, Mertens-Ravn Estimates based on Romer-Romer Narrative, 1950q1-2006q4 (90\% confidence intervals)
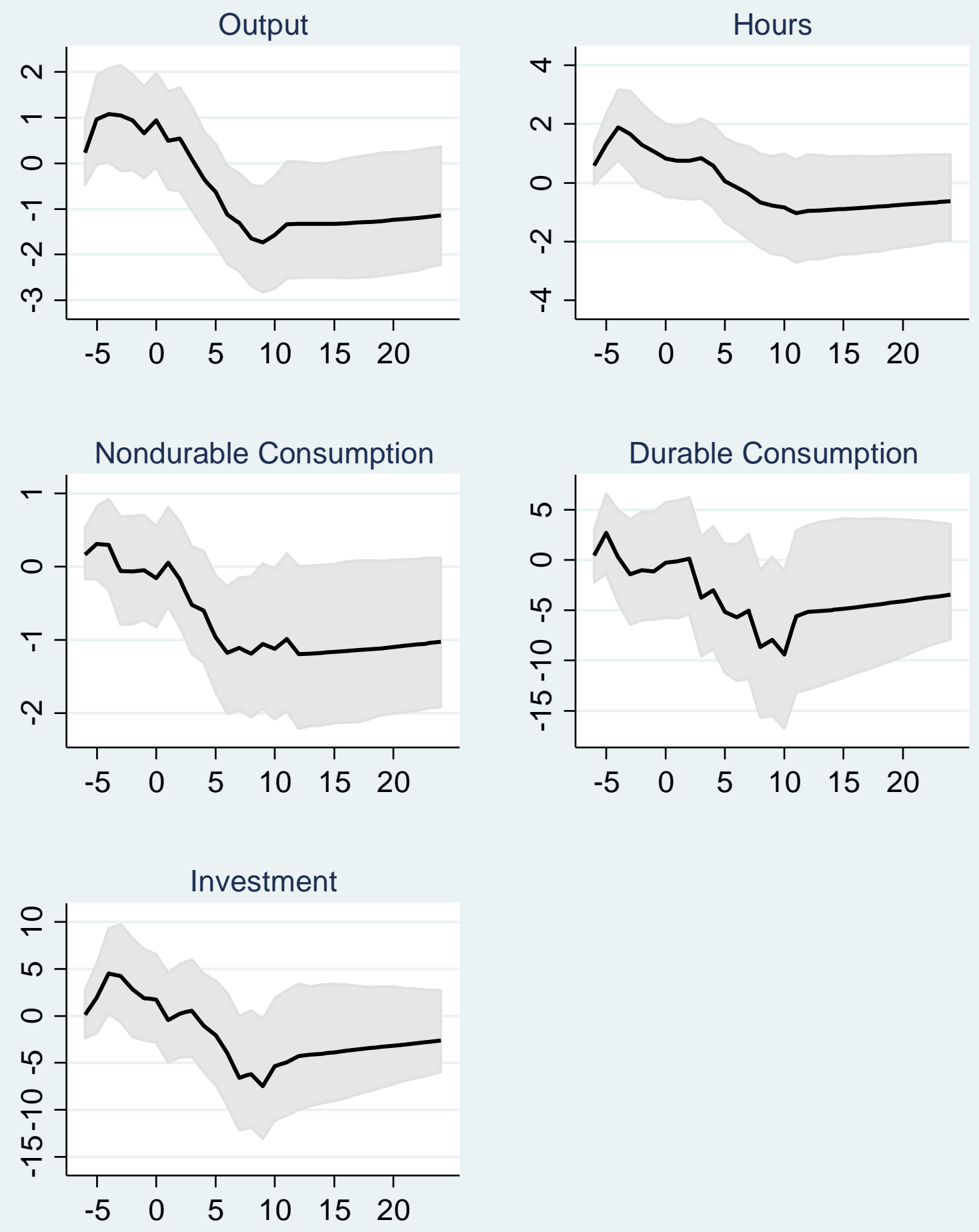
Figure 4.5 Effect of News of Future Tax Increase, Leeper, Richter, Walker (2011) Measure, Jordà local projection, 1954q1 - 2005q4.
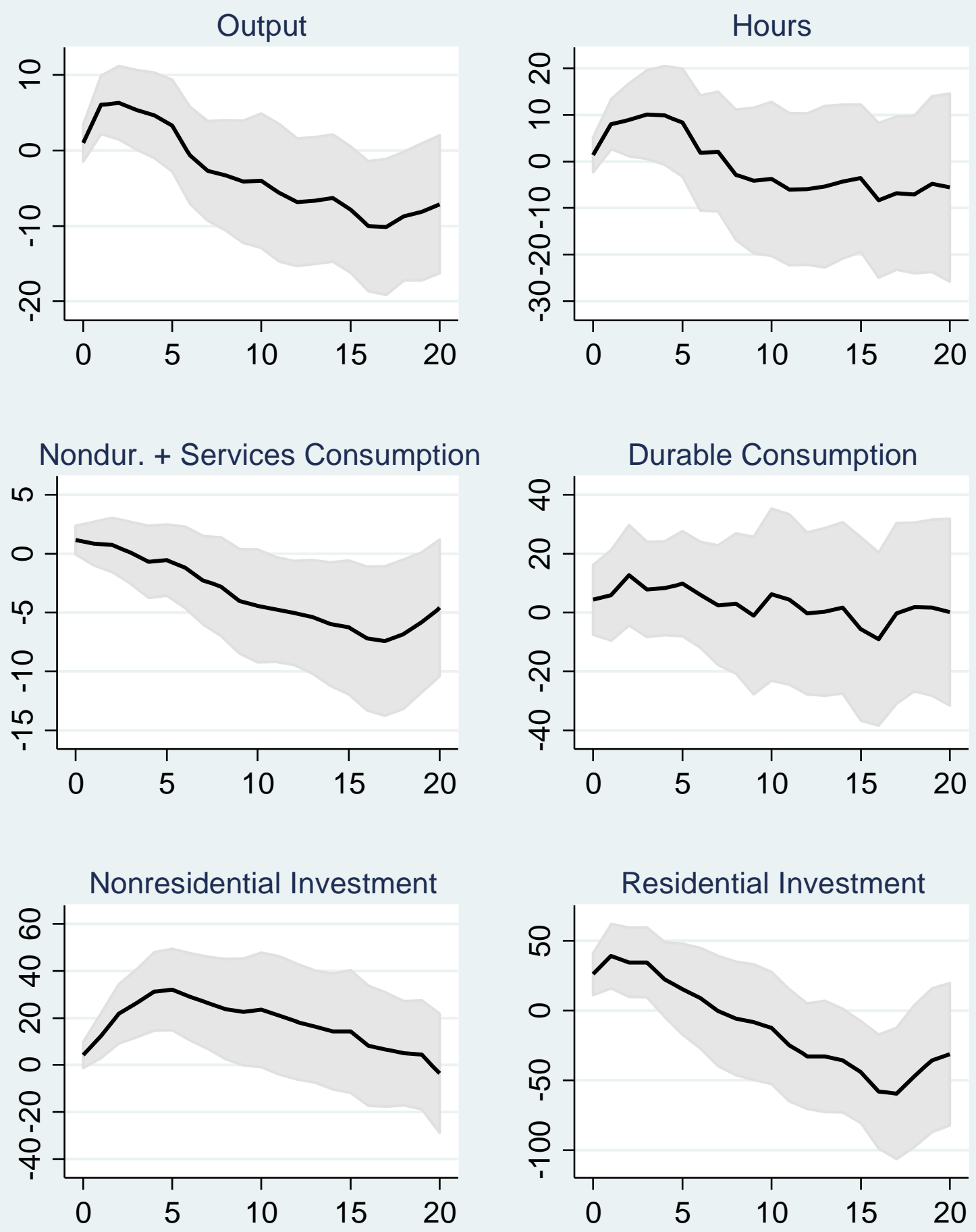
Figure 5.1. Effects of TFP Shock, Jordà local projection, various samples.

Francis, Owyang, Roush, DiCecio (FORD): blue lines with circles; Fernald utilization-adj TFP: dashed red lines; Justiniano, Primiceri, Tambalotti (JPT) DSGE TFP: solid green lines)
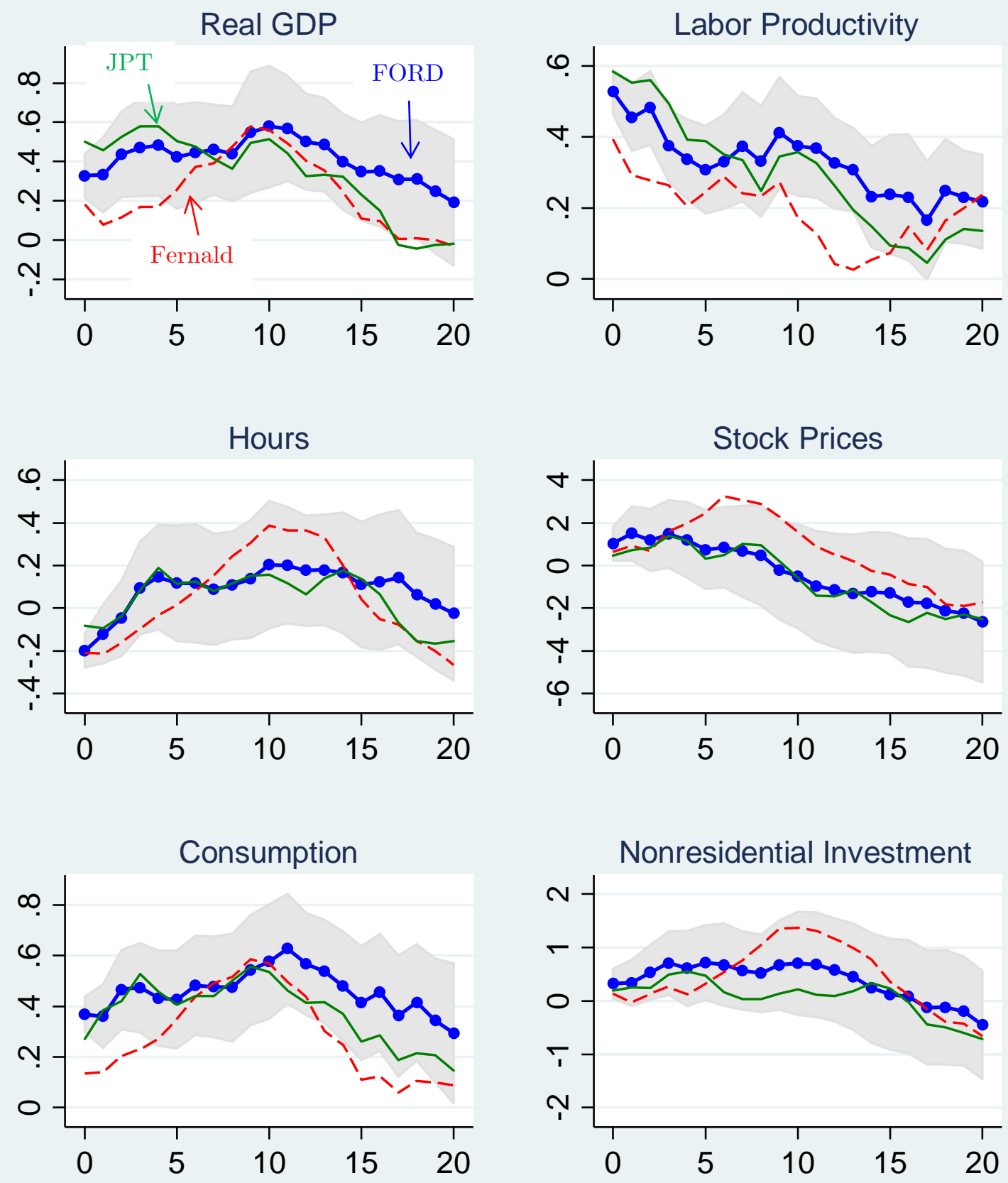
Figure 5.2 Effects of News of Investment-Specific Technolgy Shocks, Ben Zeev-Khan (2015) Measure, Jordà local projection, 1952q1 - 2012q1.
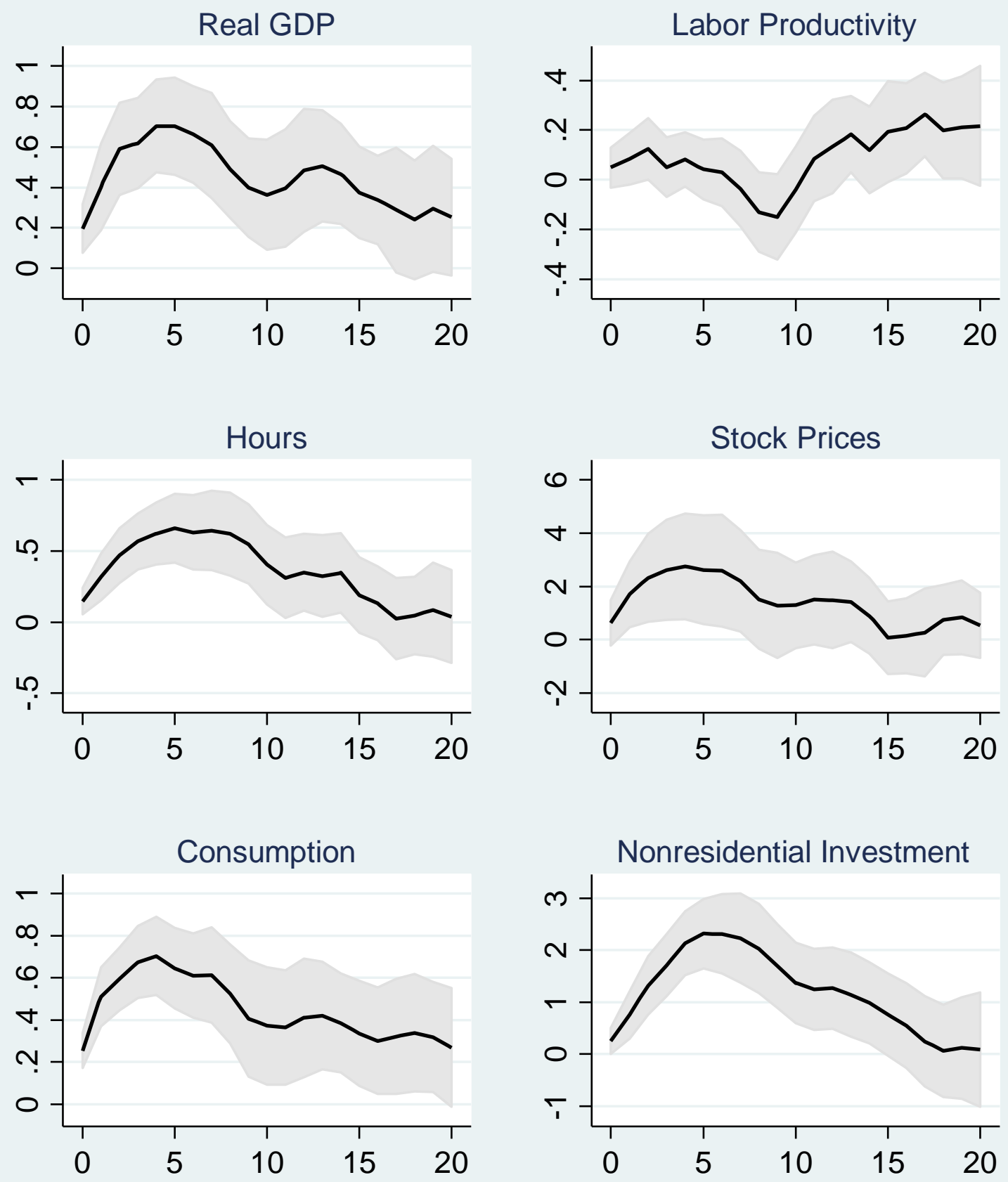
Figure 5.3. Effects of Marginal Efficiency of Investment Shock, Justiniano, Primiceri, and Tambalotti (2011) Measure, Jordà local projection, 1954q3 - 2009 q1.
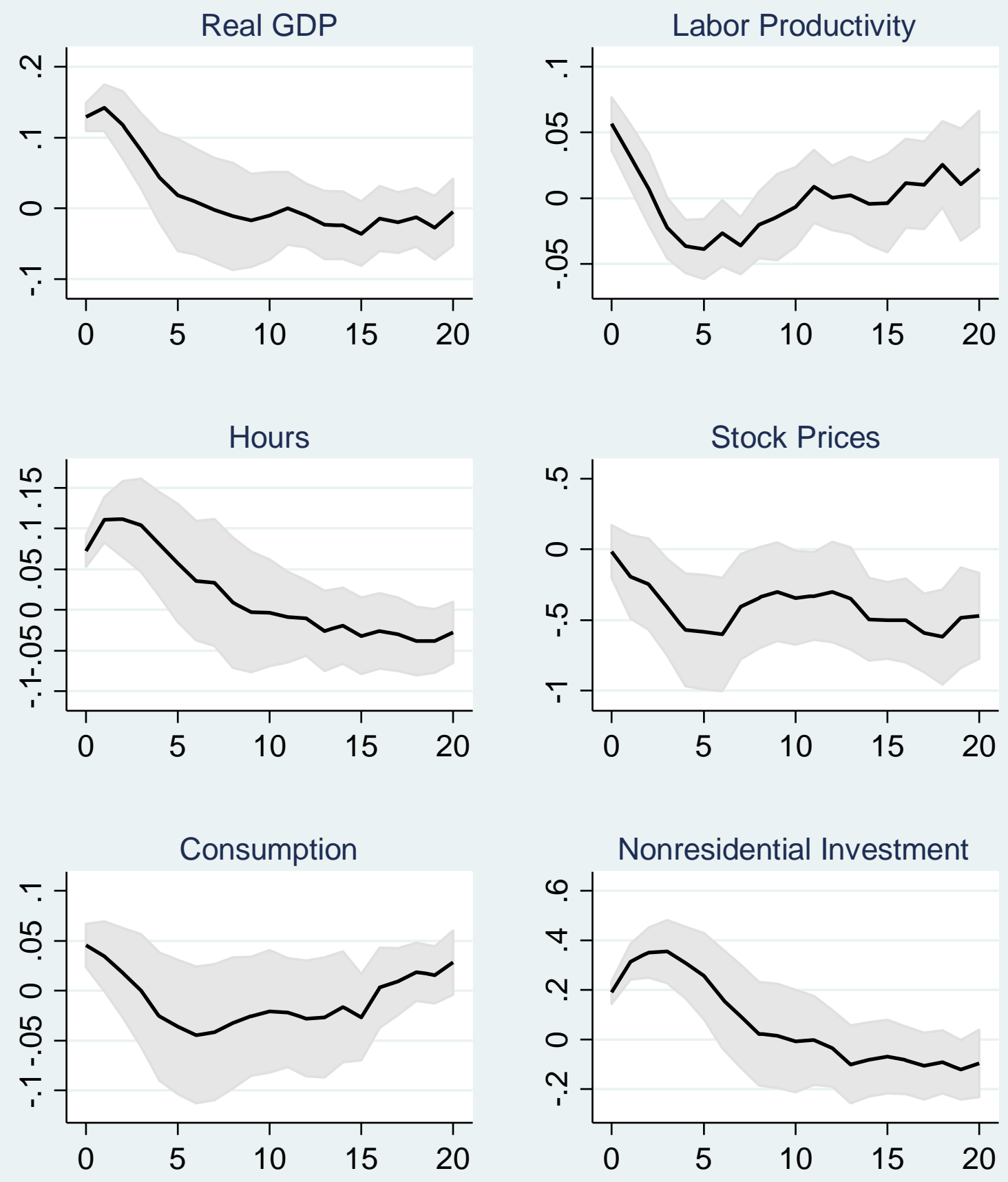